\title{
Application of low-temperature microthermometric data for interpreting multicomponent fluid inclusion compositions
}

Matthew Steele-MacInnis ${ }^{1,2, *}$, John Ridley ${ }^{3}$, Pilar Lecumberri-Sanchez ${ }^{1,2}$, Tobias Schlegel ${ }^{2}$, Christoph A. Heinrich ${ }^{2}$

1) Dept. of Geosciences, The University of Arizona, 1040 E 4th St., Tucson AZ 85721, USA

${ }^{2)}$ Institute for Geochemistry and Petrology, Clausiusstrasse 25, CH-8092 Zürich, Switzerland

${ }^{3)}$ Dept. of Geosciences, Colorado State University, Fort Collins, Colorado 80523, USA

*Corresponding author. Email: steelemacinnis@email.arizona.edu

Tel.: 520-621-1385

Fax: 520-621-2672 


\begin{abstract}
Fluid inclusions are commonly the best available source of information on the compositions of fluids in past geologic environments. Microanalytical data, predominantly from LA-ICPMS, allow assessment of the relative abundances of chemical elements in fluid inclusions. Such data show that geologic fluids commonly contain appreciable concentrations of multiple salts in addition to $\mathrm{NaCl}$, particularly $\mathrm{KCl}, \mathrm{CaCl}_{2}$, and $\mathrm{FeCl}_{2}$ as major components. Quantification of absolute salt concentrations generally requires an internal standard concentration, which is typically derived from microthermometric measurements interpreted according to the vaporsaturated liquidus relations of simpler systems such as $\mathrm{H}_{2} \mathrm{O}-\mathrm{NaCl}$ or $\mathrm{H}_{2} \mathrm{O}-\mathrm{NaCl}-\mathrm{CaCl}$. $\mathrm{Here}$, we review and reassess compositional information obtainable from microthermometric measurements in multicomponent chloride-dominated aqueous systems. To do so, we investigate the systematics of vapor-saturated liquidus phase equilibria in complex multicomponent electrolyte solutions through thermodynamic modeling based on Pitzer's equations. We focus on low- to intermediate-salinity chloride-dominated inclusions, in which ice is the liquidus phase, and on the temperature range from subsolidus conditions to $<25^{\circ} \mathrm{C}$. On the basis of measured ice and hydrohalite melting temperatures, fluids with predominantly monovalent $(\mathrm{Na} \pm \mathrm{K})$ chlorides, or mixtures of monovalent and divalent cation chlorides can be identified and a robust value of $\mathrm{m}_{\mathrm{Na}}$ as a proportion of total cations be calculated. We show that microthermometric measurements laone do not allow unequivocal determination of the identity of salts that are present in addition to $\mathrm{NaCl}$. In combination with microanalytical determination of cation ratios, however, robust compositional results for multi-salt aqueous fluid inclusions can be obtained using microthermometric measurements interpreted with generic $\mathrm{H}_{2} \mathrm{O}-(\mathrm{Na}, \mathrm{K}) \mathrm{Cl}-\sum \mathrm{X}^{n+} \mathrm{Cl}_{n}$ phase stability relations.
\end{abstract}


Keywords: Fluid inclusions; composition; salinity; electrolytes; thermodynamics; microanalysis; laser ablation; ICP-MS; hydrothermal fluids 


\section{INTRODUCTION}

Fluid inclusions (FIs) represent samples of geologic fluids trapped in minerals, and generally provide the best available tools to measure or infer properties of paleo-geologic fluids. As summarized by Roedder (1984), FIs provide information on a variety of fluid properties. Of these, fluid compositions are among the most important parameters for interpreting mass transport, element cycling, and fluid-rock interactions including metasomatism and ore formation. Methods for determining FI compositions have been the topic of numerous studies and reviews over several decades. Broadly, such techniques can be categorized into microanalytical and microthermometric methods. Microanalytical techniques (e.g., laser ablation ICPMS) permit accurate quantification of major- and trace-element concentration ratios in individual FI, but generally rely on microthermometric measurements for data reduction to obtain abslolute element concentrations. Microthermometry - i.e., measurement and interpretation of the temperatures of phase changes in an FI - thus remains the primary method for FI compositional estimates. Decades of advances in experimental and theoretical methods provide a robust basis for characterizing phase equilibria for binary and ternary aqueous systems; however, comprehensive models accounting for the diversity of geologic fluids are lacking, and most FI microthermometric data are still interpreted according to the binary system $\mathrm{H}_{2} \mathrm{O}-\mathrm{NaCl}$. Here, we provide an in-depth review of the state of knowledge of low-temperature $\left(<25^{\circ} \mathrm{C}\right)$ microthermometric properties of low- to intermediate-salinity FIs, and provide new data extending saline-aqueous FI analysis to complex fluids. We provide phase diagrams for binary, ternary and quaternary sub-systems within the system $\mathrm{H}_{2} \mathrm{O}-\mathrm{NaCl}-\mathrm{KCl}-\mathrm{CaCl}_{2}-\mathrm{MgCl}_{2}-\mathrm{FeCl}_{2}-$ $\mathrm{FeCl}_{3}$. We focus on identifying similarities, differences and overall trends to facilitate 
distinguishing various systems based on microthermometric observations. Finally, we link this information with microanalytical methods to constrain optimal procedures for data reduction for fluid inclusions in environments ranging from sedimentary basins to magmatic-hydrothermal systems and a broad range of trapping temperatures.

\section{$\underline{1.1 \text { Compositions of saline, aqueous fluid inclusions }}$}

Fluid composition is commonly quantified in terms of bulk salinity, without explicit determination of the solutes. Bulk salinity is determined from the melting (dissolution) temperature of the last solid phase during heating (the "last melting" temperature) and is expressed as wt $\% \mathrm{NaCl}$ equivalent using the phase diagram of the binary system $\mathrm{H}_{2} \mathrm{O}-\mathrm{NaCl}$ (Bodnar and Vityk, 1994). Additional information on the identities of solutes present is available from microthermometry, according to the equilibrium temperature of first appearance of liquid in the inclusion (the "first melting" temperature; generally, the eutectic temperature) as well as the melting temperatures of other (e.g., second-to-last, third-to-last, etc.) phases during heating. Such information is used extensively in the literature to classify and distinguish fluid inclusion populations according to experimentally determined phase diagrams for systems such as $\mathrm{H}_{2} \mathrm{O}$ $\mathrm{NaCl}-\mathrm{KCl}$ (Hall et al., 1988), $\mathrm{H}_{2} \mathrm{O}-\mathrm{NaCl}-\mathrm{CaCl}_{2}$ (Steele-MacInnis et al., 2011) or $\mathrm{H}_{2} \mathrm{O}-\mathrm{NaCl}-$ $\mathrm{FeCl}_{2}$ (Lecumberri-Sanchez et al., 2015). Interpretations invoking higher-order (e.g., quaternary) phase relations are extremely rare in literature, owing in part to the lack of data on higher-order systems.

Various techniques have been tested to obtain multicomponent compositional data of fluid inclusions (crush-leach extraction, e.g. Yardley et al., 1993; PIXE, e.g. Ryan et al., 1991; 
SXRF, e.g., Vanko et al., 1993; ICP-OES, e.g. Rankin et al., 1992; decrepitate mound analysis with SEM or EPMA, e.g. Haynes et al., 1988; Kontak et al, 2004; Heinrich and Cousens, 1989). The development of laser ablation inductively coupled plasma mass spectrometry (LA-ICPMS) applied to fluid inclusions (Günther et al., 1998; Heinrich et al., 2003) has been a major step towards quantifying major and trace element concentrations of solutes in individual FIs. Laser ablation ICPMS analysis provides spatial resolution sufficient to characterize individual inclusions within assemblages of cogenetic inclusions (fluid inclusion assemblages, FIAs; Diamond, 1990; Goldstein and Reynolds, 1994), and is capable of analyzing an array of major and trace element abundances during the escape of fluid from each individually opened inclusion. The development of LA-ICPMS analyses applied to FIs has thus permitted new insights into the multicomponent salt concentrations of fluids in many geological settings (e.g. Audétat et al. 2000, Garofalo et al., 2014; Rauchenstein-Martinek et al., 2014). These data demonstrate the chemical complexity of geological fluids, and also underline systematic trends in fluid compositions in specific environments. For example, magmatic-hydrothermal fluids associated with shallowly intruded crustal plutons show variable concentrations of volatile components, but generally exhibit relative concentrations of major cations in the descending order: $\mathrm{Na}>\mathrm{K} \sim \mathrm{Fe}>\mathrm{Mn}>\mathrm{Ca}$ (in order of molar concentration), although magmatichydrothermal FI more enriched in Ca have also been reported (Li et al., 2012). Sodium is the dominant cation in most cases, but not invariably so. Each of the five aforementioned cations contribute $>5 \mathrm{~mol} \%$ of total cation load in most analyzed fluids from magmatic-hydrothermal systems (e.g., Audétat et al., 2000). In contrast, in fluids associated with orogenic-Au mineralization, Na may comprise $>90$ mol\% of the dissolved cations whereas Fe and $\mathrm{Mn}$ are in most cases only minor components (e.g., Yardley et al., 1993).Fluids associated with Mississippi 
Valley-type mineralization are $\mathrm{Na}$ - plus $\mathrm{Ca}$-rich brines with relatively low $\mathrm{K}$, $\mathrm{Fe}$ and $\mathrm{Mg}$, and only trace concentrations of Mn (Haynes and Kesler, 1987; Stoffel et al., 2008; Pelch et al., 2015).

\section{$\underline{1.2 \text { Combining microthermometric and microanalytical observations }}$}

In discussing microanalytical data, we focus mostly on LA-ICPMS measurements, as these have become the standard tool for quantifying ratios of major and trace element concentrations of solutes in FIs. Many of the considerations discussed here also apply to other methods that provide element ratios in FIs. Ratios can be translated into absolute concentrations if either 1) the concentration of one solute (the internal standard) (Longerich et al., 1996) or 2) the total concentration of all solutes, in the inclusion, is known independently. The bulk salinity of the fluid inclusion, obtained from microthermometry, is commonly used as the internal standard. Raman spectroscopy of the $\mathrm{OH}$-stretching band of aqueous FI can provide an independent estimate of bulk salinity (Mernagh and Wilde, 1989), but is less commonly used than microthermometry.. Thus, microthermometric measurements and interpretation form a key facet of LA-ICPMS analysis of fluid inclusions. Note, however, that quantification of salinity from microthermometry in terms of absolute concentrations of specific analytes (e.g., Na) commonly requires additional interpretations, assumptions, and/or extrapolations to take into account chemical complexity of the solution. The techniques of standardization have thus been a topic of several contributions (e.g., Heinrich et al., 1992; Allan et al., 2005; Leisen et al., 2012). The two most commonly used approaches involve either charge-balancing on the inferred chloride concentration (Allan et al., 2005), or invoking trigonometric relations based on 
approximated liquidus isotherms (Heinrich et al., 1992), outlined below. Both methods assume that $\mathrm{Cl}$ is the dominant anion.

In the charge-balance method (Allan et al., 2005), the assumption is made that fluid inclusions of a given total chloride concentration yield the same freezing point depression as a binary $\mathrm{NaCl}-\mathrm{H}_{2} \mathrm{O}$ mixture, i.e., total chloride concentration can be computed from wt $\% \mathrm{NaCl}$ equivalent based on the temperature of final ice melting on the binary $\mathrm{H}_{2} \mathrm{O}-\mathrm{NaCl}$ liquidus. The underlying assumption in this approach is that fluids of equal chloride molality will exhibit equivalent freezing point depressions. As $\mathrm{Na}$ is typically the most abundant cation in geologic fluids, it is taken as the internal standard and charge balance is expressed as:

$$
m_{\mathrm{Cl}}=m_{\mathrm{Na}}+\sum_{i} n_{i} m_{\mathrm{x}_{i}}
$$

(Allan et al., 2005), where $m$ is molality $\left(\mathrm{mol} / \mathrm{kg} \mathrm{H} \mathrm{H}_{2} \mathrm{O}\right)$ and $n_{\mathrm{i}}$ is the charge of each $i^{\text {th }}$ cation $\mathrm{x}_{\mathrm{i}}$. Dividing both sides of Eq. (1) by $m_{\mathrm{Na}}$ and rearranging yields the expression for $m_{\mathrm{Na}}$ as a function of chloride molality and cation ratios:

$$
m_{\mathrm{Na}}=m_{\mathrm{Cl}}\left(1+\sum_{i} \frac{n_{i} m_{\mathrm{x}_{i}}}{m_{\mathrm{Na}}}\right)^{-1}
$$

The concentration ratios of cations to sodium $\left(m_{\mathrm{x}} / \mathrm{m}_{\mathrm{Na}}\right)$ are determined from LA-ICPMS analysis and the chloride molality is interpreted from microthermometry. Equation (2) is then solved to obtain absolute sodium concentration, which subsequently determines all metal concentrations according to the $m_{\mathrm{X}} / m_{\mathrm{Na}}$ ratios (Allan et al., 2005). Using synthetic fluid inclusions of known composition, Allan et al. (2005) showed that this approach is equivalent, within experimental 
uncertainty, to summing all cations on a mass fraction basis and assuming their presence as chloride salts. Note that chloride is usually not selected as an internal standard in LA-ICPMS analysis because of the low ion yield, due to its high ionization potential, which leads to poor analytical precision on $\mathrm{Cl}$ (Seo et al., 2011).

The empirical trigonometric method was originally designed for high-salinity (halite saturated fluids), based on observations regarding the temperature contours (isotherms) on the vapor-saturated liquidus in the $\mathrm{H}_{2} \mathrm{O}-\mathrm{NaCl}-\mathrm{KCl}$ (Hall et al., 1988) and $\mathrm{H}_{2} \mathrm{O}-\mathrm{NaCl}-\mathrm{CaCl}_{2}($ Vanko et al., 1988) systems. Heinrich et al. (1992) noted that, when these ternary diagrams are constructed using mass-fraction coordinates, the isotherms form approximately right angles with respect to the $\mathrm{H}_{2} \mathrm{O}-\mathrm{NaCl}$ binary join. From this observation, Heinrich et al. (1992) used trigonometric relations to derive Eq. (3), which is assumed to be applicable for monovalent- and divalent-cation chloride salts with similar characteristics to $\mathrm{K}$ and $\mathrm{Ca}$ :

$$
w_{\mathrm{NaCl}, \text { eq. }}=w_{\mathrm{NaCl}, \mathrm{true}}+0.5 \sum w_{\mathrm{M}^{n+} \mathrm{Cl}_{n}}
$$

where $w$ represents mass fraction $(\mathrm{wt} \%) ; w_{\mathrm{NaCl} \text {,eq. }}$ is the $\mathrm{wt} \% \mathrm{NaCl}$ equivalent based on liquidus relations in the $\mathrm{H}_{2} \mathrm{O}-\mathrm{NaCl}$ binary system; $w_{\mathrm{NaCl} \text {,rue }}$ is the true $\mathrm{NaCl}$ concentration; and the sum over $\mathrm{M}^{n+} \mathrm{Cl}_{n}$ represents the sum over all additional cations (expressed as chloride salts). The constant 0.5 on the right-hand side of Eq. (3) arises from the cosine of a $60^{\circ}$ angle, based on the geometric observations from ternary liquidi (Heinrich et al., 1992). Similarly to Eq. (1), Eq. (3) is divided by $w_{\mathrm{NaCl} \text {,true }}$ and rearranged to solve for the true sodium chloride concentration as:

$$
w_{\mathrm{NaCl}, \text { true }}=w_{\mathrm{NaCl}, \mathrm{eq}}\left(1+0.5 \sum \frac{w_{\mathrm{M}^{n+} \mathrm{Cl}_{n}}}{w_{\mathrm{NaCl}, \text { true }}}\right)^{-1}
$$


Note that Eqs. (1)-(2) and (3)-(4) are similar in form and function: in both cases, the parameter estimated from microthermometry $\left(m_{\mathrm{Cl}}\right.$ or $w_{\mathrm{NaCl}, \text { eq. }}$, respectively $)$ is combined with measured cation ratios from LA-ICPMS to solve for the internal standard concentration $\left(m_{\mathrm{Na}}\right.$ or $w_{\mathrm{NaCl} \text {,true }}$, respectively). Heinrich et al. (2003) suggested that the relationship of Eq. (4) can also be applied to lower-salinity inclusions, because isotherms on the ice-liquidus show similar trajectories (e.g., the $\mathrm{H}_{2} \mathrm{O}-\mathrm{NaCl}-\mathrm{KCl}$ system). However, the synthetic inclusion data of Allan et al. (2005) show that approximations without the factor of 0.5 are more accurate for lower-salinity inclusions in which ice is the last melting phase and if $\mathrm{Ca}$ is the second-most abundant salt component (e.g., Rauchenstein et al., 2014).

In principle, the need for simplifying equations can be obviated by modeling fully the temperature-solubility relations of the system, according to thermodynamic considerations. Earlier works on ion/water activity relations using the Pitzer equations (Pitzer, 1973; Pitzer and Mayorga, 1973, 1974; Harvie and Weare; 1980; Spencer et al., 1990; Marion and Kargel, 2008) provided the basis to develop this method. Based on these earlier studies, Leisen et al. (2012) proposed an iterative approach for low- to moderately-saline solutions. In the method of Leisen et al. (2012), the metal concentration ratios from LA-ICPMS are combined with activity of water $\left(a_{\mathrm{H} 2 \mathrm{O}}\right)$ from the ice melting temperature, to calculate cation and chloride concentrations using Pitzer's equations. This method reduces to the expression:

$$
a_{H_{2} O}\left(m_{\mathrm{Na}}, m_{\mathrm{Cl}}, m_{\mathrm{x}_{1}}, \ldots, m_{\mathrm{x}_{n}}\right)=K_{\text {ice }}\left(T_{\mathrm{m}, \mathrm{ice}}\right)
$$


where the $a_{\mathrm{H} 2 \mathrm{O}}$ represents the activity of $\mathrm{H}_{2} \mathrm{O}$, expressed as a function of ion molality; and $K_{\text {ice }}$ represents the equilibrium constant of ice melting (i.e., solubility product) expressed as a function of temperature (e.g., Marion, 2002). This method employs iterative solution for the molality of internal standard Na. Molalities of cations $\mathrm{x}_{1}$ to $\mathrm{x}_{\mathrm{n}}$ are determined from LA-ICPMS cation ratios, and $m_{\mathrm{Cl}}$ is determined from Eq. (2). Activity of $\mathrm{H}_{2} \mathrm{O}$ is obtained at each step in the iteration using the Pitzer equations. More details of Eq. (5) are described below (see also Marion and Kargel, 2008, for a comprehensive review of the Pitzer equations and their application).

It should be emphasized that LA-ICPMS analysis of fluid inclusions has inherently limited precision, and that all three of the aforementioned methods for data reduction tend to increase the uncertainty on absolute concentrations, compared to concentration ratios, as a result of error propagation. Although ratios of many major elements are quantifiable to about $10 \%$ relative by averaging data from multiple inclusions within a FIA (e.g. Allan et al., 2005), several major cations (notably calcium and iron) exhibit precision of approximately $\pm 20 \%$ relative or greater (e.g., Allan et al., 2005; Lecumberri-Sanchez et al., 2015). Increase of uncertainty via error propagation arises because each of Eqs. (2), (4) and (5) invokes all measured cation ratios as input parameters to estimate the internal standard concentration $\left(m_{\mathrm{Na}}\right.$ or $\left.w_{\mathrm{NaCl}}\right)$. Hence, the propagation of uncertainties via Eqs. (2), (4) and (5) implies that all uncertainties on major element ratios obtained from LA-ICPMS analysis contribute to the uncertainty on the internal standard concentration and thus, the final concentration estimate for each element. For example, if an inclusion contains $\mathrm{Na}, \mathrm{K}, \mathrm{Fe}$ and $\mathrm{Ca}$, then estimation of $m_{\mathrm{Na}}$ or $w_{\mathrm{NaCl}}$ by Eq. (2), (4) or (5) incorporates the uncertainty on $m_{\mathrm{K}} / m_{\mathrm{Na}}, m_{\mathrm{Fe}} / m_{\mathrm{Na}}$ and $m_{\mathrm{Ca}} / m_{\mathrm{Na}}\left(\right.$ or $w_{\mathrm{KCl}} / w_{\mathrm{NaCl}}, w_{\mathrm{FeCl} 2} / w_{\mathrm{NaCl}}$ and $\left.w_{\mathrm{CaCl} 2} / w_{\mathrm{NaCl}}\right)$ into the internal standard concentration. Accurate recalculation of absolute concentrations further requires that all major cations are analyzed, because their contributions are 
required in the sum-over-ratios term in Eqs. (2), (4) or (5). For small, low-salinity inclusions in particular, even cations which make up tens of percent of total solute load may have concentrations below the limit of detection, owing to low total masses of analytes and low element-specific limits of detection (notably for Ca due to Ar interferences in the inductivelycoupled plasma). Further challenges may arise when attempting to quantify salinities of FIs containing major cations also present as major elements in the host mineral (e.g., Ca-bearing fluids hosted in fluorite; Schlegel et al., 2012). Consequently, correction for elements with high uncertainties, or for elements detected only in some inclusions within an assemblage, can lead to spurious deviations and deterioration of the overall quality of compositional information obtained from an FI.

Standardizations likely improve if ternary (or higher-order) phase equilibria are considered. Schlegel et al. (2012) suggested that major- and trace-element compositions of Carich FIs can be more reliably determined by LA-ICPMS using the "true" $\mathrm{NaCl}$ concentration estimated according to the phase equilibria of the system $\mathrm{H}_{2} \mathrm{O}-\mathrm{NaCl}-\mathrm{CaCl}_{2}-$ as the internal standard. In principle, the methods described by Schlegel et al. (2012) for Ca-rich FIs should also apply to other, more complex systems.

In the present study, we reexamine the application of cryogenic microthermometry for interpreting fluid inclusions of complex compositions by including an in-depth review of phase relations predicted by electrolyte theory ( $c f$. Pitzer, 1973). We concentrate on the behavior of fluids in which chloride is the dominant anion, and which are vapor-saturated and undersaturated with respect to salts or salt-hydrates at room temperature (i.e., containing a vapor bubble but no daughter minerals). We present predicted liquidus phase relations for chemical 
sub-systems within the septenary (seven-component) system $\mathrm{H}_{2} \mathrm{O}-\mathrm{NaCl}-\mathrm{KCl}-\mathrm{MgCl}_{2}-\mathrm{CaCl}_{2}-$ $\mathrm{FeCl}_{2}-\mathrm{FeCl}_{3}$ and evaluate their application to internal standardization of LA-ICPMS data.

\section{LOW-TEMPERATURE PHASE RELATIONS IN SALINE, AQUEOUS SYSTEMS AND RELATIONS TO MICROTHERMOMETRIC OBSERVATIONS}

The equilibrium states of multicomponent systems at subsolidus temperatures (i.e., when completely frozen) are multi-phase solid assemblages. In general, in a two-component system, the vapor-saturated subsolidus assemblage will comprise two solid phases, while in a threecomponent system the subsolidus assemblage will consist of three solid phases, and so on. There are exceptions with lower numbers of phases if the bulk composition equals the composition of an intermediate solid phase, or falls within the range of a solid solution between end-member compositions. In the general case, the various solids will melt congruently or incongruently during heating from the solidus temperature (the temperature at which liquid first appears; typically, the eutectic) to the liquidus temperature (the temperature at which the last solid phase melts). The sequence of melting temperatures will depend on the bulk composition. In aqueous fluid inclusions of low to moderate salinity, which are under-saturated with respect to salts or salt-hydrates at room temperature, the last solid phase present on the liquidus is generally ice. For fluid inclusions containing sodium chloride, the second-to-last solid to melt during heating is generally hydrohalite, or metastable halite. Note that hydrohalite is typically the second-to-last solid to melt even in cases in which $\mathrm{NaCl}$ is not the dominant solute in the inclusion, owing to salting-out of $\mathrm{NaCl}$ by other salts, as described below. 


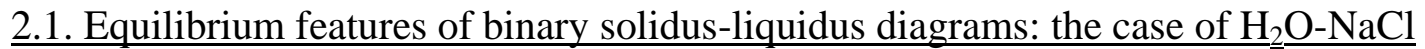

The topology and phase relations in the $\mathrm{H}_{2} \mathrm{O}-\mathrm{NaCl}$ system (Fig. 1) have been described in detail in the literature (see Roedder, 1984; Bodnar, 1993; Bodnar and Vityk, 1994), but here we review some of the key aspects in the interest of clarifying subsequent discussions of higherorder systems. The horizontal solid lines in Fig. 1 represent invariant temperatures, in this case the vapor-saturated eutectic temperature $\left(T_{\text {eut }}\right)$ and peritectic temperature $\left(T_{\text {per }}\right)$. Other water-salt binary systems may have one or more additional eutectic and/or peritectic points (see Section 4). Phase boundaries represented by vertical lines in the $T-x$ projection represent subsolidus solidsolid phase equilibria; in Fig. 1 there is only one such phase boundary, corresponding to the composition of hydrohalite $\left(\mathrm{NaCl} \cdot 2 \mathrm{H}_{2} \mathrm{O}\right)$, and separating the phase assemblage ice+hydrohalite at lower bulk salinities from the assemblage hydrohalite+halite at higher salinities. The solidsolid equilibrium phase boundaries plot as vertical lines in this projection because the mutual solubilities of the relevant solid phases are extremely limited (in $T-x$ phase diagrams involving solid solutions, solid-solid boundaries are generally not vertical, owing to the temperature dependence of mutual solubility). The curved phase boundaries delimiting the liquidus (separating liquid at higher $T$ from liquid+solid at lower $T$ ) represent the composition of the liquid in equilibrium with one solid phase. Consider a fluid inclusion with a bulk composition represented by the solid grey vertical arrow in Fig. 1. The dotted tie-lines extending horizontally from the bulk composition represent the compositions of phases coexisting in the inclusion at a given temperature. When cooled to the subsolidus temperature represented by point $a$, the inclusion contains hydrohalite (composition represented by point $b$ ) and ice (composition represented by point $c$ ). If the inclusion is heated to $T_{\text {eut }}$ (points $d-e-f$ ), the congruent melting 
reaction hydrohalite + ice $=$ liquid proceeds to produce a liquid of composition $e$. The eutectic reaction will proceed at constant temperature, $T_{\text {eut }}$, until one or both solids are melted, depending on the bulk composition. In the present case, because the bulk composition lies to the $\mathrm{H}_{2} \mathrm{O}$-rich side of the eutectic liquid composition, the reaction proceeds until hydrohalite is consumed. Upon further heating, ice progressively melts and the liquid composition evolves along the ice liquidus. For example, at the temperature of points $g-h-i$, a liquid of composition $h$ coexists with ice of composition $i$. When ice is completely consumed at the temperature of point $j$, the liquid composition on the liquidus $(j)$ equals the bulk composition, and the liquid composition remains constant with further heating thereafter (e.g., to point $k$ ).

There are several noteworthy features of the $T-x$ projection in Fig. 1. Firstly, the mass fractions of phases present at any given temperature can be calculated from the bulk composition using the lever rule. If the volume fractions of phases in the inclusion can be estimated, at any given temperature, and converted to mass fractions based on known phase densities, then the bulk composition can be calculated. Note, however, that estimating volume fractions of phases in an inclusion is generally imprecise in comparison to microthermometric measurements (see, for instance, Bakker and Diamond, 2006). In this binary system, the bulk composition is constrained by the final melting temperature on the liquidus. In principle, the homogenization temperature is also required for a complete compositional estimate (owing to the $\mathrm{H}_{2} \mathrm{O}$ content of the vapor phase), but in practice the vapor density is so low at cryogenic temperatures that it can be ignored in the case of low-salinity FIs (e.g., Diamond, 2003; Bakker, 2012a; Steele-MacInnis and Bodnar, 2013). Finally, the temperature at which liquid first appears in the inclusion (the "first melting" temperature) generally provides little information about the bulk composition. In the case of the $\mathrm{H}_{2} \mathrm{O}-\mathrm{NaCl}$ system, any bulk composition from pure $\mathrm{H}_{2} \mathrm{O}$ to the composition of 
hydrohalite $(\sim 61.9 \mathrm{wt} \% \mathrm{NaCl})$ will exhibit "first melting" at the eutectic temperature $\left(-21.2{ }^{\circ} \mathrm{C}\right.$; Hall et al., 1988).Any composition more saline than the hydrohalite composition will exhibit "first melting" at the peritectic temperature $\left(+0.1^{\circ} \mathrm{C}\right)$, rather than at the eutectic. The latter phenomenon can provide a rough constraint on the bulk salinity, although in practice such measurements are rare, and the volume fraction of halite at room temperature is a more straightforward criterion.

The foregoing discussion is centered on equilibrium phase changes and does not consider the practicalities of making observations on fluid inclusions. Importantly, consideration of mass balance indicates that, for any bulk composition from pure $\mathrm{H}_{2} \mathrm{O}$ to the eutectic liquid salinity (i.e, zero to 23.2 wt $\%$ NaCl; Hall et al., 1988; Bodnar, 1993), the amount of liquid produced at the eutectic temperature will decrease with decreasing salinity. In this case, as salinity decreases towards zero, the liquid volume fraction at the eutectic temperature decreases concomitantly. For example, an $\mathrm{H}_{2} \mathrm{O}-\mathrm{NaCl} \mathrm{FI}$ in which ice melts at $-1{ }^{\circ} \mathrm{C}$ (bulk salinity $\sim 1.7 \mathrm{wt} \% \mathrm{NaCl}$ ) would yield approximately $6 \mathrm{vol} \%$ liquid at the eutectic temperature. Precise measurement of the true eutectic temperature is consequently challenging (sometimes impossible) in small, low-salinity FIs because small pockets of liquid may be optically invisible or occluded by one or more solid phases. Indeed, Diamond (1990) reported first observable liquid of NaCl-dominated, low-salinity inclusions generally between -16 and $-11{ }^{\circ} \mathrm{C}$.

Additional complications may arise as a result of metastability. Metastable subsolidus assemblages will exhibit first melting at lower temperatures compared to the stable eutectics (Goldstein and Reynolds, 1994). For example the metastable assemblage ice+halite, which may occur in high-salinity $\mathrm{H}_{2} \mathrm{O}-\mathrm{NaCl}$ inclusions, has a eutectic temperature of $-28{ }^{\circ} \mathrm{C}$ (Roedder, 1984). In many cases, high-salinity inclusions may simply fail to solidify even when held at 
liquid $\mathrm{N}_{2}$ temperatures $\left(\sim 196^{\circ} \mathrm{C}\right)$ for extended time periods (e.g., Oakes et al., 1990;

Baumgartner and Bakker, 2010). Moreover, stable or metastable subsolidus reactions may occur (e.g., Ni et al., 2006), and may be difficult to distinguish from first melting. Interpretation of such phenomena is challenging, in some cases impossible, and commonly requires additional techniques such as combination of Raman spectroscopy and microthermometry. Hereafter, this review will focus on stable phase changes, and the reader is referred to Davis et al. (1990) and Samson and Walker (2000) for more information on metastability.

\subsection{Equilibrium features of ternary solidus-liquidus diagrams}

For ternary systems, vapor-saturated phase relations are most commonly displayed by projection onto ternary compositional axes, contoured for temperature along the liquidus. Pressure contours are also possible to construct at vapor saturation (Sterner et al., 1988; Bakker, 2012b), but are less relevant for compositional interpretation by microthermometry. Univariant cotectic and/or peritectic relations appear as curves in such a projection, representing the composition of the liquid in equilibrium with two solids plus vapor at any given temperature along the curve. In accordance with Gibbs' phase rule, three univariant curves intersect at each invariant eutectic or peritectic point, excluding the relevant binary eutectics and peritectics. Divariant liquidus surfaces, which represent equilibrium between one solid plus liquid plus vapor, plot as fields in this projection. A key feature of this projection is that isotherms of equal temperature within adjacent liquidus fields intersect at the corresponding univariant boundaries. Also, the temperature-composition relations along the binary joins naturally represent the $T-x$ projections of the relevant binary liquidus diagrams. 
Figure 2 is a schematic ternary liquidus diagram for the system $\mathrm{H}_{2} \mathrm{O}-\mathrm{NaCl}-\mathrm{CaCl}_{2}$ ( $\mathrm{Steele}$ MacInnis et al., 2011). The black heavy solid lines show the compositional evolution of the liquid within a fluid inclusion with bulk composition $x$ during heating from eutectic temperature to the temperature at which the last solid phase melts. The equilibrium subsolidus assemblage in this inclusion is ice + hydrohalite + antarcticite $\left(\mathrm{CaCl}_{2} \cdot 6 \mathrm{H}_{2} \mathrm{O}\right)$. Liquid first appears at the eutectic temperature, and the eutectic liquid composition is indicated by the point eut. In this example, antarcticite is completely consumed by the eutectic reaction (ice + hydrohalite + antarcticite $=$ liquid), and upon further heating the liquid composition evolves along the ice+hydrohalite cotectic curve. Along the cotectic curve, ice and hydrohalite both melt congruently (ice + hydrohalite $=$ liquid) until hydrohalite is consumed. At the temperature at which hydrohalite is finally consumed $\left(T_{\mathrm{m}, \mathrm{hh}}\right)$, the liquid composition is indicated by the intersection of the $T_{\mathrm{m}, \mathrm{hh}}$ isotherm and the ice-hydrohalite cotectic (labeled cot). During subsequent heating, ice continues to melt (reaction ice $=$ liquid) until the liquid composition equals the bulk composition $(x)$ at $T_{\mathrm{m} \text {,ice. }}$ Analogous heating sequences for other bulk compositions are described in detail by Steele-MacInnis et al. (2011).

One of the key observations from Fig. 2 is that, after the last melting of hydrohalite, the remaining solid phase (ice) has the composition equal to one of the ternary apices $\left(\mathrm{H}_{2} \mathrm{O}\right)$, and consequently the bulk composition $(x)$ lies along a tie line connecting the liquid composition at $T_{\mathrm{m}, \mathrm{hh}}(c o t)$ with the $\mathrm{H}_{2} \mathrm{O}$ apex. Stated differently, $T_{\mathrm{m}, \mathrm{hh}}$ provides a unique constraint on the ratio of salts in the inclusion, such as $w_{\mathrm{NaCl}} /\left(w_{\mathrm{NaCl}}+w_{\mathrm{CaCl} 2}\right)\left(\right.$ where $w_{\mathrm{X}}=$ percent mass fraction [wt $\%$ ] of $\mathrm{X})$. Thus, by measuring both the last melting temperature $\left(T_{\mathrm{m}, \mathrm{ice}}\right)$ and the second-to-last melting temperature $\left(T_{\mathrm{m}, \mathrm{hh}}\right)$, the FI composition can be completely described in terms of bulk salinity as well as relative abundances of the two salts. Melting temperatures of the two phases 
are commonly measurable in relatively large fluids inclusions, and such measurements can provide the best constraints on the ratios of salts in the inclusion, as described in detail by Sterner et al. (1988), Vanko et al. (1988) and Steele-MacInnis et al. (2011). Estimates of compositional ratios such as $w_{\mathrm{NaCl}} /\left(w_{\mathrm{NaCl}}+w_{\mathrm{CaCl} 2}\right)$ have been made in several studies based on this approach (e.g., Zwart and Touret, 1994; Xu, 2000; de Casa et al., 2003; Kontak and Kyser, 2011; Schlegel et al., 2012).

In principle, similar to the case of binary systems such as $\mathrm{H}_{2} \mathrm{O}-\mathrm{NaCl}$ described above, first melting temperatures in ternary systems are independent of bulk salinity for a wide range of low- to moderate salinities in any system (i.e. where ice is present at subsolidus conditions). Note that first melting at a peritectic point is possible (Schiffries, 1990) but only occurs for bulk compositions more saline than the composition of the lower order salt hydrate (e.g., more saline than the antarcticite composition, for $\mathrm{CaCl}_{2}$-rich fluids). In addition, it is worth noting that the eutectic temperature of a system is independent of the relative proportions of the components. The eutectic temperature is, thus, a characteristic defined by the identities of the components, rather than their concentrations. For example, in the case of $\mathrm{H}_{2} \mathrm{O}-\mathrm{NaCl}-\mathrm{CaCl}_{2}$ FIs, the eutetic point occurs at $-52{ }^{\circ} \mathrm{C}($ Yanatieva, 1946). Eutectic temperatures have been experimentally determined for several ternary $\left(\mathrm{H}_{2} \mathrm{O}+\right.$ two salts) systems relevant for FI studies (e.g. Linke, 1958; Borisenko, 1977; Crawford, 1981). First melting temperatures have been reported in many FI studies on a wide range of geologic environments, and used to attempt to classify fluids in terms of model ternary systems.

Similar to the case of binary systems noted above, mass balance considerations can also be applied to ternary systems in order to estimate volume fractions of liquid formed at the eutectic. Importantly, addition of a second salt component besides sodium chloride commonly 
results in salting-out of the $\mathrm{NaCl}$ component at low temperatures (see Section 4), such that the eutectic liquid composition typically lies close to the binary join between $\mathrm{H}_{2} \mathrm{O}$ and the second salt (e.g., close to the $\mathrm{H}_{2} \mathrm{O}-\mathrm{CaCl}_{2}$ join in the $\mathrm{H}_{2} \mathrm{O}-\mathrm{NaCl}-\mathrm{CaCl}_{2}$ system). This phenomenon is observed in essentially all known systems of $\mathrm{H}_{2} \mathrm{O}$ plus sodium chloride plus divalent-cation chlorides, owing to the greater charge density on divalent cations. Consequently, mass balance constraints indicate that the amount of liquid produced at the eutectic will be small for many common geologic fluids, especially those that are dominated by $\mathrm{NaCl}$ and/or of low total salinity (see Section 5). Precise measurement of the true eutectic temperature is therefore unlikely in many multicomponent FIs. The difficulties observing true eutectic temperatures are likely more marked in multi-component systems compared to binary systems, both because of occlusion of the small amounts of liquid, and because of metastable phase assemblages (e.g. Davis et al., 1990).

\subsection{Equilibrium features of quaternary and higher solidus-liquidus diagrams}

The addition of a fourth component sufficiently complicates the phase equilibria that few phase diagrams are available for quaternary or higher-order aqueous systems relevant for geologic fluids. Indeed, owing to the additional variance of such systems, projection into twodimensional format for constructing phase diagrams is challenging. One option is to project the features of the quaternary compositional space (a tetrahedron) from the $\mathrm{H}_{2} \mathrm{O}$ apex onto the ternary plane of three salts (e.g., see Crawford et al. (1979) for the system $\mathrm{H}_{2} \mathrm{O}-\mathrm{NaCl}-\mathrm{CaCl}_{2}-$ $\mathrm{MgCl}_{2}$, and analogous isothermal projections by Atbir et al. (1996) for the system $\mathrm{H}_{2} \mathrm{O}-\mathrm{NaCl}-$ $\mathrm{KCl}-\mathrm{FeCl}_{2}$ ). Nevertheless, few experimental data are available for such systems, especially at 
cryogenic temperatures, and currently we must rely on thermodynamic calculations in order to investigate quaternary (or higher-order) phase equilibria.

The eutectic temperature of the $\mathrm{H}_{2} \mathrm{O}-\mathrm{NaCl}-\mathrm{CaCl}_{2}-\mathrm{MgCl}_{2}$ system was estimated experimentally by Luzhnaya and Vereshchetina (1946) but has not been determined for other quaternary and higher-order systems. As a result of the increased entropy of solution, additional components will lower eutectic temperatures of quaternary (and higher) systems below those of all the corresponding ternary systems. For instance, the equilibrium eutectic temperature of any $\mathrm{NaCl}$ - and $\mathrm{CaCl}_{2}$-bearing fluid will be at or below $-52{ }^{\circ} \mathrm{C}$, even if $\mathrm{Ca}^{2+}$ is only a minor cation.

The additional components will be reflected by additional solid phases in inclusions below the solidus temperature, such that for example four phases will generally be present at subsolidus temperatures in a quaternary system, and four solid phases melt during heating experiments. Thus, Crawford et al. (1979) used the experimentally constrained projection from ice of the liquidus surface in the $\mathrm{H}_{2} \mathrm{O}-\mathrm{NaCl}-\mathrm{CaCl}_{2}-\mathrm{MgCl}_{2}$ system and interpreted four observed phase transitions at low temperatures, to estimate $\mathrm{Na}^{+}: \mathrm{Ca}^{2+}: \mathrm{Mg}^{2+}$ cation ratios within a suite of inclusions.

Even more so than in lower order systems, the equilibrium volume proportions of liquid present at or just above the eutectic in quaternary (or higher) systems will be vanishingly small in most FI, and hence difficult to observe. Further, by analogy with observed phase transitions in ternary systems, we may expect disequilibrium assemblages on freezing of multi-component fluids, and hence metastable phase changes behavior during heating, although to date such behavior has not been explicitly investigated.

\section{THERMODYNAMIC ANALYSIS OF LIQUIDUS EQUILIBRIA}




\section{$\underline{\text { 3.1. Ice }}$}

The melting temperature of last solid phase during heating (the last melting temperature) is a function of bulk salinity, as noted above. Consider FIs in which ice is the last solid phase to melt. The depression of the ice-melting temperature below $0.01{ }^{\circ} \mathrm{C}$ (the triple point of pure $\mathrm{H}_{2} \mathrm{O}$ ) occurs as a result of the shift of temperature of the ice-water equilibrium, owing to the reduced activity of $\mathrm{H}_{2} \mathrm{O}$ in the solution. The ice-water equilibrium can be expressed by the reaction:

$$
\mathrm{H}_{2} \mathrm{O}_{(\text {ice })} \leftrightarrow \mathrm{H}_{2} \mathrm{O}_{(\mathrm{l})}
$$

for which the corresponding equilibrium constant $K_{\text {ice }}$ is:

$$
K_{\text {ice }}=a_{\mathrm{H}_{2} \mathrm{O}}^{L} / a_{\mathrm{H}_{2} \mathrm{O}}^{i c e} \approx a_{\mathrm{H}_{2} \mathrm{O}}^{L}
$$

(See also Eq. (5)). Note that the activity of $\mathrm{H}_{2} \mathrm{O}$ in ice is assumed to be unity, owing to the extremely limited solid solution between chloride salts and ice. Consequently, the equilibrium constant for reaction (6) depends only upon the activity of $\mathrm{H}_{2} \mathrm{O}$ in the liquid. The equilibrium constant is related to the Gibbs energy of reaction via:

$$
\Delta G_{r}^{o}=-R T \ln K
$$


and the shift in Gibbs energy of reaction with varying temperature is related to the entropy of reaction via:

$$
\frac{\partial \Delta G_{r}^{o}}{\partial T}=-\Delta S_{r}
$$

From Equations (7) and (8), the freezing-point depression increases (i.e., the equilibrium temperature decreases) as the activity of water decreases with increasing salinity. The freezing point depression varies approximately linearly with salinity at high $\mathrm{H}_{2} \mathrm{O}$ activity, but the relationship become increasingly non-linear at higher salinities, as has been experimentally demonstrated for various binary water-salt systems (e.g. $\mathrm{H}_{2} \mathrm{O}-\mathrm{NaCl}$, Bodnar, $1993 ; \mathrm{H}_{2} \mathrm{O}-\mathrm{KCl}$, Sterner et al., 1988; $\mathrm{H}_{2} \mathrm{O}-\mathrm{CaCl}_{2}$, Linke, 1958). The activity of $\mathrm{H}_{2} \mathrm{O}$ can expressed as a function of the osmotic coefficient $(\phi)$ of the solution and the concentrations of ions $i$ according to the expression:

$$
\ln a_{H_{2} O}^{L}=-\frac{\phi}{55.5} \sum m_{i}
$$

Where $m_{i}$ represents concentration of ion $i$ in molal units, the summation represents sum over all ions in the solution, and the constant in the denominator represents mol/ $/ \mathrm{kg} \mathrm{H}_{2} \mathrm{O}(=1000 \mathrm{~g} / \mathrm{kg} /$ $18.0152 \mathrm{~g} / \mathrm{mol})$. Osmotic coefficient for aqueous solutions are measured in a variety of experiments and can be described using thermodynamic models such as the Debye-Hückel equation. 


\section{$\underline{3.2 \text { Salts and salt-hydrates }}$}

Relationships analogous to equations (6) and (7) can be similarly expressed for melting of salts or salt-hydrates, the only difference being that the equilibrium constant for the melting reaction will relate to the ion activity product of the relevant solid. For example, the hydrohalite melting reaction is expressed by

$$
\mathrm{NaCl} \cdot 2 \mathrm{H}_{2} \mathrm{O}_{\text {(Hydrohalite) }} \leftrightarrow \mathrm{Na}^{+}{ }_{(\mathrm{aq})}+\mathrm{Cl}^{-}{ }_{(\mathrm{aq})}+2 \mathrm{H}_{2} \mathrm{O}_{(\mathrm{l})}
$$

and the equilibrium constant for this reaction is

$$
K_{h h} \approx\left(a_{N a^{+}}^{L}\right)\left(a_{C l^{-}}^{L}\right)\left(a_{H_{2} O}^{L}\right)^{2}
$$

The activity of $\mathrm{H}_{2} \mathrm{O}$ is calculated similarly to the case for the ice melting equilibrium (Eq. 10), with the osmotic coefficient from a thermodynamic model. Solubility products for other salts and salt hydrates can be similarly defined.

\section{$\underline{3.3 \text { Eutectic and peritectic points; cotectic and peritectic lines }}$}

In a binary system, the invariant (eutectic and peritectic) points represent the intersection of liquidus curves, and thus represent the temperature and composition at which equilibrium constants are simultaneously satisfied for two melting reactions. The $\mathrm{H}_{2} \mathrm{O}-\mathrm{NaCl}$ eutectic point thus represents the temperature and liquid composition at which Eqs. (7) and (12) are 
simultaneously solved. In ternary systems, the eutectic point represents the simultaneous equilibrium of three solid phases plus liquid, and thus three equilibrium constants are equal to their respective ion activity products at this condition. Analogous relations can be defined for higher-order invariant points. Cotectic and peritectic lines in ternary systems (at which two solid phases are in equilibrium with liquid) or higher-order systems are similarly defined by the locus of temperature-composition conditions satisfying simultaneous equilibrium of liquid plus solids. For example, the ice+hydrohalite cotectic curve in any ternary, $\mathrm{NaCl}$-bearing system is defined by the locus of temperature-composition points satisfying Eqs. (7) and (12).

\section{CALCULATION OF VAPOR-SATURATED LIQUIDUS PHASE RELATIONS}

The empirical and thermodynamic constraints described above provide a basis for predicting the topologies and temperature-composition relationships for binary, ternary and higher-order systems. Previous studies (see Marion and Kargel, 2008) have demonstrated that phase relations predicted based on thermodynamic modeling (equations analogous to (6) through (12)) using activities of $\mathrm{H}_{2} \mathrm{O}$ and of aqueous ions calculated according to the equations of Pitzer (1973) generally compare well to experimentally determined phase diagrams (e.g., Spencer et al., 1990), even in the case of chemical systems in which ion parameters were formulated prior to experimental assessment of the liquidus relations. For example, Lecumberri-Sanchez et al. (2015) calculated cotectic and peritectic phase boundaries as well as ice-liquidus isotherms in the system $\mathrm{H}_{2} \mathrm{O}-\mathrm{NaCl}-\mathrm{FeCl}_{2}$ using the Pitzer (1973) modeling approach, and found excellent agreement with synthetic fluid inclusion experiments. Importantly, the Pitzer parameters 
employed by Lecumberri-Sanchez et al. (2015) were estimated (Marion et al., 2003) based mostly on ferrous-carbonate mineral solubility data prior to the availability of liquidus data.

In order to provide a broad coverage of liquidus relations across a spectrum of chemical sub-systems relevant for geologic fluids, low-temperature vapor-saturated liquidus relations were calculated in the present study according to the methods first described by Harvie and Weare (1980), based on the thermodynamic formalisms of Pitzer (1973) and Pitzer and Mayorga (1973, 1974). Briefly, the Pitzer model invokes binary and ternary interaction parameters to account for two-particle and three-particle electrostatic interactions between solute ions, excluding self interactions. The binary and ternary interaction parameters are themselves functions of temperature, allowing calculations of ion and water activities at variable temperatures (e.g., Spencer et al., 1990). Mineral solubilities are determined by the relevant solubility products, which are also modeled as temperature functions (Spencer et al., 1990). Mineral saturation is achieved when the ion activity product equals or exceeds the solubility product (e.g., Eqs (5), (7) and (12)). For a complete description of the implementation of Pitzer's model for lowtemperature liquid-solid equilibria, the reader is referred to Marion and Kargel (2008). One advantage of the Pitzer ion-interaction model for ion activities is that only binary and ternary interaction parameters are used, even in the case of fluids with four or more ionic species. Therefore, the method allows investigating phase equilibria of complex systems based on experimental data determined only within simpler systems. Stated differently, phase diagrams can be calculated for quaternary and higher-order systems using the Pitzer equations as long as thermodynamic data are available for the relevant ternary subsystems. Ion interaction parameters developed in the ternary subsystems are combined to extend the analysis to the higher-order 
mixtures. Thus, wide ranges of complex, multicomponent fluid compositions can be modeled based on experiments in binary and ternary systems.

Not all the Pitzer interaction parameters used in the present study have been calibrated over the same temperature ranges, especially at sub-zero temperatures. For example, calcium chloride parameters are valid to below $-50^{\circ} \mathrm{C}$, whereas potassium chloride parameters were only calibrated to $-23^{\circ} \mathrm{C}$ (Marion and Kargel, 2008). Thus, phase equilibrium assessments in $\mathrm{CaCl}_{2}+\mathrm{KCl}$ bearing fluids at temperatures below $-23^{\circ} \mathrm{C}$ are possible only by extrapolation of the potassium chloride parameters. However, ternary interaction parameters obtained from experiments at $25^{\circ} \mathrm{C}$ are commonly assumed to be constant to lower temperatures, thus providing reasonable predictions of liquidus relations at cryogenic conditions based on relatively few experiments. In the present study, such extrapolations were used to estimate the phase equilibria at low temperatures as well as to provide predicted liquidus phase relations/diagrams. A note is added in Table 1 to identify such extrapolations, as the accuracy of such extrapolations cannot be guaranteed.

In addition to $\mathrm{H}_{2} \mathrm{O}-\mathrm{NaCl}-\mathrm{KCl}-\mathrm{CaCl}_{2}-\mathrm{MgCl}_{2}-\mathrm{FeCl}_{2}-\mathrm{FeCl}_{3}$, additional solutes that were considered in this review, but not included in the table or figures, were $\mathrm{HCl}$ (Marion, 2002), $\mathrm{LiCl}$ (Dubois et al., 2010; Monnin et al. 2002), and $\mathrm{NH}_{4} \mathrm{Cl}$ (Dinane, 2006; Marion et al. 2012). Geologic fluids from diverse environments, contain variable amounts of anions other than chloride such as $\mathrm{SO}_{4}{ }^{2-}$, $\mathrm{HCO}_{3}{ }^{-}$, etc. However, the bulk of available analytical data on geologic fluids, as summarized by Yardley (2005) shows that chloride is generally the predominant anion in fluids from diverse environments, and other anions tend to have minor concentrations. It should be noted, however, that anions other than chloride may be the most important ligands for certain metals in some fluids (Yardley, 2005). Other anions as well as dissolved gases may also have important 
consequences for low-temperature thermometric properties, most significantly in fluids of relatively low salinity (e.g., Hedenquist and Henley, 1985).

Binary and ternary interaction parameter for ions, as well as temperature functions for mineral solubility products, were mainly drawn from the FREZCHEM (Marion and Kargel, 2008), with few exceptions noted below. The parameterizations used by FREZCHEM include ion interaction parameters from Spencer et al. (1990) for the system $\mathrm{H}_{2} \mathrm{O}-\mathrm{NaCl}-\mathrm{KCl}-\mathrm{CaCl}_{2}-$ $\mathrm{MgCl}_{2}$. There are two independent sets of ion interactions parameters involving ferrous iron from Marion et al (2003), based on an earlier study of Ptacek (1992), and from Moog et al (2004), the former including ferrous chloride hydrate minerals. The analogous parameters for ferric iron were added to the dataset by Marion et al. (2008), based in part on the earlier study of Christov (2004).

\section{TOPOLOGY AND INTERPRETATION OF PHASE DIAGRAMS}

Phase diagrams presented hereafter were calculated using the ion activity model as described in Section 3. Solid-liquid equilibria were assessed by solving for conditions at which the ion activity product for each solid equaled the equilibrium constant. For equilibria involving multiple solids (univariant cotectic and peritectic curves; invariant points), the same equations were solved simultaneously

\section{$\underline{5.1 \text { Binary systems }}$}


Predictions of some important binary aqueous-chloride salt systems are presented here in order to introduce some of the main cations and their chloride salts, as well as to provide a basis for understanding higher-order systems (Fig. 3). These diagrams compare well to previously determined phase diagrams for the same systems based on experimental studies (e.g. $\mathrm{H}_{2} \mathrm{O}-\mathrm{NaCl}$, Hall et al., 1988; Bodnar, 1993; $\mathrm{H}_{2} \mathrm{O}-\mathrm{KCl}$, Hall et al., 1988; $\mathrm{H}_{2} \mathrm{O}-\mathrm{MgCl}_{2}$, Spencer et al., 1990; $\mathrm{H}_{2} \mathrm{O}-\mathrm{CaCl}_{2}$, Yanatieva, 1946; $\mathrm{H}_{2} \mathrm{O}-\mathrm{FeCl}_{2}$, Borisenko, 1977; $\mathrm{H}_{2} \mathrm{O}-\mathrm{FeCl}_{3}$, Linke, 1958).

The $\mathrm{H}_{2} \mathrm{O}-\mathrm{NaCl}$ system is described in detail in Section 2.1 and Figure 1. The system $\mathrm{H}_{2} \mathrm{O}-\mathrm{KCl}$ (Fig. 3b) differs from $\mathrm{H}_{2} \mathrm{O}-\mathrm{NaCl}$ in that no salt-hydrate is present on the vaporsaturated liquidus. Thus, $\mathrm{H}_{2} \mathrm{O}-\mathrm{KCl}$ has a simple phase diagram, with the eutectic between ice and sylvite located at approximately $-11^{\circ} \mathrm{C}$ and a liquid composition of $19.7 \mathrm{wt} \%$ (3.3 molal) $\mathrm{KCl}$ (Fig. 3, Table 1). Note that owing to the geochemical similarities of the $\mathrm{K}^{+}$ion with the ammonium $\left(\mathrm{NH}_{4}^{+}\right)$ion, the liquidus relations of the $\mathrm{H}_{2} \mathrm{O}-\mathrm{NH}_{4} \mathrm{Cl}$ system are similar to those of $\mathrm{H}_{2} \mathrm{O}-\mathrm{KCl}$. Thus, the $\mathrm{H}_{2} \mathrm{O}-\mathrm{NH}_{4} \mathrm{Cl}$ eutectic occurs at $-15^{\circ} \mathrm{C}$ and 4.4 molal $\mathrm{NH}_{4} \mathrm{Cl}$, between the liquidi of ice and salammoniac (not shown).

Binary systems including divalent cation chlorides (e.g., $\mathrm{Mg}^{2+}, \mathrm{Ca}^{2+}, \mathrm{Fe}^{2+}$ ) are characterized by multiple salt hydrates along the liquidus (Fig. 3c-e). The system $\mathrm{H}_{2} \mathrm{O}-\mathrm{MgCl}_{2}$ is a double-eutectic system, with the lower- $T$ eutectic between ice and $\mathrm{MgCl}_{2} \cdot 12 \mathrm{H}_{2} \mathrm{O}$ at about -33 ${ }^{\circ} \mathrm{C}$ and a liquid salinity of $21 \mathrm{wt} \%$ (2.8 molal) $\mathrm{MgCl}_{2}$ (Table 1$)$. The higher- $T$ eutectic occurs between $\mathrm{MgCl}_{2} \cdot 12 \mathrm{H}_{2} \mathrm{O}$ and $\mathrm{MgCl}_{2} \cdot 8 \mathrm{H}_{2} \mathrm{O}$ at about $-17.5{ }^{\circ} \mathrm{C}$ and a liquid salinity of $31 \mathrm{wt} \%$ $\mathrm{MgCl}_{2}$, and additional peritectic points occur at higher $T$ and salinity. The systems $\mathrm{H}_{2} \mathrm{O}-\mathrm{CaCl}_{2}$ and $\mathrm{H}_{2} \mathrm{O}-\mathrm{FeCl}_{2}$ are both peritectic systems involving multiple hydrates; the eutectic point of the $\mathrm{H}_{2} \mathrm{O}-\mathrm{CaCl}_{2}$ system is located at about $-50{ }^{\circ} \mathrm{C}$ and a liquid salinity of $31 \mathrm{wt} \%$ (4.0 molal) $\mathrm{CaCl}_{2}$, while the eutectic in the $\mathrm{H}_{2} \mathrm{O}-\mathrm{FeCl}_{2}$ system is located at $-37^{\circ} \mathrm{C}$ and a liquid salinity of $30.4 \mathrm{wt} \%$ 
(3.4 molal) $\mathrm{FeCl}_{2}$ (Table 1). In the $\mathrm{H}_{2} \mathrm{O}-\mathrm{CaCl}_{2}$ system, the solid phases in equilibrium at the eutectic are ice plus antarcticite $\left(\mathrm{CaCl}_{2} \cdot 6 \mathrm{H}_{2} \mathrm{O}\right)$, whereas in the $\mathrm{H}_{2} \mathrm{O}-\mathrm{FeCl}_{2}$ system the eutectic solid phases are ice plus $\mathrm{FeCl}_{2} \cdot 6 \mathrm{H}_{2} \mathrm{O}$. Both of these systems have additional peritectic points and salt-hydrates on the liquidus at higher $T$.

Fewer data are available for binary systems involving trivalent-cation $\left(\mathrm{Al}^{3+}, \mathrm{Fe}^{3+}\right)$ chlorides, but these data indicate that the phase diagrams are broadly similar to those of divalent cation chlorides described above (e.g., Fig. 3f). The eutectic temperature of the system $\mathrm{H}_{2} \mathrm{O}-$ $\mathrm{FeCl}_{3}$ is around $-35{ }^{\circ} \mathrm{C}$ and a liquid salinity of $29 \mathrm{wt} \%$ (2.5 molal) $\mathrm{FeCl}_{3}$.. The eutectic temperature for the system $\mathrm{H}_{2} \mathrm{O}-\mathrm{AlCl}_{3}$ was not calculated but is estimated to be approximately $69{ }^{\circ} \mathrm{C}$, based on extrapolation of the data compiled by Linke (1958), with solid phases ice plus $\mathrm{AlCl}_{3} \cdot 6 \mathrm{H}_{2} \mathrm{O}$. It should be noted that trivalent cations such as $\mathrm{Al}^{3+}$ and $\mathrm{Fe}^{3+}$ are not expected to occur in high concentrations in saline FI, owing to the formation of insoluble oxides or hydroxides. In the case of iron, the ferrous ion is the stable form under essentially the entire range of $f_{\mathrm{O} 2}$ conditions of most hydrothermal systems (e.g., Simon et al., 2013), further indicating that ferric iron is unlikely to occur in high concentrations in most aqueous FI. In the present review, we include data on ferric iron in order to convey the behavior of solutions with trivalent cations, while noting that monovalent and divalent cations are the more important cations for saline FIs, in general.

Although their abundances in most geologic fluids are generally low, it is worth noting that chlorides of the small-radius cations $\mathrm{Li}^{+}$and $\mathrm{H}^{+}$exhibit binary aqueous systems that differ from those of other monovalent-cation chlorides (e.g. those of $\mathrm{Na}^{+}, \mathrm{K}^{+}$), and more closely resemble those of the divalent-cation chlorides (e.g., Dubois et al., 2010). This phenomenon relates to the high charge density of the divalent and small monovalent ions. As a result, $\mathrm{LiCl}$ 
and $\mathrm{HCl}$ both form multiple salt hydrates, and are capable of depressing the ice melting temperature to well below $-50{ }^{\circ} \mathrm{C}$ (i.e., lower than the $\mathrm{H}_{2} \mathrm{O}$-divalent cation chlorides). However, buffering of fluids by mineral assemblages normally implies that geologic fluids do not attain $\mathrm{H}^{+}$ concentrations sufficient to significantly affect liquidus relations. Significant $\mathrm{Li}^{+}$concentrations may be attained, for example in pegmatites (Sirbescu et al., 2013), and in such systems accurate quantification of fluid chemistry is a challenge. Reports of high $\mathrm{LiCl}$ concentrations in other environments are summarized by Dubois et al. (2010).

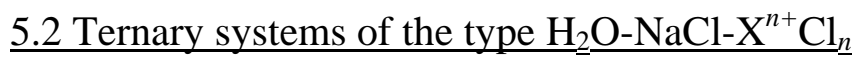

Vapor-saturated ternary liquidus phase diagrams for systems of the type $\mathrm{H}_{2} \mathrm{O}-\mathrm{NaCl}$ $\mathrm{X}^{n+} \mathrm{Cl}_{n}$ (wherein $\mathrm{X}^{n+} \mathrm{Cl}_{n}$ represents a second chloride salt) calculated using Pitzer-type ion interaction modeling are shown in Figs. 4 and 5. These diagrams compare well to previously determined phase diagrams for the same systems based on experimental studies (e.g., $\mathrm{H}_{2} \mathrm{O}-\mathrm{NaCl}-$ $\mathrm{KCl}$, Sterner et al., 1988; $\mathrm{H}_{2} \mathrm{O}-\mathrm{NaCl}-\mathrm{CaCl}_{2}$, Vanko et al., 1988, Oakes et al., 1990; $\mathrm{H}_{2} \mathrm{O}-\mathrm{NaCl}-$ $\mathrm{MgCl}_{2}$, Dubois and Marignac, 1997; $\mathrm{H}_{2} \mathrm{O}-\mathrm{NaCl}-\mathrm{FeCl}_{2}$, Lecumberri-Sanchez et al., 2015). One of the striking features of these diagrams is that nearly all have essentially the same topology, with the exception of the system $\mathrm{H}_{2} \mathrm{O}-\mathrm{NaCl}-\mathrm{KCl}$. Moreover, Dubois et al. (2010) presented a ternary phase diagram for the system $\mathrm{H}_{2} \mathrm{O}-\mathrm{NaCl}-\mathrm{LiCl}$ which also shows essentially the same topology as those shown in Fig. 4. The similarities are most strongly apparent when composition is plotted as mole fraction (Figure 5). In all cases (except $\mathrm{H}_{2} \mathrm{O}-\mathrm{NaCl}-\mathrm{KCl}$ ), the liquid composition at the eutectic is dominated by the second chloride salt $\left(\mathrm{CaCl}_{2}, \mathrm{MgCl}_{2}, \mathrm{FeCl}_{2}\right.$ or $\left.\mathrm{FeCl}_{3}\right)$, whereas the $\mathrm{NaCl}$ concentration in the eutectic liquid is only about 2-5 wt $\%$. The enrichment of the second 
salt in the eutectic liquid, relative to $\mathrm{NaCl}$, is a result of salting-out of sodium chloride by the divalent or trivalent cation chlorides, as well as lithium chloride (Dubois et al., 2010). Thus, the halite liquidus extends to within a few wt $\%$ of the $\mathrm{NaCl}$-free, $\mathrm{H}_{2} \mathrm{O}-\mathrm{X}^{n+} \mathrm{Cl}_{n}$ binaries, except in the $\mathrm{H}_{2} \mathrm{O}-\mathrm{NaCl}-\mathrm{KCl}$ system. The wide compositional extent of the halite liquidus indicates that highsalinity inclusions will generally contain halite daughter minerals at room temperature, rather than respective divalent-cation chloride salts or salt hydrates, even if $\mathrm{Ca}, \mathrm{Mg}$, or Fe significantly exceed Na. Hence, Roedder (1984) cautioned that halite daughter minerals in fluid inclusions should not be interpreted as evidence of $\mathrm{NaCl}$-dominated fluids.

The shapes of the phase diagrams shown in Figs. 4 and 5 are governed principally by the temperature-composition relationships of the hydrohalite liquidus fields, which separate other liquidus surfaces in most of the diagrams. In each diagram, the hydrohalite+ice cotectic extends from the ternary eutectic point to the binary $\mathrm{H}_{2} \mathrm{O}-\mathrm{NaCl}$ eutectic. The similarity in the shape of this cotectic between the different systems is constrained by two features. Firstly, at compositions close to the $\mathrm{H}_{2} \mathrm{O}-\mathrm{NaCl}$ binary, variations in the $\mathrm{NaCl}-\mathrm{X}^{n+} \mathrm{Cl}_{n}$ ratio have little effect on ice or hydrohalite ion activity products, and thus the cotectic boundary runs nearly parallel to the isotherms in the ice and hydrohalite stability fields. Secondly, at compositions closer to the $\mathrm{H}_{2} \mathrm{O}-\mathrm{X}^{n+} \mathrm{Cl}_{n}$ binary, the cotectic diverges to asymptotically approach the binary join.

As a consequence of the similarities in phase diagrams between the various NaCl-bearing ternary systems, the sequence of phase changes expected during heating from subsolidus temperatures to the liquidus is quite similar between different systems. The sequence expected in low- to moderate-salinity FIs in which $\mathrm{Na}^{+}$constitutes more than $\sim 20 \%$ of cation load would be analogous to that shown in Fig. 2. For each different ternary, the eutectic temperature and 
identity of the second salt hydrate would differ (e.g. $\mathrm{FeCl}_{2} \cdot 6 \mathrm{H}_{2} \mathrm{O}, \mathrm{MgCl}_{2} \cdot 12 \mathrm{H}_{2} \mathrm{O}$, etc.), but otherwise the heating path would be topologically identical to the path shown in Fig. 2.

The only exception to the broad similarity of ternary liquidus diagrams involving $\mathrm{NaCl}$ is the system $\mathrm{H}_{2} \mathrm{O}-\mathrm{NaCl}-\mathrm{KCl}$, which has a distinctly different eutectic temperature (around $-20{ }^{\circ} \mathrm{C}$ ) and will commonly show sylvite rather than hydrohalite as the second-to-last solid phase to melt (Fig. 4a). A mechanistic explanation for the differences of $\mathrm{KCl}$ compared to other second salts of type $\mathrm{H}_{2} \mathrm{O}-\mathrm{NaCl}-\mathrm{X}^{n+} \mathrm{Cl}_{n}$ likely relates to the similarity in charge and ionic radius of $\mathrm{K}^{+}$compared to $\mathrm{Na}^{+}$. In addition, the absence of salt hydrates in the $\mathrm{H}_{2} \mathrm{O}-\mathrm{KCl}$ system implies a notably different $\mathrm{H}_{2} \mathrm{O}-\mathrm{X}^{n+} \mathrm{Cl}_{n}$ binary join. It is worth noting that the anhydrous $\mathrm{KCl}-\mathrm{NaCl}$ system also differs from the other $\mathrm{NaCl}-\mathrm{X}^{n+} \mathrm{Cl}_{n}$ binaries in that complete solid solution between halite and sylvite occurs at elevated temperatures (Chou, 1987; Sterner et al., 1988; Bakker, 2012b). It is known empirically that ternary systems exhibiting solid solutions may show smooth transitions from cotectic (congruent melting) to peritectic (incongruent melting) reactions along the univariant curves (i.e., without an associated invariant point), and indeed this is the case in the $\mathrm{H}_{2} \mathrm{O}-\mathrm{NaCl}-\mathrm{KCl}$ system: At low temperatures the halite+sylvite boundary represents a peritectic reaction (sylvite + liquid $=$ halite + liquid; thus, halite shows retrograde solubility in sylvitesaturated solutions at low temperature), but this boundary transitions into a cotectic reaction (halite + sylvite $=$ liquid $)$ with increasing temperature $\left(\sim 100{ }^{\circ} \mathrm{C} ; c f\right.$. Sterner et al., 1988). In practice, these phenomena are unlikely to have major implications for interpreting thermometric properties of $\mathrm{H}_{2} \mathrm{O}-\mathrm{NaCl}-\mathrm{KCl}$ FIs, but they provide hints at the unique properties of this system compared to other $\mathrm{H}_{2} \mathrm{O}-\mathrm{NaCl}-\mathrm{X}^{n+} \mathrm{Cl}_{n}$ systems.

Temperature-salt ratio relations along the ice-hydrohalite cotectic curves (Fig. 6) are fairly similar for all $\mathrm{H}_{2} \mathrm{O}-\mathrm{NaCl}-\mathrm{X}^{n+} \mathrm{Cl}_{n}$ systems. Thus, estimation of $m_{\mathrm{NaCl}} / \sum m$ (where $\sum m=$ 
sum of molal concentration of salts) may be possible without prior knowledge of the identity of the second salt $\left(\mathrm{X}^{n+} \mathrm{Cl}_{n}\right)$. Fairly robust estimates of $m_{\mathrm{NaCl}} / \sum m$ ratio may be obtained independently of the identity of $\mathrm{X}^{n+}$ particularly in cases in which $\mathrm{Na}^{+}$is the dominant cation (i.e., towards the right-hand side of Fig. 6) and the ratio of $m_{\mathrm{K}} / m_{\mathrm{Na}}$ is less than $\sim 0.2$ such that the second-to-last solid phase to melt is hydrohalite and not sylvite. However, the corollary of this observation is that differentiation between $\mathrm{NaCl}$-bearing ternary systems is in principle only possible if we can determine additional subsolidus phases in the inclusion, or by precise measurement of the equilibrium eutectic temperature. The former procedure is generally not possible petrographically, although it can be achieved by cryogenic Raman spectroscopic analysis (e.g., Samson and Walker, 2000; Baumgartner and Bakker, 2010). The challenges of precise eutectic $T$ measurements are discussed above. In addition, note that $\mathrm{H}_{2} \mathrm{O}-\mathrm{NaCl}-\mathrm{X}^{n+} \mathrm{Cl}_{n}$ systems (except $\left.\mathrm{H}_{2} \mathrm{O}-\mathrm{NaCl}-\mathrm{KCl}\right)$ generally show similar eutectic temperatures $\left(\sim-35\right.$ to $-50{ }^{\circ} \mathrm{C}$; Table 1) and distinction would be equivocal except in rare cases. Thus, while estimating the relative proportions (ratios) of $\mathrm{Na}^{+}$to $\mathrm{X}^{n+}$ is generally straightforward, distinguishing the specific type of second salt $\mathrm{X}^{n+} \mathrm{Cl}_{n}$ may be impossible based on petrography and microthermometry alone.

Temperature-salinity relations along the ice liquidi of various ternary systems are also generally quite similar, especially when plotted on a molar basis. The ice-liquidus isotherms tend to overlap, when the various phase diagrams are superimposed (see Lecumberri-Sanchez et al., 2015). This result is expected, based on the thermodynamic relations for ice melting described in Section 3.1 - from Eq. (7), we recognize that the ice melting temperature is a function of the activity of $\mathrm{H}_{2} \mathrm{O}$, which depends mainly on the molal concentration of ions in solution. As an example, Figure 7 shows contours on the ice liquidi for systems of the type $\mathrm{H}_{2} \mathrm{O}-\mathrm{NaCl}-\mathrm{XCl}_{2}$, the 
left hand panel contoured for temperature, and the right-hand panel contoured for activity of $\mathrm{H}_{2} \mathrm{O}$ (activity isopleths). As expected, the match between isotherms and activity isopleths is probably within the error of experiments and the thermodynamic model, and the consistency between different systems (different second salt identity) is noteworthy. Similar overlap is obtained for systems including monovalent (e.g., $\mathrm{KCl}$ ) or trivalent (e.g., $\mathrm{FeCl}_{3}$ ) cation chlorides, provided correction for equivalent number of ions per mole of solute (e.g., recasting $\mathrm{KCl}$ as $\mathrm{K}_{3 / 2} \mathrm{Cl}_{3 / 2}$ and $\mathrm{FeCl}_{3}$ as $\mathrm{Fe}_{3 / 4} \mathrm{Cl}_{9 / 4}$, for plotting on the same diagram as $\mathrm{XCl}_{2}$ ).

\section{$\underline{5.3 .}$ Ternary systems of the type $\mathrm{H}_{2} \underline{O} \underline{\mathrm{O}-\mathrm{KCl}-\mathrm{X}^{n+} \mathrm{Cl}_{n}}$}

Phase diagrams for $\mathrm{NaCl}$-absent saline aqueous systems are generally unavailable in literature. Comparison of liquidus relations in such systems allows identification of features diagnostic of ion-solvent and ion-ion interactions characteristic of different salts. The features of $\mathrm{NaCl}$-absent ternary diagrams further provide constraints to the features of $\mathrm{NaCl}$-bearing quaternary (and higher-order) systems. For example, the ternary $\mathrm{H}_{2} \mathrm{O}-\mathrm{KCl}-\mathrm{FeCl}_{2}$ phase relations contribute directly to observations in the $\mathrm{H}_{2} \mathrm{O}-\mathrm{NaCl}-\mathrm{KCl}-\mathrm{FeCl}_{2}$ quaternary system.

Liquidus relations in systems of the type $\mathrm{H}_{2} \mathrm{O}-\mathrm{KCl}-\mathrm{X}^{n+} \mathrm{Cl}_{n}$ are topologically somewhat similar to those of $\mathrm{H}_{2} \mathrm{O}-\mathrm{NaCl}-\mathrm{X}^{n+} \mathrm{Cl}_{n}$ systems, described above, in that the eutectic liquid composition generally lies close to the binary join between $\mathrm{H}_{2} \mathrm{O}$ and (divalent- or trivalent-cation chloride) $\mathrm{X}^{n+} \mathrm{Cl}_{\mathrm{n}}$. This observation implies salting-out of $\mathrm{KCl}$ by other salts (Fig. 8 and 9). The most obvious difference, compared to $\mathrm{H}_{2} \mathrm{O}-\mathrm{NaCl}-\mathrm{X}^{n+} \mathrm{Cl}_{n}$ systems, is the lack of a stable $\mathrm{KCl}-$ hydrate (Figs. 8 and 9). Thus, unlike the $\mathrm{H}_{2} \mathrm{O}-\mathrm{NaCl}-\mathrm{X}^{n+} \mathrm{Cl}_{n}$ system, in which the ice and halite 
fields are separated by a wedge-shaped stability field of hydrohalite, in the $\mathrm{H}_{2} \mathrm{O}-\mathrm{KCl}-\mathrm{X}^{n+} \mathrm{Cl}_{n}$ systems the ice and sylvite fields share the ice+sylvite cotectic.

The predicted sequence of phase changes in low- to moderately-saline $\mathrm{H}_{2} \mathrm{O}-\mathrm{KCl}-\mathrm{X}^{n+} \mathrm{Cl}_{n}$ FIs during heating is generally similar to that for $\mathrm{H}_{2} \mathrm{O}-\mathrm{NaCl}-\mathrm{X}^{n+} \mathrm{Cl}_{n}$ FIs. In this case, sylvite would be the second-to-last solid phase to melt rather than hydrohalite. The subsolidus assemblage is ice plus sylvite plus a third solid phase, the last of which is typically the first to be consumed at the eutectic. The liquid composition then evolves along the ice+sylvite cotectic until sylvite is consumed, and thereafter evolves along a straight-line trajectory towards the $\mathrm{H}_{2} \mathrm{O}$ apex during progressive heating.

Exceptions to this general description for $\mathrm{H}_{2} \mathrm{O}-\mathrm{KCl}-\mathrm{X}^{n+} \mathrm{Cl}_{n}$ systems occur in systems involving complex chlorides on the liquidus. For example, carnallite $\left(\mathrm{KMgCl}_{3} \cdot 6 \mathrm{H}_{2} \mathrm{O}\right)$ is a liquidus phase in the system $\mathrm{H}_{2} \mathrm{O}-\mathrm{KCl}-\mathrm{MgCl}_{2}$ at high salinity and low potassium content. However, such compositions are unlikely in aqueous natural FIs. In the system $\mathrm{H}_{2} \mathrm{O}-\mathrm{KCl}-\mathrm{FeCl}_{3}$, erythrosiderite $\left(\mathrm{FeK}_{2} \mathrm{Cl}_{5} \cdot \mathrm{H}_{2} \mathrm{O}\right)$ is apparently a eutectic solid phase in this system (Figs. 8 and 9), and persists in high-salinity FIs up to at least $15^{\circ} \mathrm{C}$. Potassium-iron chloride salts involving ferrous iron are also possible (e.g., douglasite: $\mathrm{FeK}_{2} \mathrm{Cl}_{4} \cdot 2 \mathrm{H}_{2} \mathrm{O}$ ), but these salts are not included here owing to lack of thermodynamic data. Either erythrosiderite or douglasite may be the potassium-iron chloride daughter minerals reported by Audétat et al. (2000) in high-salinity brines from the Mole Granite, Australia. Additional examination of such daughter minerals (e.g., by Raman spectroscopy) and the relevant phase equilibria would be very useful in interpreting such FIs.

Finally, we note that the eutectic temperatures of $\mathrm{H}_{2} \mathrm{O}-\mathrm{KCl}-\mathrm{X}^{n+} \mathrm{Cl}_{n}$ systems are all similar to their respective $\mathrm{H}_{2} \mathrm{O}-\mathrm{NaCl}-\mathrm{X}^{n+} \mathrm{Cl}_{n}$ counterparts (Table 1). 


\section{$\underline{5.4 \text { Ternary systems of divalent-cation chlorides }}$}

Although aqueous FIs lacking significant concentrations of monovalent cations seem to be quite rare in nature, saline FIs containing significantly higher concentration of $\mathrm{CaCl}_{2}$ (e.g., Schiffries, 1990) or $\mathrm{FeCl}_{2}$ (e.g., Grant et al., 1977) compared to $\mathrm{NaCl}$ have been reported. Regardless, the divalent-cation-only ternaries provide information on liquidus relations relevant for higher-order (NaCl-bearing) systems.

The liquidus relations (Fig. 10) reveal that, unlike the differences between $\mathrm{Na}^{+}$and $\mathrm{K}^{+}$ (which both showed strong salting out) compared to divalent cations, there is no clearly favored divalent cation in terms of salting-out tendency. Salting out of $\mathrm{Ca}^{2+}$ and $\mathrm{Fe}^{2+}$ by the lower ionic radius $\mathrm{Mg}^{2+}$ ion is subtle and is only observed at higher salinities (Fig. 10). Moreover, in the ternary systems involving two divalent cations, salt hydrates of both cations occupy wide compositional ranges, and a general sequence of phase changes cannot be assigned. The eutectic temperatures for each ternary system are lower than those of the two binary end-members, and also generally lower than those of the to $\mathrm{H}_{2} \mathrm{O}-\mathrm{XCl}-\mathrm{ZCl}_{2}$ (monovalent plus divalent cation chloride) systems (Table 1). The latter observation reflects the compounding effects of multiple divalent cations in lowering the first melting temperature. For example, the system $\mathrm{H}_{2} \mathrm{O}-\mathrm{CaCl}_{2}$ $\mathrm{FeCl}_{2}$ has a eutectic temperature of $-58{ }^{\circ} \mathrm{C}$, lower than both its relevant binaries $\left(\mathrm{H}_{2} \mathrm{O}-\mathrm{CaCl}_{2}: T_{\text {eut }}\right.$ $=-50{ }^{\circ} \mathrm{C} ; \mathrm{H}_{2} \mathrm{O}-\mathrm{FeCl}_{2}: T_{\text {eut }}=-37^{\circ} \mathrm{C}$; Table 1$)$.

\subsection{Quaternary systems}


As noted above, the addition of a fourth component renders straightforward projection of the complete phase relations onto a two-dimensional plane impossible. The approach taken here is to project from the $\mathrm{H}_{2} \mathrm{O}$ apex of the compositional tetrahedron onto the plane of three salts ( $c f$. Crawford et al., 1979). In principle, various features can be projected this way; here, we focus on the quaternary cotectic surfaces, on which ice is one of two stable solid phases, and the intersections of such cotectic surfaces at three-solid-phase cotectic curves. By focusing on the ice-present phase assemblages, we implicitly focus on low-salinity fluid inclusions in which ice is the last solid phase to melt. The eutectic point is captured in all such projections, as ice is a stable phase at the eutectic in all the relevant binary and ternary end-member systems (Table 1).

We focus on two quaternary systems: $\mathrm{H}_{2} \mathrm{O}-\mathrm{NaCl}-\mathrm{CaCl}_{2}-\mathrm{MgCl}_{2}$, and $\mathrm{H}_{2} \mathrm{O}-\mathrm{NaCl}-\mathrm{KCl}-$ $\mathrm{FeCl}_{2}$. The former can be considered broadly representative of basinal brines/saline groundwater, such as fluids in many sedimentary-hosted base metal deposits (e.g., Mississippi Valley-type deposits; e.g., Stoffel et al., 2008) and is also relevant to subseafloor hydrothermal systems (e.g., Vanko et al., 1988) where Ca:Mg exchange occurs between seawater and basalt. The latter quaternary system can be considered to represent typical continental magmatic-hydrothermal fluids such as those involved in formation of porphyry-type and granite-related ore deposits (e.g., Audétat et al., 2000).

\subsubsection{The system $\mathrm{H}_{2} \mathrm{O}-\mathrm{NaCl}-\mathrm{CaCl}_{2}-\mathrm{MgCl}_{2}$}

The projection from ice onto the cotectics of the $\mathrm{H}_{2} \mathrm{O}-\mathrm{NaCl}-\mathrm{CaCl}_{2}-\mathrm{MgCl}_{2}$ system is shown in Fig. 11. A similar projection in this system was first presented by Crawford et al. (1979), who applied insights from this system to FIs from calc-silicate metamorphic rocks. 
Figure 11 shows only slight differences compared to the earlier projection by Crawford et al. (1979), most likely as a result of additional vapor-saturated liquidus data (e.g., Oakes et al., 1990; Dubois and Marignac, 1997).

For low-salinity FIs (in which ice is the last solid phase to melt), the subsolidus assemblage in the system $\mathrm{H}_{2} \mathrm{O}-\mathrm{NaCl}-\mathrm{CaCl}_{2}-\mathrm{MgCl}_{2}$ consists of ice, hydrohalite, antarcticite and $\mathrm{MgCl}_{2} \cdot 12 \mathrm{H}_{2} \mathrm{O}$ plus vapor (Fig. 11). The eutectic temperature is approximately $-52{ }^{\circ} \mathrm{C}$, only incrementally lower than that of the system $\mathrm{H}_{2} \mathrm{O}-\mathrm{NaCl}-\mathrm{CaCl}_{2}$ (Table 1). The latter observation highlights the relative insensitivity of first melting temperatures to additional components; for aqueous systems of $N$ major cation-chlorides $(N>2)$, the eutectic temperature is generally only incrementally lower than that of lowest associated $(N-1)$ cation-chloride system eutectic (Table 1). This rule-of-thumb provides a useful guide for estimating eutectic temperatures for higherorder systems.

Upon heating to the eutectic temperature, the first solid phase to be consumed in most $\mathrm{H}_{2} \mathrm{O}-\mathrm{NaCl}-\mathrm{CaCl}_{2}-\mathrm{MgCl}_{2}$ FIs will be antarcticite, thus yielding a $\mathrm{CaCl}_{2}$-enriched eutectic liquid (Table 1, Fig. 11). With further heating, the liquid composition will evolve along the ice+hydrohalite $+\mathrm{MgCl}_{2} \cdot 12 \mathrm{H}_{2} \mathrm{O}$ cotectic curve, along which the liquid composition becomes more $\mathrm{MgCl}_{2}$-rich, until $\mathrm{MgCl}_{2} \cdot 12 \mathrm{H}_{2} \mathrm{O}$ is consumed. Thereafter, with additional heating the liquid composition will follow a straight-line trajectory (when projected onto the plane of three salts as in Fig. 11) towards the composition of hydrohalite (which plots at the $\mathrm{NaCl}$ apex in this projection) until hydrohalite is consumed. Between the temperature of hydrohalite melting and the temperature of ice melting, the liquid becomes progressively diluted but the ratio of salts is unchanged, and thus the salt ratio obtained from $\mathrm{MgCl}_{2} \cdot 12 \mathrm{H}_{2} \mathrm{O}$ and hydrohalite melting temperatures on Fig. 11 represents the bulk $\mathrm{NaCl}: \mathrm{CaCl}_{2}: \mathrm{MgCl}_{2}$ ratio (cf. Crawford et al., 1979). 
In practice, it may be extremely challenging (or impossible) to observe and recognize $\mathrm{MgCl}_{2} \cdot 12 \mathrm{H}_{2} \mathrm{O}$ melting; even so, Fig. 11 suggests that in $\mathrm{H}_{2} \mathrm{O}-\mathrm{NaCl}-\mathrm{CaCl}_{2}-\mathrm{MgCl}_{2}$ FIs, phasechange observations between -52 to $-35{ }^{\circ} \mathrm{C}$ may provide a suggestion of the ratios between divalent cations. Such ratios provide useful constraints on bulk composition, particularly because isotherms on the hydrohalite surface are essentially parallel to the $\mathrm{CaCl}_{2}-\mathrm{MgCl}_{2}$ join; thus, the hydrohalite melting temperature is essentially independent of the ratios between divalent-cation chlorides (Fig. 11).

\subsubsection{The system $\mathrm{H}_{2} \mathrm{O}-\mathrm{NaCl}-\mathrm{KCl}-\mathrm{FeCl} \mathrm{Cl}_{2}$}

Audétat et al. (2000) reported that sodium, potassium and iron are the three most concentrated cations in fluids related to Sn-W mineralization at the Mole Granite. Interestingly, manganese is the next most abundant cation in those fluids. Similar observations on $\mathrm{Na}$, K and Fe concentrations have been reported from several magmatic-hydrothermal systems (e.g., see Yardley, 2005), and the phase relations in the $\mathrm{H}_{2} \mathrm{O}-\mathrm{NaCl}-\mathrm{KCl}-\mathrm{FeCl}_{2}$ system are thus of particular interest for such environments.

Figure 12 shows a projection from ice onto the cotectic surface of the liquidus in the system $\mathrm{H}_{2} \mathrm{O}-\mathrm{NaCl}-\mathrm{KCl}-\mathrm{FeCl}_{2}$. For low- to moderate-salinity inclusions (in which ice is the last solid phase to melt, the subsolidus assemblage is ice, hydrohalite, sylvite and $\mathrm{FeCl}_{2} \cdot 6 \mathrm{H}_{2} \mathrm{O}$. Neither douglasite nor rinneite $\left(\mathrm{NaK}_{3} \mathrm{FeCl}_{6}\right)$ stability in the subsolidus is included here because of lack of thermodynamic data. The predicted eutectic temperature is approximately $-40{ }^{\circ} \mathrm{C}$, again only incrementally lower than that of ternary systems of the type $\mathrm{H}_{2} \mathrm{O}-(\mathrm{Na}, \mathrm{K}) \mathrm{Cl}-\mathrm{FeCl}_{2}$, as well as the $\mathrm{H}_{2} \mathrm{O}-\mathrm{FeCl}_{2}$ binary (Table 1). At the eutectic temperature, for most geologic fluid 
compositions, $\mathrm{FeCl}_{2}$-rich solution is produced and ferrous-chloride hydrate is the first phase to be completely melted (Fig. 12). With additional heating, the liquid composition evolves along the ice+sylvite+hydrohalite cotectic, keeping a roughly constant $\mathrm{NaCl} / \mathrm{KCl}$ ratio but slowly becoming more enriched in $\mathrm{NaCl}$, until either sylvite or hydrohalite is completely consumed. With further heating, the liquid composition evolves along a straight-line trajectory (in this projection) towards either the $\mathrm{KCl}$ apex (until sylvite is consumed) or the $\mathrm{NaCl}$ apex (until hydrohalite is consumed). Ice is the last solid phase to melt, and as in the case of $\mathrm{H}_{2} \mathrm{O}-\mathrm{NaCl}-$ $\mathrm{CaCl}_{2}-\mathrm{MgCl}_{2}$ described above, the ratios of salts are unchanged between second-to-last and last melting. Also similar to the case of hydrohalite in the $\mathrm{H}_{2} \mathrm{O}-\mathrm{NaCl}-\mathrm{CaCl}_{2}-\mathrm{MgCl}_{2}$ system, in the $\mathrm{H}_{2} \mathrm{O}-\mathrm{NaCl}-\mathrm{KCl}-\mathrm{FeCl}_{2}$ system the isotherms on the sylvite surface are nearly parallel to the $\mathrm{NaCl}-$ $\mathrm{FeCl}_{2}$ join, indicating that sylvite melting temperature provides essentially no information on the $\mathrm{NaCl}: \mathrm{FeCl}_{2}$ ratio.

To test the predicted liquidus relations shown in Fig. 12, we conducted freezing/heating experiments on synthetic $\mathrm{H}_{2} \mathrm{O}-\mathrm{NaCl}-\mathrm{KCl}-\mathrm{FeCl}_{2}$ FIs of known composition. The inclusions were synthesized according to the procedures described by Lecumberri-Sanchez et al. (2015), based on the procedures developed by Sterner and Bodnar (1984). The composition of the fluid inclusions studied here is: $8.7 \mathrm{wt} \% \mathrm{NaCl}, 4.1 \mathrm{wt} \% \mathrm{KCl}, 8.7 \mathrm{wt} \% \mathrm{FeCl}_{2}$, and $78.5 \mathrm{wt} \% \mathrm{H}_{2} \mathrm{O}$. Microthermometric observations were made using the temperature cycling method (Zwart and Touret, 1994; Goldstein and Reynolds, 1994; Schlegel et al., 2012), with one modification: because the fluid inclusions exhibited three solid phases above the eutectic temperature, it proved difficult to grow large, single crystals of solids other than ice. This was because heating to the point at which only a small single crystal of sylvite remained (in order to grow a single sylvite crystal) would result in complete melting of hydrohalite. Conversely, heating only to the point at 
which a small hydrohalite crystal remained (in order to grow a single hydrohalite crystal) would leave many small crystallites of sylvite, which were difficult to observe. Therefore, the best compromise seemed to be to repeatedly rapidly heat the inclusion above the hydrohalite melting temperature (as high as possible, up to the sylvite melting temperature), then immediately re-cool the inclusion to the eutectic temperature. This way, a reasonably well-resolved sylvite crystal could be grown, along with a few obvious hydrohalite grains (owing to the sluggish melting of this latter phase).

Figure 13 firstly shows that in the synthetic inclusions, liquid is clearly present well below the eutectic temperature (upper-left panel; $-50{ }^{\circ} \mathrm{C}$ ). This reflects a metastable state in the inclusions, in which ferrous-chloride hydrate fails to nucleate. Similar observations were noted for calcium chloride hydrates by Oakes et al. (1990) and Baumgartner and Bakker (2010). Regardless, the sequence of phase changes above the eutectic temperature represents the expected stable (equilibrium) sequence: Hydrohalite is consumed at $-25^{\circ} \mathrm{C}$, sylvite melts at -22.5 ${ }^{\circ} \mathrm{C}$, and ice is the last solid phase to melt at $-14.5^{\circ} \mathrm{C}$ (Fig. 13). The lower-right panel in Fig. 13 shows the projection of the measured microthermometric data onto a heating path on the phase diagram. Above the eutectic temperature (although the eutectic event itself is not observed), the liquid composition evolves along the ice+hydrohalite+sylvite curve until hydrohalite is consumed at $T_{\mathrm{m}, \mathrm{hh}}\left(-25^{\circ} \mathrm{C}\right.$; Fig. 13). With further heating, the liquid composition evolves along a path that projects as a straight line, towards the $\mathrm{KCl}$ apex until sylvite is consumed at $T_{\mathrm{m}, \mathrm{syl}}(-22.5$ ${ }^{\circ} \mathrm{C}$; Fig. 13). These two data uniquely constrain the ratios of the three salts in the inclusion (independently of $T_{\mathrm{m}, \mathrm{ice}}$ ); in this example, the predicted ratios are $36 \mathrm{wt} \% \mathrm{NaCl}, 18.5 \mathrm{wt} \% \mathrm{KCl}$ and $45.5 \mathrm{wt} \% \mathrm{FeCl}_{2}$ (on an anhydrous basis). The true salt ratios in the inclusion, known from the masses of starting materials used in the fluid inclusion synthesis experiment, are $40 \mathrm{wt} \%$ 
$\mathrm{NaCl}, 20 \mathrm{wt} \% \mathrm{KCl}$ and $40 \mathrm{wt} \% \mathrm{FeCl}_{2}$ (on an anhydrous basis). Thus, the predicted phase relations in this system provide a good match with empirical observations on salt ratios. From the ice melting temperature, $T_{\mathrm{m}}$, ice $\left(-14.6^{\circ} \mathrm{C}\right.$; Fig. 13), we can also calculate the absolute concentrations of salts (using Eqs. (5) and (7) plus the Pitzer ion-interaction equations), which yields $7.0 \mathrm{wt} \% \mathrm{NaCl}, 3.7 \mathrm{wt} \% \mathrm{KCl}$ and $8.8 \mathrm{wt} \% \mathrm{FeCl}_{2}\left(80.5 \mathrm{wt} \% \mathrm{H}_{2} \mathrm{O}\right)$. The calculated $\mathrm{KCl}$ and $\mathrm{FeCl}_{2}$ concentrations are thus both accurate to within a few tenths of a wt $\%$, whereas the calculated $\mathrm{NaCl}$ concentration is about $1.7 \mathrm{wt} \%$ too low in this example. Nevertheless, this example shows how multiple melting temperatures can be interpreted using phase diagrams for multicomponent systems to yield reasonable estimates for concentrations of each component.

\section{$\underline{5.6 \text { Higher-order systems }}$}

Calculation of liquidus surfaces, as well as the temperature and liquid composition at the eutectic of various higher-order systems is possible in principle using the solubility-product relations and an ion-interaction model as employed in this review. The accuracy of such predictions is unknown, because no experimental data in such higher-order systems are available. Nevertheless, prediction of the eutectic temperatures is useful in order to assess whether significant depression of the first-melting temperature would be expected in complex systems. We do not include phase diagrams for systems of more than four components. In part, this is because of the challenge of projecting such systems onto a two-dimensional plane.

Table 1 lists the calculated eutectic temperatures for two systems of more than four components: Firstly, the senary (six-component) system containing all the monovalent and divalent cations considered here, $\mathrm{H}_{2} \mathrm{O}-\mathrm{NaCl}-\mathrm{KCl}-\mathrm{CaCl}_{2}-\mathrm{MgCl}_{2}-\mathrm{FeCl}_{2}$; secondly, the septenary 
(seven-component) system containing the aforementioned chlorides plus $\mathrm{FeCl}_{3}$. As noted above, high concentrations of ferric iron are not normally expected in saline FI, and thus the senary system is probably a better approximation of most FIs.

The eutectic point of the senary system (monovalent plus divalent cations) is approximately $-58.5^{\circ} \mathrm{C}$; the subsolidus assemblage includes ice, hydrohalite, sylvite, antarcticite, $\mathrm{MgCl}_{2} \cdot 12 \mathrm{H}_{2} \mathrm{O}$ and $\mathrm{FeCl}_{2} \cdot 6 \mathrm{H}_{2} \mathrm{O}$ (Table 1). For most geologic fluids, the solid phases to be consumed first at the eutectic would be either antarcticite or $\mathrm{FeCl}_{2} \cdot 6 \mathrm{H}_{2} \mathrm{O}$, to yield a calcium- and iron-rich liquid. Interestingly, the eutectic liquid composition is almost magnesium-free (Table 1). Based on comparison with the quaternary systems described in Section 5.5, we predict that $\mathrm{MgCl}_{2} \cdot 12 \mathrm{H}_{2} \mathrm{O}$ would normally be the third-to-last solid phase to melt, and the second-to-last solid to melt would likely be either sylvite or hydrohalite, depending on the sodium-to-potassium ratio.

Addition of ferric chloride to the senary system yields a further depression of the eutectic temperature to $-64.5^{\circ} \mathrm{C}$, and the appearance of erythrosiderite $\left(\mathrm{FeK}_{2} \mathrm{Cl}_{5} \cdot \mathrm{H}_{2} \mathrm{O}\right)$ as a subsolidus phase (Table 1). Not surprisingly, $\mathrm{FeCl}_{3}$ addition has a somewhat stronger effect on the depression of the eutectic temperature, compared to monovalent and divalent cation chlorides. The first solid phases to melt at and above the eutectic would be antarcticite, erythrosiderite and $\mathrm{FeCl}_{2} \cdot 6 \mathrm{H}_{2} \mathrm{O}$, again yielding a calcium- and iron-rich liquid. The sequence of phase changes upon further heating would resemble that of the senary system.

\subsection{Eutectic abundances of liquid}


In principle, precise measurements of liquid volume fractions at the eutectic temperature could supplement microthermometric observations and allow various chemical systems with similar eutectic temperatures to be differentiated. Knowledge of the eutectic liquid composition for various water-salt systems (Table 1) permits computation of the mass and volume fractions of liquid produced at the eutectic, for given bulk compositions of aqueous FI. The procedure involves mass balance calculation for the mass of liquid produced, and invokes empirical expressions for composition-density relations of the fluid (Novotny and Söhnel, 1988) to convert mass fractions to volume fractions. In practice, because volume fractions are difficult to estimate petrographically, and yield high uncertainties, this method of differentiating systems would only be practical if liquid volume fractions differ substantially between different systems.

For example, consider FIs represented by the systems $\mathrm{H}_{2} \mathrm{O}-\mathrm{NaCl}$ and $\mathrm{H}_{2} \mathrm{O}-\mathrm{NaCl}-\mathrm{KCl}$. As the eutectic temperatures of these two systems are similar (ca. $-20{ }^{\circ} \mathrm{C}$; Table 1 ), differences in eutectic liquid fractions may be of interest. Based on the data presented in Table 1, an $\mathrm{H}_{2} \mathrm{O}-\mathrm{NaCl}$ FI with an ice melting temperature of $-10^{\circ} \mathrm{C}$ contains $\sim 55$ vol\% liquid at the eutectic temperature. In the case of $\mathrm{H}_{2} \mathrm{O}-\mathrm{NaCl}-\mathrm{KCl}$ FIs with ice melting temperatures of $-10{ }^{\circ} \mathrm{C}$, the eutectic liquid volume fraction depends on the $\mathrm{NaCl} / \mathrm{KCl}$ ratio. For a molar ratio $m_{\mathrm{KCl}} / m_{\mathrm{NaCl}}=$ 0.2 , the eutectic liquid volume fraction will be $\sim 53 \mathrm{vol} \%$, thus essentially equal to the $\mathrm{H}_{2} \mathrm{O}-\mathrm{NaCl}$ binary system. In contrast, for a more KCl-rich fluid with the molar ratio $m_{\mathrm{KCl}} / m_{\mathrm{NaCl}}=1$ (with the same ice melting $T=-10{ }^{\circ} \mathrm{C}$ ), the FI contains $\sim 32$ vol\% liquid at the eutectic. Nevertheless, in this simple example, the temperatures of phase changes are more likely to be diagnostic of salt ratios, rather than the volume fractions.

In the case of ternary systems of the type $\mathrm{H}_{2} \mathrm{O}-\mathrm{NaCl}-\mathrm{XCl}_{2}\left(\mathrm{X}=\mathrm{Ca}^{2+}, \mathrm{Mg}^{2+}, \mathrm{Fe}^{2+}\right)$, the similarities between phase relations noted in Section 5.2 (see Fig. 7) imply that eutectic liquid 
volume fractions are generally also similar. For example, for a fluid inclusion exhibiting ice melting at $-10{ }^{\circ} \mathrm{C}$ and with cation molar ratio $m_{\mathrm{Na}} / m_{\mathrm{X}}=0.2$, the volume fraction of liquid produced at the eutectic is $11 \mathrm{vol} \%$ if $\mathrm{X}=\mathrm{Ca}, 16 \mathrm{vol} \%$ if $\mathrm{X}=\mathrm{Mg}$, and $12 \mathrm{vol} \%$ if $\mathrm{X}=\mathrm{Fe}$. Not surprisingly, $\mathrm{MgCl}_{2}$ differs most strongly with respect to the other divalent cations; even so, all three systems show quite similar volume fractions, within likely precision of such observations.

In the quaternary and higher-order systems shown in Figs. 11 and 12 cotectic curves most likely followed by the liquid composition above the eutectic temperature run nearly parallel to one binary join. Consequently, in $\mathrm{H}_{2} \mathrm{O}-\mathrm{NaCl}-\mathrm{CaCl}_{2}-\mathrm{MgCl}_{2}$ inclusions in which $\mathrm{NaCl}$ is the dominant salt (for example), the volume fraction of liquid remains low from the eutectic until the magnesium chloride hydrate is completely melted. A corollary of this observation is that first clear observation of liquid in the inclusion may coincide more closely with departure from the ice+hydrohalite $+\mathrm{MgCl}_{2} \cdot 12 \mathrm{H}_{2} \mathrm{O}$ cotectic curve, rather than the "true" eutectic event. Similarly, FI in the system $\mathrm{H}_{2} \mathrm{O}-\mathrm{NaCl}-\mathrm{KCl}-\mathrm{FeCl}_{2}$ containing relatively low concentrations of $\mathrm{FeCl}_{2}$ may exhibit the first clearly observable liquid closer to the departure from the ice+sylvite+hydrohalite cotectic curve, rather than the eutectic point itself. In these and other quaternary and higher-order systems, a range of reported first melting temperatures may thus be expected, and would be consistent with the phase relations at the precision of optical first-melt observations.

In the case of the senary (monovalent plus divalent cation chloride) system, the concentrations of $\mathrm{NaCl}$ and $\mathrm{KCl}$ in the eutectic liquid are even lower (Table 1) and FIs in which $\mathrm{NaCl}$ and/or $\mathrm{KCl}$ are the dominant salt components will generally yield vanishingly small mass fractions of liquid at the eutectic. Based on phase relations in the quaternary systems described above, we expect that between the senary eutectic $\left(-58.5^{\circ} \mathrm{C}\right)$ and the $\mathrm{H}_{2} \mathrm{O}-\mathrm{MgCl}_{2}$ binary eutectic temperature $\left(-35^{\circ} \mathrm{C}\right)$, the mass fraction of liquid produced will remain low until all divalent- 
cation salt hydrates are melted. Thus, senary FIs dominated by $\mathrm{NaCl}$ and/or $\mathrm{KCl}$ may exhibit low volume fraction of liquid until $\mathrm{MgCl}_{2} \cdot 12 \mathrm{H}_{2} \mathrm{O}$ is fully melted, which will generally occur between about -50 to $-35{ }^{\circ} \mathrm{C}$ depending on the bulk salinity. Liquid in senary FIs may therefore not generally be observed until $T$ significantly exceeds the true eutectic $\left(-58.5^{\circ} \mathrm{C}\right.$; Table 1$)$. Similar arguments can be applied also to the septenary system.

\section{DISCUSSION}

\subsection{Differentiating fluid inclusion salt contents by the sequence of phase changes}

The vapor-saturated liquidus phase diagrams presented here indicate that the sequences of likely observable phase changes during heating from the eutectic to the liquidus are similar for FIs throughout a wide range of common complex compositions. If $\mathrm{Na}^{+}$is the dominant cation in a low- to moderate-salinity inclusion, the last solid phase to melt will be ice, and the second-tolast solid phase will be hydrohalite. This sequence applies whichever divalent or trivalent cations are present in the inclusion, and their individual concentrations. Exceptions are cases in which molar ratio $m_{\mathrm{K}} / m_{\mathrm{Na}}>\sim 0.2$, for which the second-to-last solid phase to melt will be sylvite (Fig. 5), or rare cases in which other salt hydrates (particularly those of divalent cations) are the second-to-last solid to melt in fluids with a very high ratio of the cation of that hydrate to sodium. These conclusions can likely be extended to cations that have not been explicitly considered here, including $\mathrm{H}^{+}, \mathrm{Li}^{+}, \mathrm{NH}_{4}{ }^{+}, \mathrm{Cu}^{+}, \mathrm{Cu}^{2+}$ and $\mathrm{Mn}^{2+}$. Petrographic observations thus generally do not provide information on which are the dominant cations present in a fluid. For instance, recognition of hydrohalite melting will not normally distinguish between the Na- plus 
Ca-rich brines associated with saline groundwaters and Mississippi Valley-type mineralization (Stoffel et al., 2008) versus many magmatic-hydrothermal fluids in which $\mathrm{Na}>\mathrm{K} \sim \mathrm{Fe}>\mathrm{Mn}>$ Ca (Audétat et al., 2000). Hydrohalite melting temperatures will however be lower in FIs with higher proportions of additional salts other than $\mathrm{NaCl}$ (Fig. 6).

The present results indicate that microthermometric observations will also not be distinctive of secondary cations. Except for the case of $\mathrm{H}_{2} \mathrm{O}-\mathrm{NaCl}-\mathrm{KCl}$, equilibrium eutectic temperatures of all ternary $\mathrm{H}_{2} \mathrm{O}-\mathrm{NaCl}-\mathrm{X}^{n+} \mathrm{Cl}_{n}$ systems $\left(-52\right.$ to $-35^{\circ} \mathrm{C}$; Table 1$)$ are significantly depressed below the binary $\mathrm{H}_{2} \mathrm{O}-\mathrm{NaCl}$ eutectic. For multi-component geologic fluids, equilibrium eutectic temperatures will be lower than the eutectic temperatures of all relevant binary or ternary subsystems. For instance, any multicomponent solution containing $\mathrm{CaCl}_{2}$ will exhibit a eutectic temperature lower than that of the ternary $\mathrm{H}_{2} \mathrm{O}-\mathrm{NaCl}-\mathrm{CaCl}_{2}$ system (Table 1), even if $\mathrm{Ca}^{2+}$ is only a minor component. Observations of low eutectic temperatures only allow the qualitative conclusion that one or more metal-chloride salts are present together with $\mathrm{NaCl}$. Such observations generally cannot be used to infer a specific chemical system, without additional evidence. For example, Kontak and Kyser (2011), used SEM analysis of decrepitate mounds to support interpretation from microthermometry that $\mathrm{NaCl}$ and $\mathrm{CaCl}_{2}$ are the dominant salts in a studied suite of inclusions. Cryogenic Raman spectroscopy also has the potential to differentiate between different assemblages at temperatures both below and above the eutectic, thus providing further evidence of the identities of solutes in an FI (Samson and Walker, 2000; Baumgartner and Bakker, 2010; Uriarte et al., 2015). Together, these results indicate that (despite our best efforts), it is generally impossible to differentiate between FI throughout a wide range of types and proportions of major cations based on petrographic and microthermometric properties alone. 
Fluids of some specific compositional types do show distinctive behavior. Potassium-rich fluids, with molar ratio $m_{\mathrm{K}} / m_{\mathrm{Na}}>\sim 0.2$, are predicted to have sylvite as the second-to-last solid phase to dissolve. A further distinction possible from microthermometric observations is between fluids of most ternary and higher-order systems (which generally exhibit eutectic temperatures below $-35^{\circ} \mathrm{C}$ ) and fluids that belong effectively to the binary $\mathrm{H}_{2} \mathrm{O}-\mathrm{NaCl}$ system, such as in orogenic-Au systems. Fluids in orogenic-Au systems are also multi-component in nature, although commonly $\mathrm{NaCl}$-dominated. Thus, although the equilibrium eutectic in such systems should be much lower than $-20^{\circ} \mathrm{C}$, in practice the first observable liquid may only be visible around this temperature. The observation that eutectic temperatures of fluid inclusions from orogenic-Au deposits generally exceed those of intrusion-centered ore deposits (e.g. Diamond, 1990; Hagemann and Lüders, 2003) presumably reflects the extremely small amounts of liquid present in FI in the former systems at temperatures lower than the $\mathrm{H}_{2} \mathrm{O}-\mathrm{NaCl}$ binary eutectic. By mass balance, we can infer that for inclusions of equivalent size and salinity, the volume of liquid present just above the equilibrium eutectic temperature will be proportional to the concentration of components other than $\mathrm{NaCl}$. The presence of significant concentrations of other anions (e.g. $\mathrm{HCO}_{3}{ }^{-}, \mathrm{SO}_{4}{ }^{2-}$ ) may give rise to distinctive behaviors that deserve further investigation.

On the other hand, the similarity of the liquidus phase diagrams between different systems, and the relatively small changes to the phase relations due to the addition of moderate amounts of additional components, can be utilized in order to obtain robust information on fluid inclusion compositions of generic types. The similarities between phase diagrams for different chemical systems imply that, provided that $m_{\mathrm{K}} / m_{\mathrm{Na}}<0.2$, the bulk salinity and ratio of sodium to divalent and/or trivalent cations can be obtained from microthermometric observations, 
without knowing the specific types of cations in the inclusion. In these cases, the $m_{\mathrm{Na}} / m_{\sum^{+}}$ratio ( $m_{\sum^{+}}=$molal concentration sum of all cations) obtained from the measured hydrohalite melting temperature and Fig. 6, will be reasonably precise, without specifying the type(s) of other cations. Note, however, that precision will decrease with decreasing hydrohalite melting temperature, owing to the divergence of the iron-bearing cotectic curves; more precise estimates are obtained if the relative abundance of iron can be determined or inferred. The bulk salinity of an inclusion may be estimated with reasonable precision from the ice melting temperature, using Figure 7, again without a specific requirement to assign an identity to the different cations.

\subsection{Quantitative interpretation of microthermometric plus microanalytical data}

Estimation of absolute concentrations of major and minor cations by microanalytical methods generally requires input parameters obtained from interpretation of microthermometric data. Several methods have been described for simultaneously interpreting microthermometric and microanalytical data (Eqs. (1) to (5)). Note that all these methods tend to propagate all analytical uncertainties into the final uncertainty on concentrations of all analytes. Equations (1) to (4) have the disadvantage of lacking thermodynamic rigor, although in many cases either method yields reasonably accurate estimates (e.g., Allan et al., 2005). Equation (5) provides an improvement in terms of thermodynamic rigor, and also can yield accurate results (Leisen et al., 2012). However, none of these methods overcomes the more insidious challenge related to the error propagated from imprecision of analytical element ratios. 
Our data suggest an alternative method for internal standardization of FI data based on parameters obtained from microthermometric interpretation. The method follows in part Schlegel et al. (2012), who interpreted the last and second-to-last (usually ice and hydrohalite, respectively) melting temperatures of saline aqueous FI according to the ternary $\mathrm{H}_{2} \mathrm{O}-\mathrm{NaCl}$ $\mathrm{CaCl}_{2}$ phase relations (Steele-MacInnis et al., 2011), thus obtaining an estimate of the absolute sodium chloride concentration to use as the internal standard for LA-ICPMS data reduction. Here we present the extension of this method to the generic case of $\mathrm{H}_{2} \mathrm{O}-(\mathrm{Na}, \mathrm{K}) \mathrm{Cl}-\Sigma \mathrm{X}^{n+} \mathrm{Cl}_{n} \mathrm{FI}$.

As noted above, the similarity of the liquidus phase relations of different ternary systems, and the relatively small changes to the phase relations upon addition of moderate amounts of further salts, taken together imply that compositions of many fluid inclusions can be interpreted according to a generic "pseudo"-ternary system $\mathrm{H}_{2} \mathrm{O}-\mathrm{NaCl}-\Sigma \mathrm{X}^{n+} \mathrm{Cl}_{n}$. Whenever possible, the best practice would be to measure both ice and hydrohalite melting temperatures ( $c f$. Schlegel et al., 2012). Based on these data, two parameters can be estimated:

(1) The activity of $\mathrm{H}_{2} \mathrm{O}$. From the ice melting temperature, $a_{\mathrm{H} 2 \mathrm{O}}$ can be obtained from the solubility product of ice (e.g., Marion, 2002). The traditional "salinity" units used to describe fluid inclusions in terms of $\mathrm{wt} \% \mathrm{NaCl}$ equivalent can be considered a direct proxy for $a_{\mathrm{H} 2 \mathrm{O}}$. Although the specific identities of solutes will have some effect on $a_{\mathrm{H} 2 \mathrm{O}}$, for common fluid compositions $a_{\mathrm{H} 2 \mathrm{O}}$ will closely track the total molal concentration of ions $\left(m_{\sum^{ \pm}}\right)$. Thus, $a_{\mathrm{H} 2 \mathrm{O}}$ can be recalculated directly to $m_{\sum^{ \pm}}$using (for example) the Debye-Hückel equation. Alternatively, for low- to moderate-salinity fluids, salinity in terms of wt $\% \mathrm{NaCl}$ equivalent can be converted to $m_{\sum^{ \pm}}$directly at an accuracy of (at worst) a few percent relative, irrespective of the identity of the cations. 
(2) The ratio of $\mathrm{Na}^{+}$to total cations. The molar ratio $\left(m_{\mathrm{Na}}\right) / m_{\sum^{+}}$, i.e., the molar proportion of sodium relative to the total cation load in solution, is obtained as a function of the observed depression of the hydrohalite melting temperature below that of the $\mathrm{H}_{2} \mathrm{O}-\mathrm{NaCl}$ binary system. The ice+hydrohalite cotectic represents the intersection of liquidus surfaces of ice and hydrohalite (i.e., simultaneous solution of Eq. (7) and (12)), and for chloride-dominated multicomponent fluids $a_{\mathrm{Na}+}$ is thus the main factor that controls the hydrohalite melting temperature. Knowing the ratio $\left(m_{\mathrm{Na}}\right) / m_{\sum^{+}}, m_{\mathrm{Na}}$ can be obtained directly from $m_{\sum^{ \pm}}$determined above, assuming that divalent cations make up most of the remainder of $m_{\sum^{+}}$, and that total charge is balanced by chloride as the dominant anion.

We suggest the following equations to implement this approach. The activity of $\mathrm{H}_{2} \mathrm{O}$ is calculated from (Marion, 2002):

$a_{\mathrm{H}_{2} \mathrm{O}}=K_{\mathrm{ice}}=1.906354-1.880285 \mathrm{e}-2\left(T_{\mathrm{K}}\right)+6.603001 \mathrm{e}-5\left(T_{\mathrm{K}}{ }^{2}\right)-3.419967 \mathrm{e}-8\left(T_{\mathrm{K}}{ }^{3}\right)$

where $T_{\mathrm{K}}$ is the ice melting temperature $(\mathrm{K})$. The molality of ions appropriate for the measured ice melting temperature is calculated from the wt\% $\mathrm{NaCl}$ equivalent salinity (Bodnar, 1993):

$$
w_{\mathrm{NaCl}, \mathrm{eq} .}=-1.78(T)-0.0442\left(T^{2}\right)-0.000557\left(T^{3}\right)
$$


where $T$ represents the ice melting temperature $\left({ }^{\circ} \mathrm{C}\right)$. The wt $\% \mathrm{NaCl}$ equivalent concentration obtained from Eq. (14) can be converted into an estimate of molal concentration of ions $\left(m_{\sum^{ \pm}}\right)$ according to the molar mass of $\mathrm{NaCl}$ (and two ions per mole $\mathrm{NaCl}$ ) as

$$
m_{\sum \pm}=\frac{2\left(w_{\mathrm{NaCl}, \mathrm{eq} .} / M_{\mathrm{NaCl}}\right)}{\left(100-w_{\mathrm{NaCl}, \mathrm{eq}}\right)}
$$

where $M_{\mathrm{NaCl}}$ represents the molar mass of $\mathrm{NaCl}(0.05844 \mathrm{~kg} / \mathrm{mol})$.

The ratio of sodium to total cations is calculated from the depression $\left(T^{*}=T_{\mathrm{m}, \mathrm{hh}}+21.2\right.$ ${ }^{\circ} \mathrm{C}$ ) of the melting point of hydrohalite below that of the $\mathrm{H}_{2} \mathrm{O}-\mathrm{NaCl}$ binary (Figure 6). If we assume that $\mathrm{Fe}^{3+}$ is not significant we can derive two end-member expressions from the data on Fig. 6 for the depression of the hydrohalite melting temperature:

$$
\begin{aligned}
& \ln R_{\text {low }}=0.1057\left(T^{*}\right)+0.001268\left(T^{*}\right)^{2} \\
& \ln R_{\text {high }}=0.1703\left(T^{*}\right)+0.002536\left(T^{*}\right)^{2}
\end{aligned}
$$

where $R$ represents the mole ratio of $\mathrm{Na}^{+}$over total cation load $\left(R=m_{\mathrm{Na}} / m_{\sum^{+}}\right.$on a molal basis; $\ln R=$ natural logarithm of $R) . R_{\text {low }}$ and $R_{\text {high }}$ provide upper and lower boundary values on the ratio of $\mathrm{Na}^{+}$to total cations (note that $\left(R=m_{\mathrm{Na}} / m_{\Sigma^{+}}\right.$on a molal basis; $\ln R=$ natural $\operatorname{logarithm}$ of $R$ ). Equation (16) is more suitable for inclusions in which the main secondary salts besides $\mathrm{NaCl}$ are $\mathrm{KCl}, \mathrm{CaCl}_{2}$ or $\mathrm{MgCl}_{2}$, whereas Equation (17) is more suitable for inclusions in which the main secondary salt is $\mathrm{FeCl}_{2}$. Thus, one may choose to apply only one of Eqs. (16) and (17) if a high proportion of specific secondary cation(s) is known independently or inferred; otherwise the two equations bracket $R$, at a given hydrohalite melting $T$. If additional information is available 
on the ratios of Fe to other cations, then a linear mixing rule can be applied to obtain the best estimate of $R$ according to the mole fraction of Fe versus $\mathrm{K}, \mathrm{Ca}$ and $\mathrm{Mg}$.

Using Eqs. (13) to (17) and the information on Figs. 6 and 7, the interpretation of microanalytical (e.g., LA-ICPMS) data can be completed independently of Eqs. (1)-(4). The molal concentration of ions can be obtained from Eqs. (14) and (15) or from the activity of $\mathrm{H}_{2} \mathrm{O}$ (Eq. (13)) and Eq. (10) in conjunction with the Debye-Hückel equation. The molal sodium concentration ( $m_{\mathrm{Na}}$, an internal standard) can then be obtained from the total ion concentration and the ratio $R$, estimated from Eq. (16) and/or (17), using the following approximation:

$$
m_{N a}=m_{\Sigma \pm} /\left(\frac{3}{R}-1\right)\left(1+\frac{m_{K}}{m_{\mathrm{Na}}}\right)
$$

Alternatively, the salt ratios can be estimated graphically from Fig. 6 and plotted directly onto Fig. 7 (as straight lines connecting the $\mathrm{H}_{2} \mathrm{O}$-apex with the value of $R$ on the anhydrous two-salt join). The intersection of the salt-ratio tie-line with either (i) the isotherm representing the ice melting temperature, or (ii) the iso-activity contour obtained from Eq. (13), yields a unique estimate of the $\mathrm{NaCl}$ concentration $w_{\mathrm{NaCl}}-$ a suitable internal standard. Note that the parameter $m_{\mathrm{K}} / m_{\mathrm{Na}}$ is included in the denominator of Eq. (18) because of the different effects of potassium versus other (divalent) cations. The ratio $m_{\mathrm{K}} / m_{\mathrm{Na}}$ can generally be determined with high precision by LA-ICPMS, but even in the case in which the ratio is unknown, provided that hydrohalite is the second-to-last solid to melt, the $m_{\mathrm{K}} / m_{\mathrm{Na}}$ is constrained to between 0 and 0.2 (Fig. 6); thus, the maximum uncertainty propagated into $\mathrm{m}_{\mathrm{Na}}$ will be $\sim 9 \%$ relative.

As an example, consider an inclusion containing a basinal brine in which ice melts at -10 ${ }^{\circ} \mathrm{C}$. From Eq. (14), this inclusion has a bulk salinity ( $\left.w_{\mathrm{NaCl}, \text { eq. }}\right)$ of $13.94 \mathrm{wt} \% \mathrm{NaCl}$ equivalent (Eq. 
(14); Bodnar, 1993). This salinity can be converted to molal units using Eq. (15), yielding approximately 5.5 moles of ions per $\mathrm{kg} \mathrm{H}_{2} \mathrm{O}\left(m_{\Sigma^{ \pm}}=5.5\right.$ molal $)$. The ratio $m_{\mathrm{K}} / m_{\mathrm{Na}}$ can be determined with good accuracy and precision from LA-ICPMS analysis (Allan et al., 2005), or we can assume that the $m_{\mathrm{K}} / m_{\mathrm{Na}} \sim 0$. If hydrohalite melting is observed at $-24.6^{\circ} \mathrm{C}$, we can estimate that the molar proportion of $\mathrm{Na}^{+}$compared to other cations is 0.6 to 0.7 (Fig. 7, Eqs. (16) and (17)). Thus on a mole basis, sodium makes up 60-70\% of the cation load. The ratio of $m_{\mathrm{Na}} / m_{\Sigma^{+}}$can be compared directly with raw LA-ICPMS analytical data, which are expressed in terms of element ratios, as a quality check. If the computed ratio appears low compared to the analytical data, then we might infer that some potentially important analyte(s) is/are missing from the analysis, or in concentrations below a high detection limit (e.g., Ca; Schlegel et al., 2012). The absolute concentration of sodium (as a sum) can be computed from Eq. (18), yielding 1.4 to 1.7 molal. The Na concentration serves as internal standard (e.g., Longerich et al., 1996) for further data reduction and quantification of major- and trace-element concentrations. Notice that in this method, the only analytical uncertainties that propagate into the absolute concentration of individual element $\mathrm{X}$ are (i) the uncertainty on the microthermometric measurement; (ii) the uncertainty on the $m_{\mathrm{K}} / m_{\mathrm{Na}}$ ratio, and (iii) the uncertainty on the individual element-to-sodium ratio $m_{\mathrm{X}} / m_{\mathrm{Na}}$. The first of these is normally small because the precision of microthermometric measurements is typically better than $\pm 0.1^{\circ} \mathrm{C}$, at the temperature range of cryogenic measurements. Similarly, the analytical uncertainty on the sodium-to-potassium ratio is typically small compared to uncertainties on ratios of other elements (e.g., $m_{\mathrm{Ca}} / m_{\mathrm{Na}}$, or $m_{\mathrm{Fe}} /$ $\left.m_{\mathrm{Na}}\right)$. Thus, the main analytical uncertainty reduces to that on the $m_{\mathrm{X}} / m_{\mathrm{Na}}$ ratio for each element. In the rare cases that last, second-to-last and third-to-last melting temperatures can all be observed and measured (e.g., Fig. 13 - see Section 5.5.1), the microthermometric measurements 
and application to LA-ICPMS data interpretation should be interpreted on a case-to-case basis in order to add a third constraint on the solute make up (e.g., using quaternary liquidus phase diagrams such as Figs. 11 and 12).

\section{RECOMMENDATIONS}

In light of the results of this review, a few general recommendations for best practices in lowtemperature microthermometry are warranted. These recommendations should be considered supplementary to comprehensive overviews and instruction in previous in-depth reviews of saline-aqueous liquidus relations applied to fluid inclusions (Roedder, 1984; Bodnar and Vityk, 1994; Goldstein and Reynolds, 1994; Bodnar, 2006).

(1) Measuring the last-melting temperature remains the primary method for estimating FI salinity.

(2) The eutectic temperature allows inference of the identities of solutes in the inclusion, but such data should be interpreted cautiously. As outlined in Table 1 and described in Sections 5 and 6, eutectic temperatures and volume fractions are commonly equivocal, particularly for multicomponent solutions.

(3) Measurement of the second-to-last (commonly, hydrohalite) melting temperature should be included as part of routine microthermometry whenever possible. The temperature of hydrohalite melting typically does not aid in identifying which cations are present besides $\mathrm{Na}^{+}$, but provides a direct constraint on the ratio of $\mathrm{Na}^{+}$ to all other cations. 
(4) In combining low-temperature microthermometric with LA-ICPMS data, best results are obtained using an estimate of the "true" $\mathrm{Na}$ (or $\mathrm{NaCl}$ ) concentration constrained according to the cation ratios from second-to-last melting.

(5) Because microanalytical data by LA-ICPMS and other methods have high uncertainties on element concentrations in any individual inclusion (partly due to variable complexities of inclusion shapes, leading to random fluctuations in sequentially recorded element signals), it is essential to analyze and average data from multiple inclusions in a petrographically defined Fluid Inclusion Assemblage (FIA). Such co-genetic FIAs commonly exhibit consistent microthermometric properties, with relatively small variations in the ice and hydrohalite melting temperatures. In comparison, relative variations in element ratios obtained by LA-ICPMS are significantly greater than the relative variations in microthermometric properties. To avoid cumulative and internally correlated errors in elemental concentrations, best estimates of fluid composition may be obtained as follows. First, compute the average estimated concentration for each cation (other than the internal standard) from LA-ICPMS analysis based on the $\mathrm{NaCl}$ equivalent salinity. Second, use the average cation concentrations (or cation ratios) for the FIA to re-calculate the "true" internal standard concentration in each inclusion. Third, recalculate the cation concentrations for each inclusion using the corrected ("true") internal standard concentration using equations (16) to (18). 
$\begin{array}{lll}\text { Multicomponent FI compositions } & \text { Revision } 1 \quad \text { v.042016 }\end{array}$

(6) Compositions of FIs with appreciable concentrations of multiple salts can be reasonably estimated according to measured second-to-last plus third-to-last (etc.) melting temperatures, if observable (e.g., Fig. 13).

Measurement of hydrohalite (and other salt or salt-hydrate) melting temperatures can be challenging in practice, and may be impossible in small inclusions and/or inclusions with poor optical quality. Temperature cycling should be used routinely (Zwart and Touret, 1994;

Goldstein and Reynolds, 1994; Schlegel et al., 2012). The benefits of such measurements are clear in terms of compositional estimation, particularly when combined with LA-ICPMS analysis.

\section{CONCLUSIONS}

This review of the solidus/liquidus phase relations of binary to septenary saline aqueous systems representative of complex geological fluids reveals systematic trends and similarities between major systems that can be exploited to obtain the most robust FI compositional estimates. Furthermore, the phase relations and microthermometric interpretations can be applied to optimize LA-ICPMS data analysis. The results demonstrate close similarity of liquidus phase relations of most ternary systems of the type $\mathrm{H}_{2} \mathrm{O}-\mathrm{NaCl}-\mathrm{X}^{n+} \mathrm{Cl}_{n}$, where $\mathrm{X}=\mathrm{Mg}, \mathrm{Ca}, \mathrm{Fe}$, etc. - the important exception being K. General observations applicable to all systems include:

(1) Salt-hydrates of "secondary" salt components (hydrates of $\mathrm{CaCl}_{2}, \mathrm{MgCl}_{2}, \mathrm{FeCl}_{2}$, etc.) will typically melt at the eutectic in ternary systems or be the first solids to completely melt on the cotectic curves in salt-undersaturated FI of higher-order systems. 
(2) Where ice is the last solid phase to melt during heating, hydrohalite is typically the second-to-last solid phase to melt. This commonality between inclusions of different chemical systems limits our ability to distinguish different systems, but conversely provides useful constraints on the sodium concentrations in FI, independently of the specific chemical system.

(3) Eutectic liquid compositions are virtually always depleted in $\mathrm{NaCl}$, relative to most or all other components in aqueous FI; thus, the volume fraction of liquid formed at the eutectic temperature for multicomponent FI will in many cases be vanishingly small. For FI of higher-order systems in which more than one "secondary" salt hydrate is present, first observation of liquid in the FI may correspond to melting of the last divalent salt-hydrate.

The similarity of the phase relations in different salt - water systems present a major limitation in deriving compositional information from microthermometry alone, but is a distinct advantage if two microthermometric measurements are supplemented by element-ratio analysis from LAICPMS. In most cases, we can neither identify specific salts (other than $\mathrm{NaCl}$, and perhaps $\mathrm{KCl}$ ) in a lower-salinity fluid inclusion, nor determine unequivocally the specific chemical system of a fluid inclusion from microthermometry alone. Rather, we can identify "generic" complex fluids of the form $\mathrm{H}_{2} \mathrm{O}-(\mathrm{Na}, \mathrm{K}) \mathrm{Cl}-\Sigma \mathrm{X}^{n+} \mathrm{Cl}_{n}$ where $\mathrm{X}$ is one or more monovalent, divalent or trivalent ion(s). Conversely, irrespective of the specific "secondary" salt (or salts) present in solution (in addition to $\mathrm{NaCl}$ ), the hydrohalite melting temperature provides a measure of the proportion of the solute load made up by $\mathrm{NaCl}$.

These results can be applied to the interpretation of microthermometric observations, as well as the quantification of relative and absolute abundances of elements in fluid inclusions 
determined by microanalytical methods. Microthermometric data on ice- and hydrohalite-melting temperatures are proxies for the total salinity of an inclusion, and the proportion of the cation/solute load represented by $\mathrm{Na}( \pm \mathrm{K})$, respectively. The ratios of salts determined from microthermometric observations (e.g., hydrohalite melting) can provide an internal check on the consistency of multi-element analysis and interpretation, especially for concentrations of major elements (e.g., $\mathrm{Ca}, \mathrm{Fe})$ that show relatively poor analytical precision.

Ultimately, the difficulty in measuring multiple solid-phase melting temperatures in FI (especially small FI) implies that in many cases the approaches outlined here may be challenging, even impossible. In such cases, the charge-balance approach or the treatment of salts as additive components affecting freezing-point depression (generally best for low- to moderate-salinity inclusions where only ice melting can be observed; Allan et al., 2005), the empirical-trigonometric approaches (although not the main topic of this study, more appropriate for hypersaline inclusions of which salinity is estimated from the halite dissolution temperature; Heinrich et al. 2003), or the Pitzer-based calculation (Leisen et al., 2012) remain viable options for interpreting microanalytical data. The solidus/liquidus phase diagrams presented in this review also provide methods to cross-check and verify results thus obtained, for example by comparison of fluid-inclusion observations with predicted sequences of phase changes. One final note on accuracy and precision of microanalytical data is that, despite the relative simplicity of the charge-balancing and empirical-trigonometric approaches, more complex thermodynamic approaches (i.e., Pitzer modeling) to data reduction as described here in practice yield only incremental improvement over such methods ( $c f$. , Leisen et al., 2012). Thus, the greater opportunities for improvement in major- and trace-element compositional determination are likely related to technical/instrumental developments, rather than data-reduction techniques. 


\section{ACKNOWLEDGMENTS}

The research leading to these results has received funding from the European Union Seventh Framework Programme (FP7/2007-2013) under grant agreements $n^{\circ} .331171$ and $n^{\circ} .624767$. We are grateful to Antoni Camprubí, Paolo Garofalo and an anonymous reviewer for their constructive reviews, which helped improve this paper. Finally, we wish to thank Robert J. Bodnar for introducing two of us (MS-M and PL-S) to liquidus phase relations applied to fluid inclusions, and for his long-term support and encouragement to complete this review. 


\section{REFERENCES}

Allan, M.M., Yardley, B.W.D., Forbes, L.J., Shmulovich, K.I., Banks, D.A., Shepherd, T.J., 2005. Validation of LA-ICP-MS fluid inclusion analysis with synthetic fluid inclusions. American Mineralogist 90, 1767-1775.

Atbir, A., Aneflous, L., El Hadek, M., Cohen-Adad, R., Cohen-Adad, M.-Th., 1996. Etude du diagramme polythermique du système quaternaire $\mathrm{K}^{+}, \mathrm{Na}^{+}, \mathrm{Fe}^{2+} / \mathrm{Cl}^{-}-\mathrm{H}_{2} \mathrm{O}$. I. Isothermes 0 et $15^{\circ} \mathrm{C}$. Annales de Chimie-Science des Materiaux 21, 239-250.

Audétat, A., Günther, D., Heinrich, C.A., 2000. Causes for large-scale metal zonation around mineralized plutons: Fluid inclusion LA-ICP-MS evidence from the Mole Granite, Australia. Economic Geology 95, 1563-1581.

Bakker, R.J., 2012a. Can the vapour phase be neglected to estimate bulk salinity of halite bearing aqueous fluid inclusions? Central European Journal of Geosciences 4, 238-245.

Bakker R.J., 2012b. Package FLUIDS. Part 4: Thermodynamic modelling and purely empirical equation of state for H2O-NaCl-KCl solutions. Mineralogy and Petrology105, 1-29.

Bakker, R.J., Diamond, L.W. 2006. Estimation of volume fractions of liquid and vapor phases in fluid inclusions, and definition of inclusion shapes. American Mineralogist 91, 635-657.

Baumgartner, M., Bakker, R.J., 2010. Raman spectra of ice and salt hydrates in synthetic fluid inclusions. Chemical Geology 275, 58-66.

Bodnar R.J., 1993. Revised equation and table for determining the freezing point depression of $\mathrm{H}_{2} \mathrm{O}-\mathrm{NaCl}$ solutions. Geochimica et Cosmochimica Acta 57, 683-684.

Bodnar, R.J., 2003, Introduction to aqueous-electrolyte fluid inclusions. In: I. Samson, A. Anderson, D. Marshall (eds.), Fluid Inclusions: Analysis and Interpretation. Mineralogical Association of Canada, Short Course Series Volume 32, 81-100.

Bodnar, R.J., Vitkyk, M.O., 1994. Interpretation of microthermometric data for $\mathrm{H}_{2} \mathrm{O}-\mathrm{NaCl}$ fluid inclusions. In: B. De Vivo, M.L. Frezzotti (eds.), Fluid Inclusions in Minerals, Methods and Applications. Virginia Tech: Blacksburg VA, 117-130.

Borisenko, A.S., 1977. Study of the salt compositions of solutions of gas-liquid inclusions in minerals by the cryometric method. Geologiya i Geofizika 18, 16-27. 
Chou, I.-M., 1987. Phase relations in the system NaCl-KCl-H $\mathrm{H}_{2} \mathrm{O}$. III: Solubilities of halite in vapor-saturated liquids above $445^{\circ} \mathrm{C}$ and redetermination of phase equilibrium properties in the system $\mathrm{NaCl}-\mathrm{H}_{2} \mathrm{O}$ to $1000^{\circ} \mathrm{C}$ and 1500 bars. Geochimica et Cosmochimica Acta 51, 1965-1975.

Christov, C., 2004. Pitzer ion-interaction parameters for Fe(II) and Fe(III) in the quinary $\left\{\mathrm{Na}+\mathrm{K}+\mathrm{Mg}+\mathrm{Cl}+\mathrm{SO}_{4}+\mathrm{H}_{2} \mathrm{O}\right\}$ system at $\mathrm{T}=298.15 \mathrm{~K}$. Journal of Chemical Thermodynamics $36,223-235$.

Crawford, M.L., 1981. Phase equilibria in aqueous fluid inclusions. L.S. Hollister, M.L. Crawford (eds.), Fluid Inclusions: Applications to Petrology. Mineralogical Association of Canada, Short Course Handbook Volume 6, 75-100.

Crawford, M.-L., Kraus, D.W., Hollister, L.S., 1979. Petrologic and fluid inclusion study of calcsilicate rocks, Prince Rupert, British Columbia. American Journal of Science 279, 1135 1159.

Davis, D.W., Lowenstein, T.K., Spencer, R.J., 1990. Melting behavior of fluid inclusions in laboratory-grown halite crystals in the systems $\mathrm{NaCl}-\mathrm{H}_{2} \mathrm{O}, \mathrm{NaCl}-\mathrm{KCl}-\mathrm{H}_{2} \mathrm{O}, \mathrm{NaCl}-\mathrm{MgCl}_{2}-$ $\mathrm{H}_{2} \mathrm{O}$, and $\mathrm{NaCl}-\mathrm{CaCl}_{2}-\mathrm{H}_{2} \mathrm{O}$. Geochimica et Cosmochimica Acta 54, 591-601.

De Casa, G., Manni, A., Saviano, G., Violo, M., 2003. Gold occurrence in Central Italy - the Ponte San Pietro mineralization. Ore Geology Revews 23, 99-106.

Diamond, L.W., 1990. Fluid inclusion evidence for P-V-T-X evolution of hydrothermal solutions in late-Alpine gole-quartz veins at Brusson, Val d'Ayas, Northwest Italian Alps. American Journal of Science 290, 912-958.

Diamond, L.W., 2003. Introduction to gas-bearing aqueous fluid inclusions. In: I. Samson, A. Anderson, D. Marshall (eds.), Fluid Inclusions: Analysis and Interpretation. Mineralogical Association of Canada, Short Course Series Volume 32, 101-157.

Dinane, A., 2006. Thermodynamic properties of aqueous mixtures $\mathrm{NaCl}-\mathrm{KCl}-\mathrm{NH}_{4} \mathrm{Cl}-\mathrm{H}_{2} \mathrm{O}$ : Water activity and osmotic and activity coefficients at 298.15 K. Journal of Chemical and Engineering Data 51, 1602-1608.

Dubois, M., Marignac, C., 1997. The $\mathrm{H}_{2} \mathrm{O}-\mathrm{NaCl}-\mathrm{MgCl}_{2}$ ternary phase diagram with special application to fluid inclusion studies. Economic Geology 92, 114-119.

Dubois, M., Monnin, C., Castelain, T., Coquinot, Y., Gouy, S., Gauthier, A., Goffé, B., 2010. Investigation of the $\mathrm{H}_{2} \mathrm{O}-\mathrm{NaCl}-\mathrm{LiCl}$ system: A synthetic fluid inclusion study and 
thermodynamic modeling from $-50^{\circ}$ to $+100^{\circ} \mathrm{C}$ and up to $12 \mathrm{~mol} / \mathrm{kg}$. Economic Geology 105, 329-338.

Garofalo, P.A., Fricker, M.B., Günther, D., Bersani, D., Lottici, P.P., 2014. Physical-chemical properties and metal budget of Au-transporting hydrothermal fluids in orogenic deposits. In: P.S. Garofalo \& J.R. Ridley (eds.) Gold-Transporting Hydrothermal Fluids in the Earth's Crust. London: Geological Society Special Publication 402.

Goldstein, R.H., Reynolds, T.J., 1994. Systematics of Fluid Inclusions in Diagenetic Minerals. SEPM Short Course 31 Society for Sedimentary Geology, Tulsa OK, 199 pp.

Grant, J.N., Halls, C., Avila, W., Avila, G., 1977. Igneous geology and the evolution of hydrothermal systems in some sub-volcanic tin deposits of Bolivia. Geological Society of London Special Publication 7, 117-126.

Günther D., Audétat A., Frischknecht R., Heinrich C.A., 1998. Quantitative analysis of major, minor and trace elements in fluid inclusions using laser ablation inductively coupled plasma mass spectrometry. Journal of Analytical Atomic Spectrometry 13, 263-270.

Hagemann, S.G., Lüders, V., 2003. P-T-X conditions of hydrothermal fluids and precipitation mechanism of stibnite-gold mienralization at the Wiluna lode-gold deposits, Western Australia: conventional and infrared microthermometricd constraints. Mineralium Deposita 38, 936-952.

Hall, D.L., Sterner, M.S., Bodnar, R.J., 1988. Freezing point depression of aqueous sodium chloride solutions. Economic Geology 83, 197-202.

Harvie, C.E., Weare, J.H., 1980. The prediction of mineral solubilities in natural waters: the Na$\mathrm{K}-\mathrm{Mg}-\mathrm{Ca}-\mathrm{Cl}-\mathrm{SO}_{4}-\mathrm{H}_{2} \mathrm{O}$ system from zero to high concentrations at $25^{\circ} \mathrm{C}$. Geochimica et Cosmochimica Acta 44, 981-997.

Haynes, F.M., Kesler, S.E., 1987. Chemical evolution of brines during Mississippi Valley-type mineralization: Evidence from East Tennessee and Pine Point. Economic Geology 82, 5371.

Haynes, F.M., Sterner, S.M., Bodnar, R.J., 1988. Synthetic fluid inclusions in natural quartz. IV. Chemical analyses of fluid inclusions by SEM/EDA: Evaluation of method. Geochimica et Cosmochimica Acta 52, 969-977. 
Hedenquist, J.W., Henley, R.W., 1985. The importance of $\mathrm{CO}_{2}$ on freezing-point measurements of fluid inclusions: Evidence from active geothermal systems and implications for epithermal ore deposition. Economic Geology 80, 1379-1406.

Heinrich, C.A., Cousens, D.R., 1989. Semiquantitative electron microprobe analysis of fluid inclusion salts from the Mount Isa copper deposit (Queensland, Australia). Geochimica et Cosmochimica Acta 53, 21-28.

Heinrich, C.A., Pettke, T., Halter, W.E., Aigner-Torres, M., Audétat, A., Günther, D., Hattendorf, B., Bleiner, D., Guillong, M., Horn, I., 2003. Quantitative multi-element analysis of minerals, fluid and melt inclusions by laser-ablation inductively-coupled-plasma mass-spectrometry. Geochimica et Cosmochimica Acta 67.

Heinrich, C.A., Ryan, C.G., Mernagh, T.P, Eadington, P.J., 1992. Segregation of ore metals between magmatic brine and vapor: A fluid inclusion study using PIXE microanalysis. Economic Geology 87, 1566-1583.

Kontak, D.J., 2004. Analysis of evaporate mounds as a complement to fluid-inclusion thermometric data: case studies from granitic environments in Nova Scotia and Peru. The Canadian Mineralogist 42, 1315-1329.

Kontak, D.J., Kyser, K. 2011. A fluid inclusion and isotopic study of an intrusion-related gold deposit (IRGD) setting in the 380 Ma South Mountain Batholith, Nova Scotia, Canada: evidence for multiple fluid reservoirs. Mineralium Deposita 46, 337-363.

Lecumberri-Sanchez, P., Steele-MacInnis, M., Bodnar, R.J., 2015. Synthetic fluid inclusions XIX. Experimental determination of the vapor-saturated liquidus of the system $\mathrm{H}_{2} \mathrm{O}-\mathrm{NaCl}$ $\mathrm{FeCl}_{2}$. Geochimica et Cosmochimica Acta 148, 34-49.

Leisen, M., Dubessy, J., Boiron, M.-C., Lach, P., 2012. Improvement of the determination of element concentrations in quartz-hosted fluid inclusions by LA-ICP-MS and Pitzer thermodynamic modeling of ice melting temperature. Geochimica et Cosmochimica Acta 90, 110-125.

Li, N., Ulrich, T., Chen, Y.-J., Thomsen, T.B., Pease, V., Pirajno, F., 2012. Fluid evolution of the Yuchiling porphyry Mo deposit, East Qinling, China. Ore Geology Reviews 48, 442-459.

Linke W.F., 1958. Solubilities, Inorganic and Metal Organic Compounds: a Compilation of Solubility Data from the Periodical Literature. $4^{\text {th }}$ edition pp. 1287 Van Nostrand, Princeton NJ. 
Longerich, H.P, Jackson, S.E., Günther, D., 1996. Laser ablation inductively coupled plasma mass spectrometric transient signal data acquisition and analyte concentration calculation. Journal of Analytical Atomic Spectrometry 11, 899-904.

Luzhnaya, N.P., Vereshchetina, I.P., 1946. Sodium, calcium, magnesium chlorides in aqueous solutions at -57 to $+25^{\circ}$ (polythermic solubility). Zhurnal Prikladnoi Khimii 19, 723-733.

Marion G.M., 2002. A molal-based model for strong acid chemistry at low temperatures ( $<200$ to 298 K). Geochimica et Cosmochimica Acta 66, 2499-2516.

Marion, G.M., Catling, D.C., Kargel, J.S., 2003. Modeling aqueous ferrous iron chemistry at low temperatures with application to Mars. Geochimica et Cosmochimica Acta 67, 4251-4266.

Marion, G.M., Kargel, J.S., 2008. Cold aqueous planetary geochemistry with FREZCHEM: From modeling to the search for life at the limits. Springer-Verlag, Berlin.

Marion, G.M., Kargel, J.S., Catling, D.C., 2008. Modeling ferrous-ferric iron chemistry with application to martian surface geochemistry. Geochimica et Cosmochimica Acta 72, 242266.

Marion, G.M., Kargel, J.S., Catling, D.C., Lunine, J.I., 2012. Modeling ammonia-ammonium aqueous chemistries in the Solar System's icy bodies. Icarus 220, 932-946.

Mernagh, T.P., Wilde, A.R., 1989. The use of laser Raman microprobe for the determination of salinity in fluid inclusions. Geochimica et Cosmochimica Acta 53, 765-771.

Monnin, C., Dubois, M., Papaiconomou, N., and Simonin, J.P., 2002, Thermodynamics of the $\mathrm{H}_{2} \mathrm{O}+\mathrm{LiCl}$ system. Journal of Chemical Engineering Data 47, 1331-1336.

Moog, H.C., Hagemann, S., and Rumyantsev, A.V., 2004, Isopiestic investigations of the systems $\left.\mathrm{FeCl}_{2}-(\mathrm{Na}, \mathrm{K}, \mathrm{Mg}, \mathrm{Ca}) \mathrm{Cl}_{\mathrm{n}}-\mathrm{H}_{2} \mathrm{O}\right)$ at $298.25 \mathrm{~K}$. Zeitschrift für Physikalische Chemie 218, 1063-1087.

Ni, P., Ding, J.Y., Rao, B. 2006. In situ cryogenic Raman spectroscopic studies on the synthetic fluid inclusions in the systems $\mathrm{H}_{2} \mathrm{O}$ and $\mathrm{NaCl}-\mathrm{H}_{2} \mathrm{O}$. Chinese Science Bulletin 51, 108-114.

Novotny, P., Söhnel, O. 1988. Densities of Binary Aqueous Solutions of 306 Inorganic Substances. Journal of Chemical and Engineering Data 33, 49-55.

Oakes, C.S., Bodnar, R.J., Simonson, J.M., 1990. The system NaCl-CaCl $2-\mathrm{H}_{2} \mathrm{O}$ : 1. The ice liquidus at 1 atm total pressure. Geochimica et Cosmochimica Acta 54, 603-610. 
Pelch, M.A., Appold, M.S., Emsbo, P., and Bodnar, R.J., 2015. Constraints from fluid inclusion composition on the origin of Mississippi Valley-Type mineralization in the IllinoisKentucky district. Economic Geology 110, 787-806.

Pitzer, K.S., 1973. Thermodynamics of electrolytes. I. Theoretical basis and general equations. The Journal of Physical Chemistry 77, 268-277.

Pitzer, K.S., Mayorga, G., 1973. Thermodynamics of electrolytes. II. Activity and osmotic coefficients for strong electrolytes with one or both ions univalent. The Journal of Physical Chemistry 77, 2300-2308.

Pitzer, K.S., Mayorga, G., 1974. Thermodynamics of electrolytes. III. Activity and osmotic coefficients for 2-2 electrolytes. Journal of Solution Chemistry 3, 539-546.

Ptacek, C.J., 1992, Experimental investigations of siderite solubility in high ionic-strength aqueous solutions. PhD Thesis, University of Waterloo, Waterloo, Ontario.

Rankin, A .H., Ramsey, M.H., Coles, B., Van Langevelde, F., Thomas, C.R., 1992. The composition of hypersaline, iron-rich granitic fluids based on laser-ICP and synchrotronXRF microprobe analysis of individual fluid inclusions in topaz, Mole Granite, eastern Australia. Geochimica et Cosmochimica Acta 56, 67-79.

Rauchenstein-Martinek, K., Wagner, T., Wälle, M., Heinrich, C.A., 2014. Gold concentrations in metamorphic fluids: A LA-ICPMS study of fluid inclusions from the Alpine orogenic belt. Chemical Geology 385, 70-83.

Roedder, E., 1984. Fluid Inclusions. Reviews in Mineralogy 12, 644 pp.

Ryan, C.G., Cousens, D.R., Heinrich, C.A., Griffin, W.L., Sie, S.H., Mernagh, T.P., 1991. Quantitative PIXE microanalysis of fluid inclusions based on a layered yield model. Nuclear Instruments and Methods B 54, 292-297.

Samson, I.M., Walker, R.T. 2000. Cryogenic Raman spectroscopic studies in the system NaCl$\mathrm{CaCl}_{2}-\mathrm{H}_{2} \mathrm{O}$ and implications for low-temperature phase behavior in aqueous fluid inclusions. Canadian Mineralogist 38, 35-43.

Schiffries, C.M., 1990. Liquid-absent aqueous fluid inclusions and phase-equilibria in the system $\mathrm{CaCl}_{2}-\mathrm{NaCl}-\mathrm{H}_{2} \mathrm{O}$. Geochimica et Cosmochimica Acta 54, 611-619.

Schlegel, T., Wälle, M., Steele-MacInnis, M., Heinrich, C.A., 2012. Accurate and precise quantification of major and trace element compositions of calcic-sodic fluid inclusions by combined microthermometry and LA-ICPMS analysis. Chemical Geology 334, 144-153. 
Seo, J.H., Guillong, M., Aerts, M., Zajacz, Z., Heinrich, C.A., 2011. Microanalysis of S, Cl, and $\mathrm{Br}$ in fluid inclusions by LA-ICP-MS. Chemical Geology, 284, 35-44.

Simon, A., Bilenker, L. and Bell, A., 2013. The importance of iron mobility in magmatichydrothermal systems. Mineralogical Magazine 77, 2215.

Sirbescu, M.-L.C. Krukowski, E.G., Schmidt, C., Thomas, R., Samson, I.M., Bodnar, R.J. 2013. Analysis of boron in fluid inclusions by microthermometry, laser ablation ICP-MS, and Raman spectroscopy: Application to the Cryo-Genie Pegmatite, San Diego County, California, USA. Chemical Geology 342, 138-150.

Spencer, R.J., Møller, N., Weare, J.H., 1990. The prediction of mineral solubilities in natural waters: A chemical equilibrium model for the $\mathrm{Na}-\mathrm{K}-\mathrm{Ca}-\mathrm{Mg}-\mathrm{Cl}-\mathrm{SO}_{4}-\mathrm{H}_{2} \mathrm{O}$ system at temperatures below $25^{\circ} \mathrm{C}$. Geochimica et Cosmochimica Acta 54, 575-590.

Steele-MacInnis, M., Bodnar, R.J., 2013. Effect of the vapor phase on the salinity of halitebearing aqueous fluid inclusions. Geochimica et Cosmochimica Acta 115, 205-216.

Steele-MacInnis, M., Bodnar, R.J., Naden, J., 2011. Numerical model to determine the composition of $\mathrm{H} 2 \mathrm{O}-\mathrm{NaCl}-\mathrm{CaCl} 2$ fluid inclusions based on microthermometric and microanalytical data. Geochimica et Cosmochimica Acta 75, 21-40.

Sterner, S.M., Bodnar, R.J., 1984. Synthetic fluid inclusions in natural quartz. I. Compositional types synthesized and applications to experimental geochemistry. Geochimica et Cosmochimica Acta 48, 2659-2668.

Sterner, S.M., Hall, D.L., Bodnar, R.J., 1988. Synthetic fluid inclusions. V. Solubility relations in the system $\mathrm{NaCl}-\mathrm{KCl}-\mathrm{H}_{2} \mathrm{O}$ under vapor-saturated conditions. Geochimica et Cosmochimica Acta 52, 989-1005.

Stoffel, B., Appold, M.S., Wilkinson, J.J., McClean, N.A., Jeffries, T.E., 2008. Geochemistry and evolution of Mississippi Valley-Type mineralizing brines from the Tri-State and Northern Arkansas Districts determined by LA-ICP-MS microanalysis of fluid inclusions. Economic Geology 103, 1411-1435.

Uriarte, L.M., Dubessy, J., Boulet, P., Baonza, V.G., Bihannic, I., Robert, P., 2015. Reference Raman spectra of synthesized $\mathrm{CaCl}_{2} \cdot n \mathrm{H}_{2} \mathrm{O}$ solids $(n=0,2,4,6)$. Journal of Raman Spectroscopy 46, 822-828. 
Vanko, D.A., Bodnar, R.J., Sterner, S.M., 1988. Synthetic fluid inclusions: VIII. Vapor-saturated halite solubility in part of the system $\mathrm{NaCl}-\mathrm{CaCl}_{2}-\mathrm{H}_{2} \mathrm{O}$, with application to fluid inclusions from oceanic hydrothermal systems. Geochimica et Cosmochimica Acta 52, 2451-2456.

Vanko, D.A., Sutton, S.R., Rivers, M.L., Bodnar, R.J., 1993. Major-element ratios in synthetic fluid inclusions by synchrotron X-ray fluorescence microprobe. Chemical Geology, 109, 125-134.

$\mathrm{Xu}, \mathrm{G} ., 2000$. Fluid inclusions with $\mathrm{NaCl}-\mathrm{CaCl}_{2}-\mathrm{H}_{2} \mathrm{O}$ composition from the Cloncurry hydrothermal system, NW Queensland, Australia. Lithos 53, 21-35.

Yanatieva, O.K., 1946. Solubility polytherms in the systems $\mathrm{CaCl}_{2}-\mathrm{MgCl}_{2}-\mathrm{H}_{2} \mathrm{O}$ and $\mathrm{CaCl}_{2}-\mathrm{NaCl}-$ $\mathrm{H}_{2} \mathrm{O}$. Russian Journal of Applied Chemistry (Zhurnal Prikladnoi Khimii) 19, 709-722.

Yardley, B.W.D., 2005. Metal concentrations in crustal fluids and their relationship to ore formation. Economic Geology 100, 613-632.

Yardley, B.W.D., Banks, D.A., Bottrell, S.H., Diamond, L.W., 1993. Postmetamorphic goldquartz veins from N.W. Italy: The composition and origin of the ore fluid. Mineralogical Magazine 57, 407-422.

Zwart, E.W., Touret, J.L.R., 1994. Melting behavior and composition of aqueous fluid inclusions in fluorite and calcite - applications within the system $\mathrm{H}_{2} \mathrm{O}-\mathrm{CaCl}_{2}-\mathrm{NaCl}$. European Journal of Mineralogy 6, 773-786. 


\section{Figure Captions:}

Figure 1. Schematic temperature-composition vapor-saturated solidus-liquidus diagram for the system $\mathrm{H}_{2} \mathrm{O}-\mathrm{NaCl}$. The solid grey line represents a fluid inclusion composition, and the phase assemblages and compositions of each phase are represented by the open points marked $a-k$. See text for additional details and discussion.

Figure 2. Schematic ternary compositional projection of the vapor-saturated liquidus for the system $\mathrm{H}_{2} \mathrm{O}-\mathrm{NaCl}-\mathrm{CaCl}_{2}$. Thin solid lines show representative isotherms on the liquidi surfaces. Inset shows the known cotectic and peritectic boundaries and highlights the part of the system shown in the main panel. The main panel shows the path followed by the liquid composition during heating from the eutectic temperature (point eut) to the temperature of melting of the last solid phase (point $x$, the bulk composition of this inclusion). The parameter " $R$ " shows the geometric definition of the ratio of two salts. See text for additional details and discussion.

Figure 3. Calculated vapor-saturated liquidus relations for binary $\mathrm{H}_{2} \mathrm{O}-\mathrm{X}^{n+} \mathrm{Cl}_{n}$ systems. Abbreviations listed in Table 1. a) $\mathrm{H}_{2} \mathrm{O}-\mathrm{NaCl}$. b) $\mathrm{H}_{2} \mathrm{O}-\mathrm{KCl}$. c) $\mathrm{H}_{2} \mathrm{O}-\mathrm{MgCl}_{2}$. d) $\mathrm{H}_{2} \mathrm{O}-\mathrm{CaCl}_{2}$. e) $\mathrm{H}_{2} \mathrm{O}-\mathrm{FeCl}_{2}$. f) $\mathrm{H}_{2} \mathrm{O}-\mathrm{FeCl}_{3}$.

Figure 4. Calculated vapor-saturated liquidus relations for $\mathrm{H}_{2} \mathrm{O}-\mathrm{NaCl}-\mathrm{X}^{n+} \mathrm{Cl}_{n}$ ternary systems, with axes in units of wt\%. Abbreviations listed in Table 1. a) $\mathrm{H}_{2} \mathrm{O}-\mathrm{NaCl}$ $\mathrm{KCl}$. b) $\mathrm{H}_{2} \mathrm{O}-\mathrm{NaCl}-\mathrm{CaCl}_{2}$. c) $\mathrm{H}_{2} \mathrm{O}-\mathrm{NaCl}-\mathrm{FeCl}_{2}$. d) $\mathrm{H}_{2} \mathrm{O}-\mathrm{NaCl}-\mathrm{MgCl}_{2}$. e) $\mathrm{H}_{2} \mathrm{O}-$ $\mathrm{NaCl}-\mathrm{FeCl}_{3}$.

Figure 5. Calculated vapor-saturated liquidus relations for $\mathrm{H}_{2} \mathrm{O}-\mathrm{NaCl}-\mathrm{X}^{n+} \mathrm{Cl}_{n}$ ternary systems (cf. Fig. 4), but with axes in units of mol\%. Abbreviations listed in Table 1. a) $\mathrm{H}_{2} \mathrm{O}-\mathrm{NaCl}-\mathrm{KCl}$. b) $\mathrm{H}_{2} \mathrm{O}-\mathrm{NaCl}-\mathrm{CaCl}_{2}$. c) $\mathrm{H}_{2} \mathrm{O}-\mathrm{NaCl}-\mathrm{FeCl}_{2}$. d) $\mathrm{H}_{2} \mathrm{O}-\mathrm{NaCl}-$ $\mathrm{MgCl}_{2}$. e) $\mathrm{H}_{2} \mathrm{O}-\mathrm{NaCl}-\mathrm{FeCl}_{3}$.

Figure 6. Temperature-salt ratio relations along the ice-bearing cotectic curves in various $\mathrm{H}_{2} \mathrm{O}-\mathrm{NaCl}-\mathrm{X}^{n+} \mathrm{Cl}_{n}$ ternary systems $\left(\mathrm{X}^{n+}=\mathrm{K}^{+}, \mathrm{Ca}^{2+}, \mathrm{Mg}^{2+}, \mathrm{Fe}^{2+}\right.$ and $\left.\mathrm{Fe}^{3+}\right)$. Note that the salt ratios here are analogous to the parameter $R$ in Fig. 2, except expressed on a chloride-free $(\mathrm{mol} \%)$ basis.

Figure 7 Overlays of temperature (a) and activity-of-water (b) contours on the ice liquidus for various $\mathrm{H}_{2} \mathrm{O}-\mathrm{NaCl}-\mathrm{XCl}_{2}$ ternary systems (after Lecumberri-Sanchez et al., 2015), showing the overall consistency of freezing-point depression of various salts.

Figure 8. Vapor-saturated liquidus relations for $\mathrm{H}_{2} \mathrm{O}-\mathrm{KCl}-\mathrm{X}^{n+} \mathrm{Cl}_{n}$ ternary systems, with axes in units of wt\%. Abbreviations listed in Table 1. a) $\mathrm{H}_{2} \mathrm{O}-\mathrm{KCl}-\mathrm{CaCl}_{2}$. b) $\mathrm{H}_{2} \mathrm{O}-\mathrm{KCl}$ $\mathrm{FeCl}_{2}$. c) $\mathrm{H}_{2} \mathrm{O}-\mathrm{KCl}-\mathrm{MgCl}_{2}$. d) $\mathrm{H}_{2} \mathrm{O}-\mathrm{KCl}-\mathrm{FeCl}_{3}$. 
Figure 9. Vapor-saturated liquidus relations for $\mathrm{H}_{2} \mathrm{O}-\mathrm{KCl}-\mathrm{X}^{n+} \mathrm{Cl}_{n}$ ternary systems, with axes in units of mol\%. Abbreviations listed in Table 1. a) $\mathrm{H}_{2} \mathrm{O}-\mathrm{KCl}-\mathrm{CaCl}_{2}$. b) $\mathrm{H}_{2} \mathrm{O}$ $\mathrm{KCl}-\mathrm{FeCl}_{2}$. c) $\mathrm{H}_{2} \mathrm{O}-\mathrm{KCl}-\mathrm{MgCl}_{2}$. d) $\mathrm{H}_{2} \mathrm{O}-\mathrm{KCl}-\mathrm{FeCl}_{3}$.

Figure 10. Vapor-saturated liquidus relations for ternary systems of two divalent cations $\left(\mathrm{Ca}^{2+}, \mathrm{Mg}^{2+}, \mathrm{Fe}^{2+}\right)$. Abbreviations listed in Table 1. a) $\mathrm{H}_{2} \mathrm{O}-\mathrm{CaCl}_{2}-\mathrm{FeCl}_{2}$. b) $\mathrm{H}_{2} \mathrm{O}-$ $\mathrm{CaCl}_{2}-\mathrm{MgCl}_{2}$. c) $\mathrm{H}_{2} \mathrm{O}-\mathrm{FeCl}_{2}-\mathrm{MgCl}_{2}$

Figure 11. The quarternary system $\mathrm{H}_{2} \mathrm{O}-\mathrm{NaCl}-\mathrm{CaCl}_{2}-\mathrm{MgCl}_{2}$. a) schematic representation of the ice-bearing cotectic surfaces within the compositional tetrahedron. $b$ ) projection from ice through the vapor-saturated eutectic and cotectic relations, projected onto the plane of three salts. See text for additional details.

Figure 12. The quarternary system $\mathrm{H}_{2} \mathrm{O}-\mathrm{NaCl}-\mathrm{KCl}-\mathrm{FeCl}_{2}$. a) schematic representation of the ice-bearing cotectic surfaces within the compositional tetrahedron. b) projection from ice through the vapor-saturated eutectic and cotectic relations, projected onto the plane of three salts. See text for additional details.

Figure 13. (a) to (h) Microthermometric observations during heating from below the solidus to the last melting of ice, for a synthetic $\mathrm{H}_{2} \mathrm{O}-\mathrm{NaCl}-\mathrm{KCl}-\mathrm{FeCl}_{2}$ fluid inclusion. i) heating path (thick black arrows) inferred from the measured hydrohalite and sylvite melting temperatures $\left(-25\right.$ and $-22.5{ }^{\circ} \mathrm{C}$, respectively) plotted on the quaternary cotectic projection from Fig. 12. The star symbol marks the estimated bulk composition in terms of ratios of three salts, determined from the microthermometric measurements. The open-square symbol marks the known true salt ratio, from fluid inclusion synthesis. See text for additional details. 


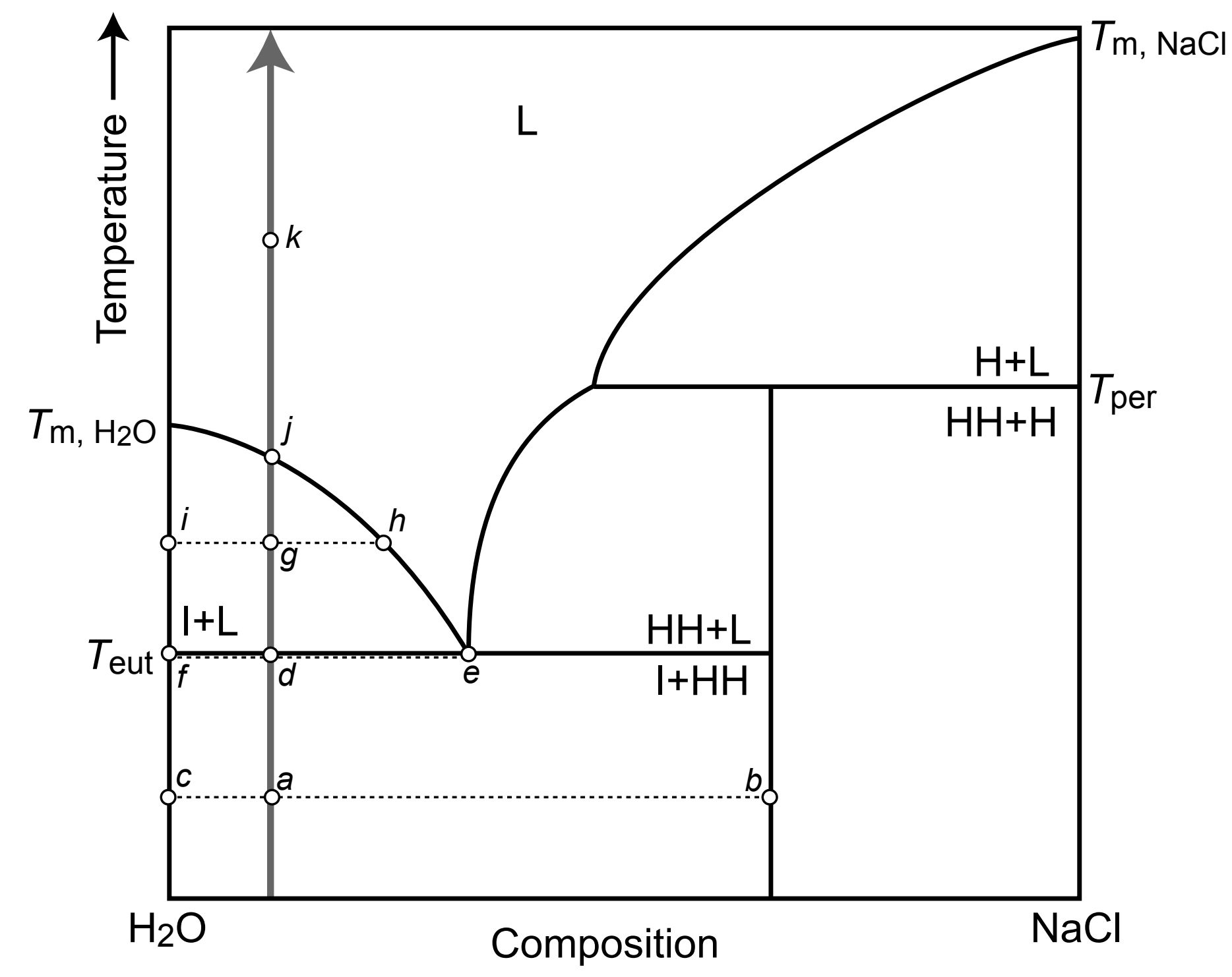

Figure 1 


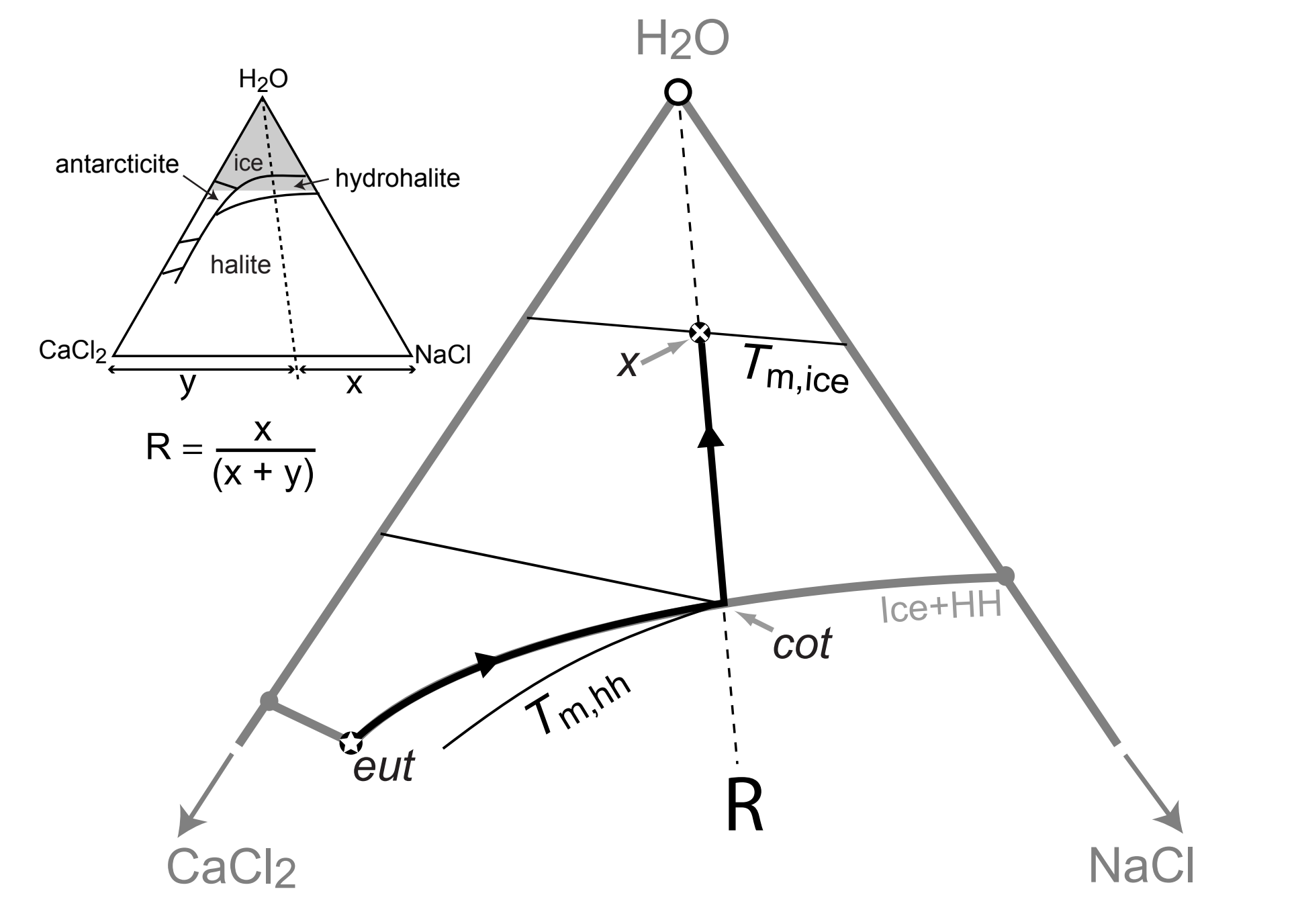

Figure 2

$\mathrm{H}_{2} \mathrm{O}$

\section{Figure}

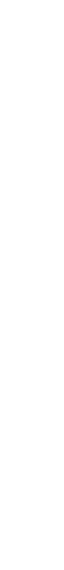

(

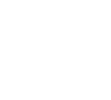

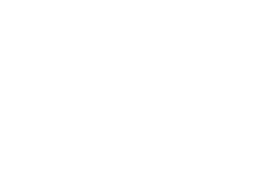

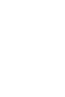

(

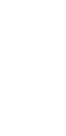



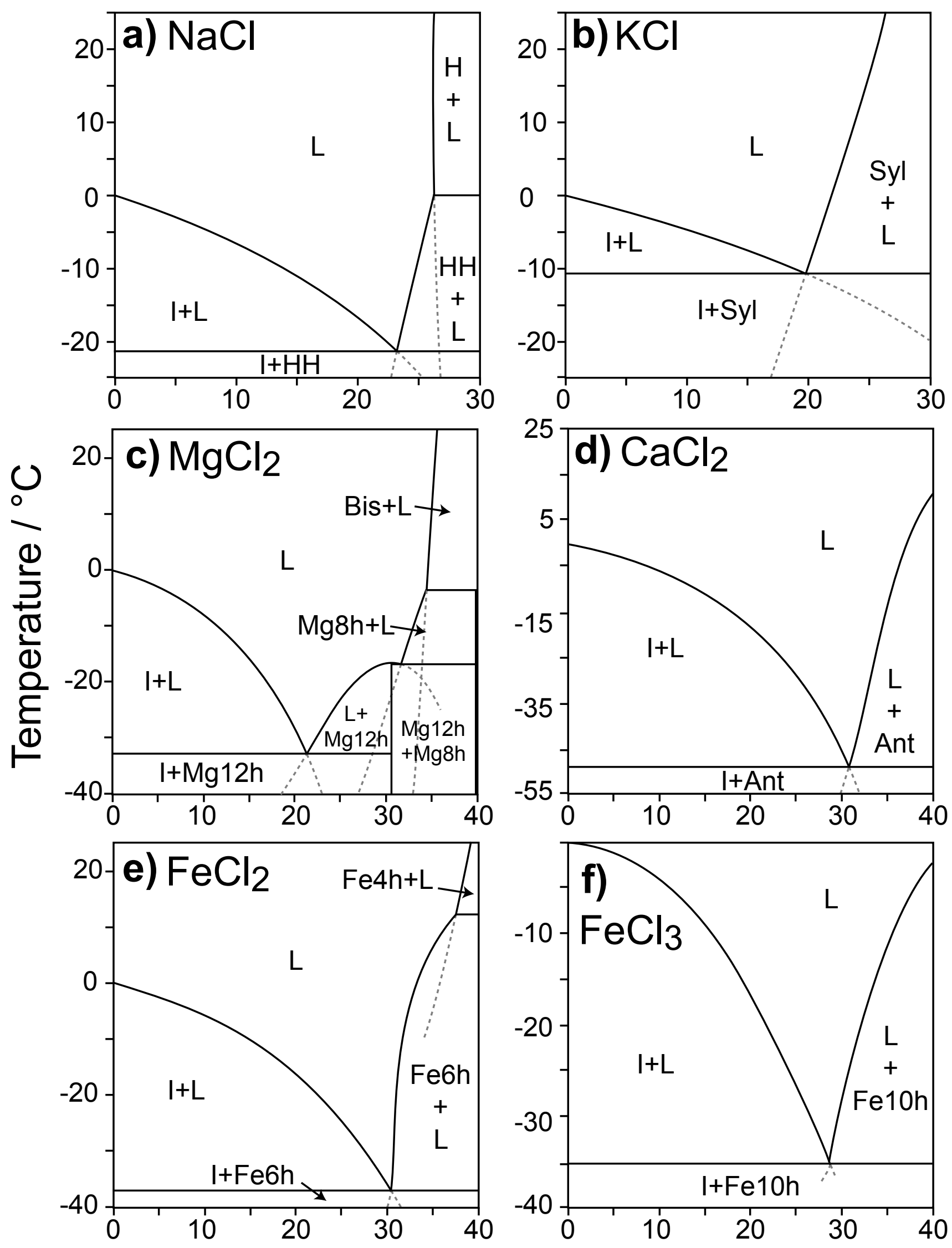

Salinity / wt\% 


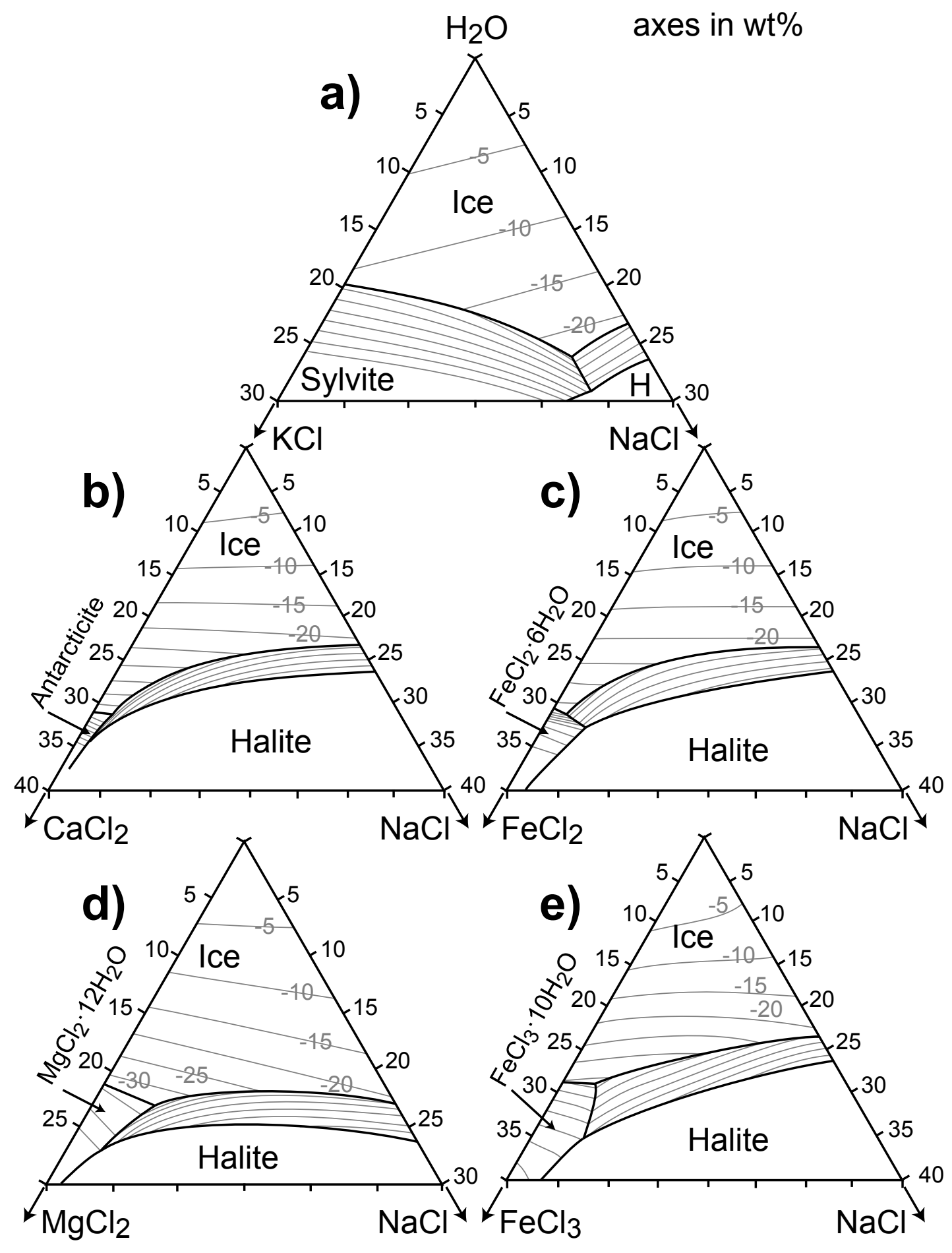




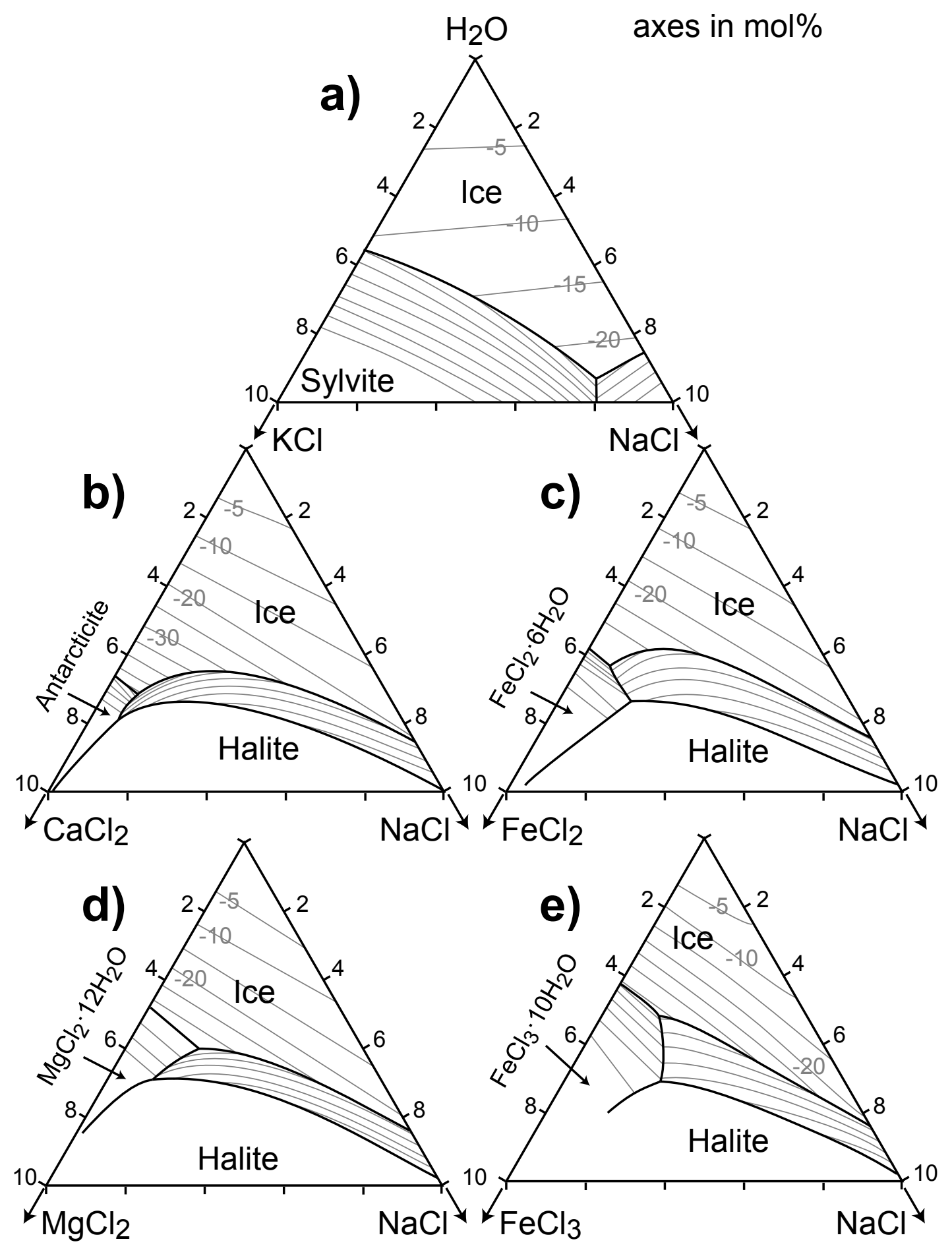




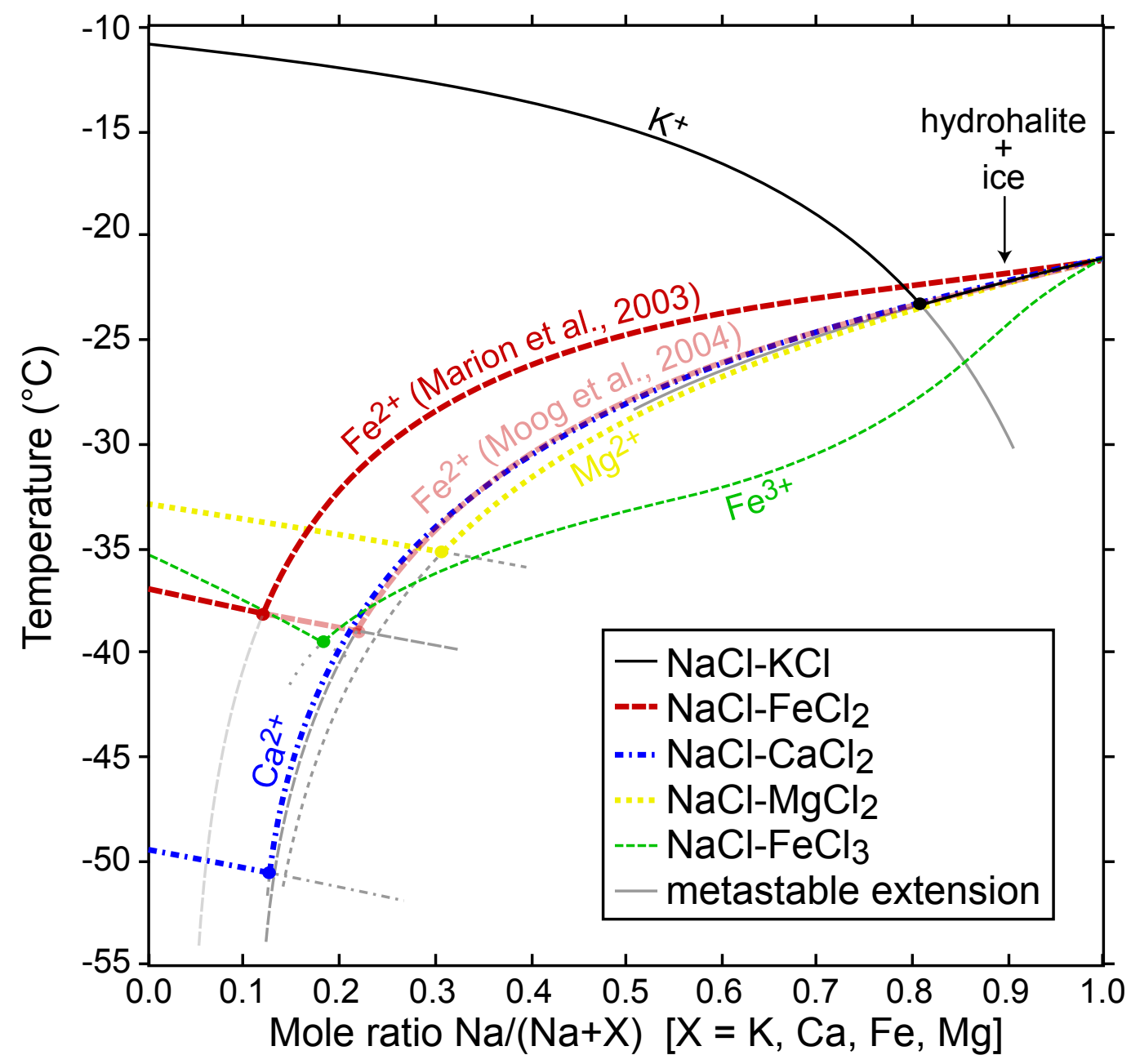




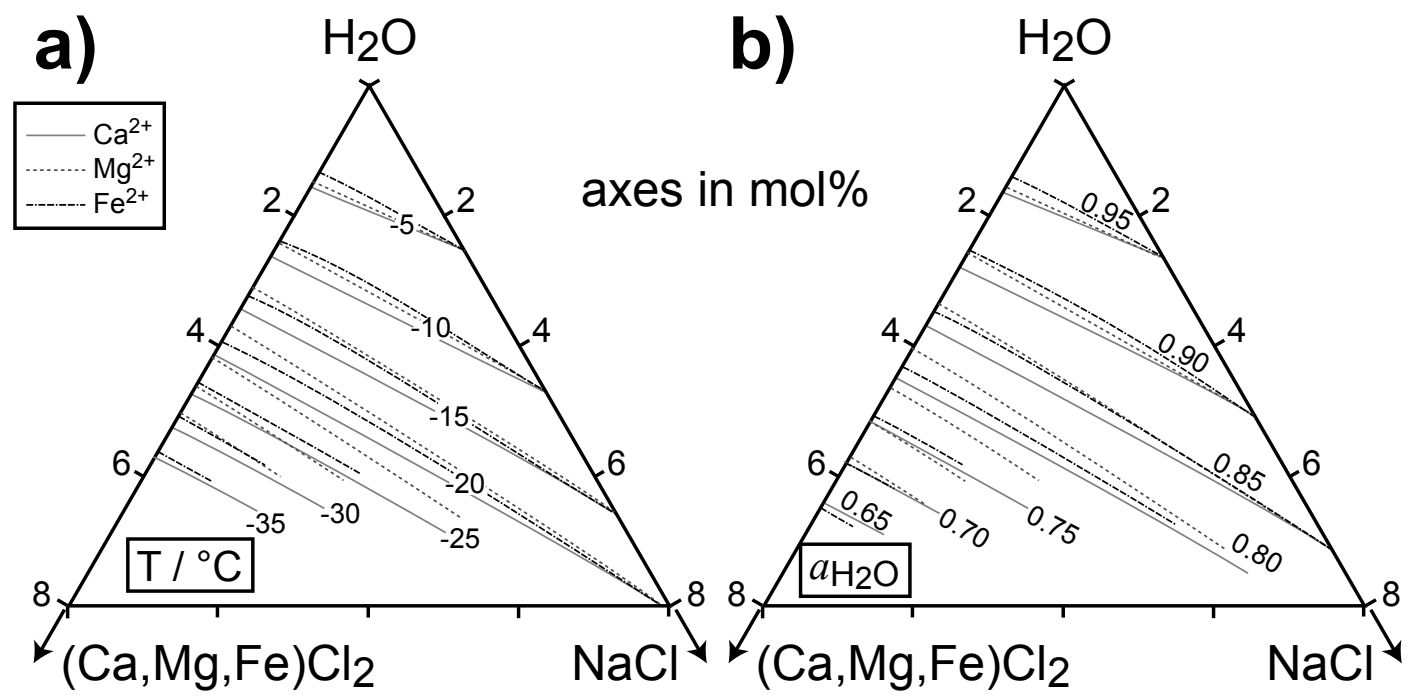




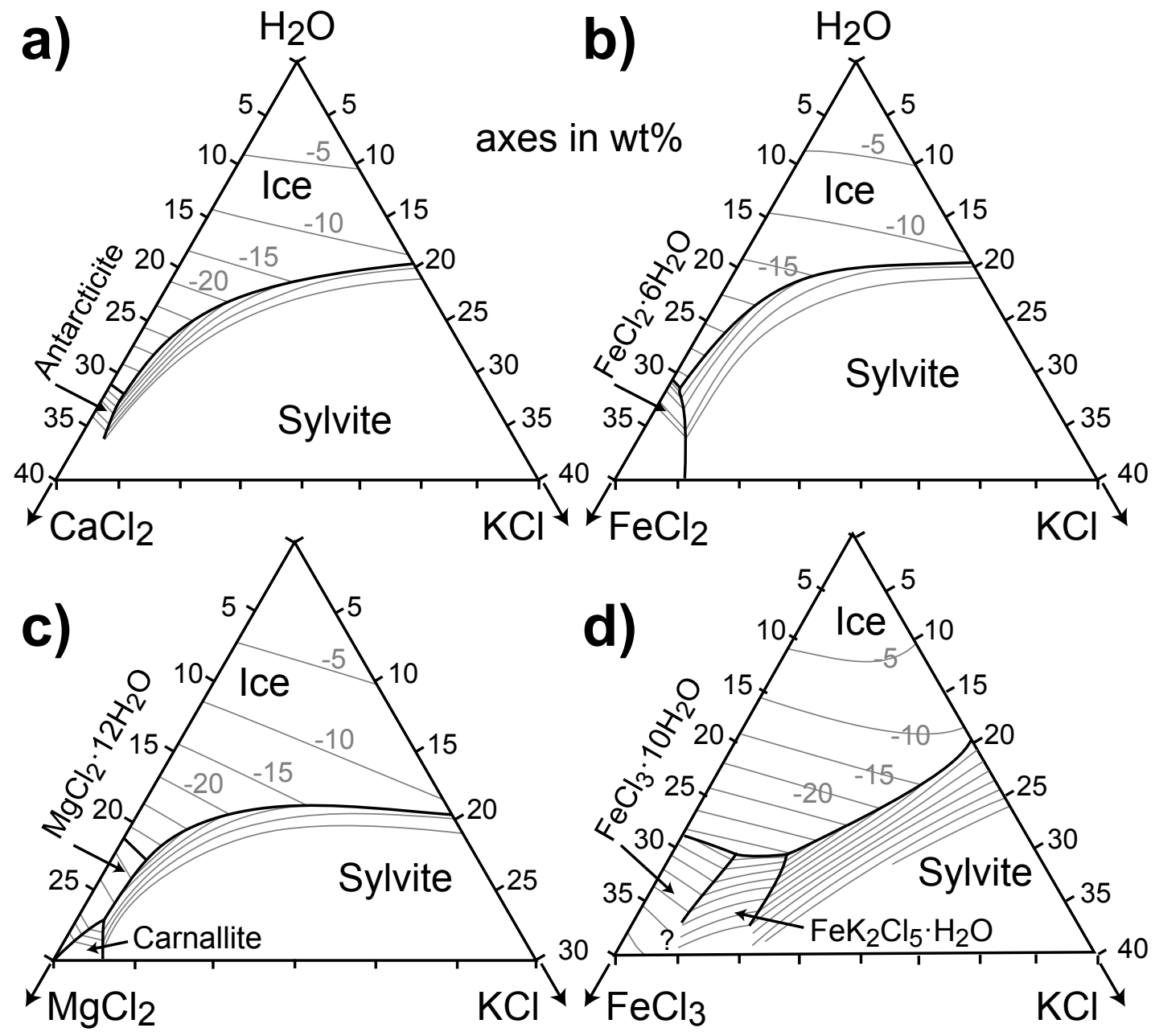



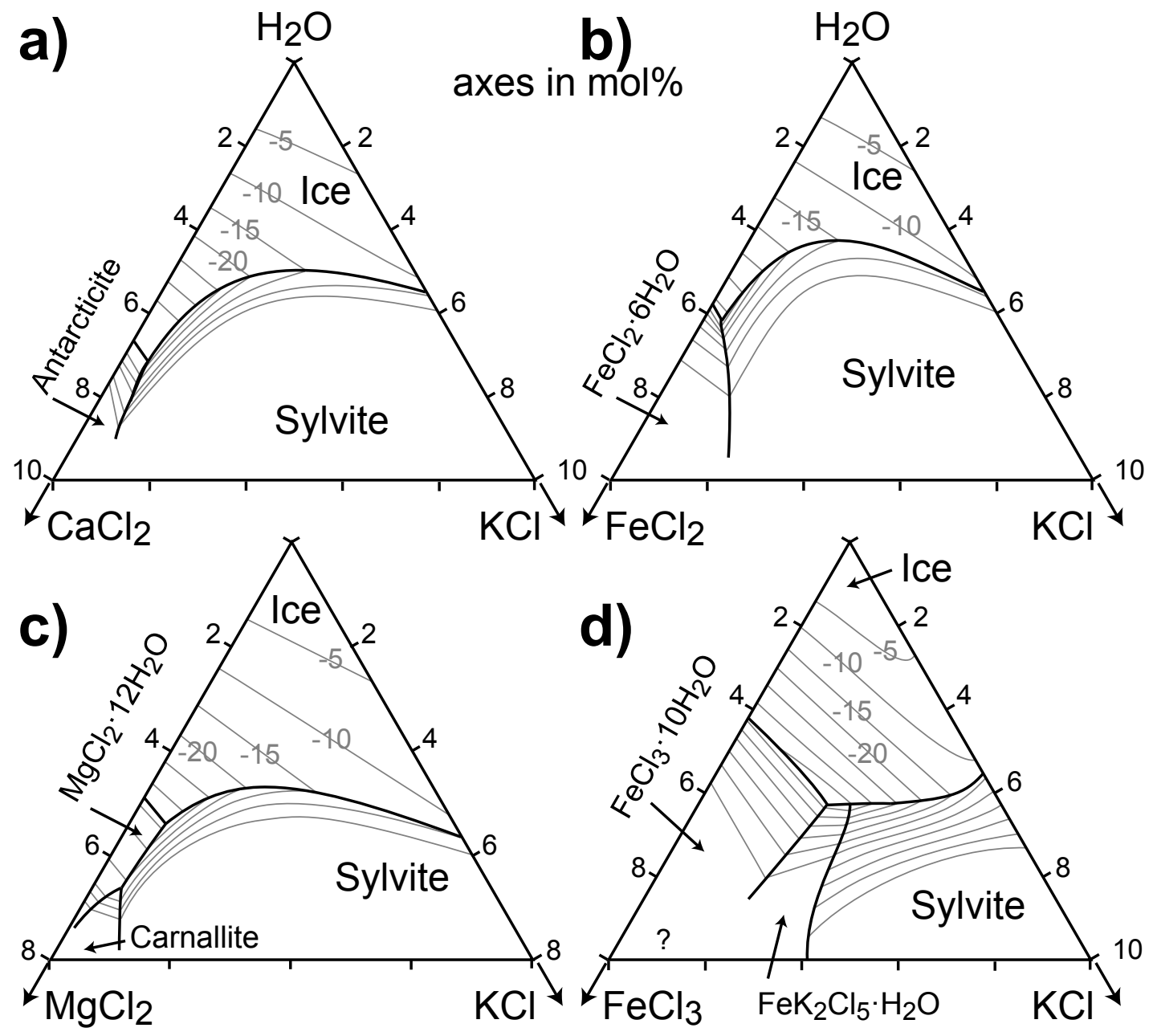
a) $\quad \mathrm{H}_{2} \mathrm{O} \quad$ axes in $\mathrm{wt} \%$

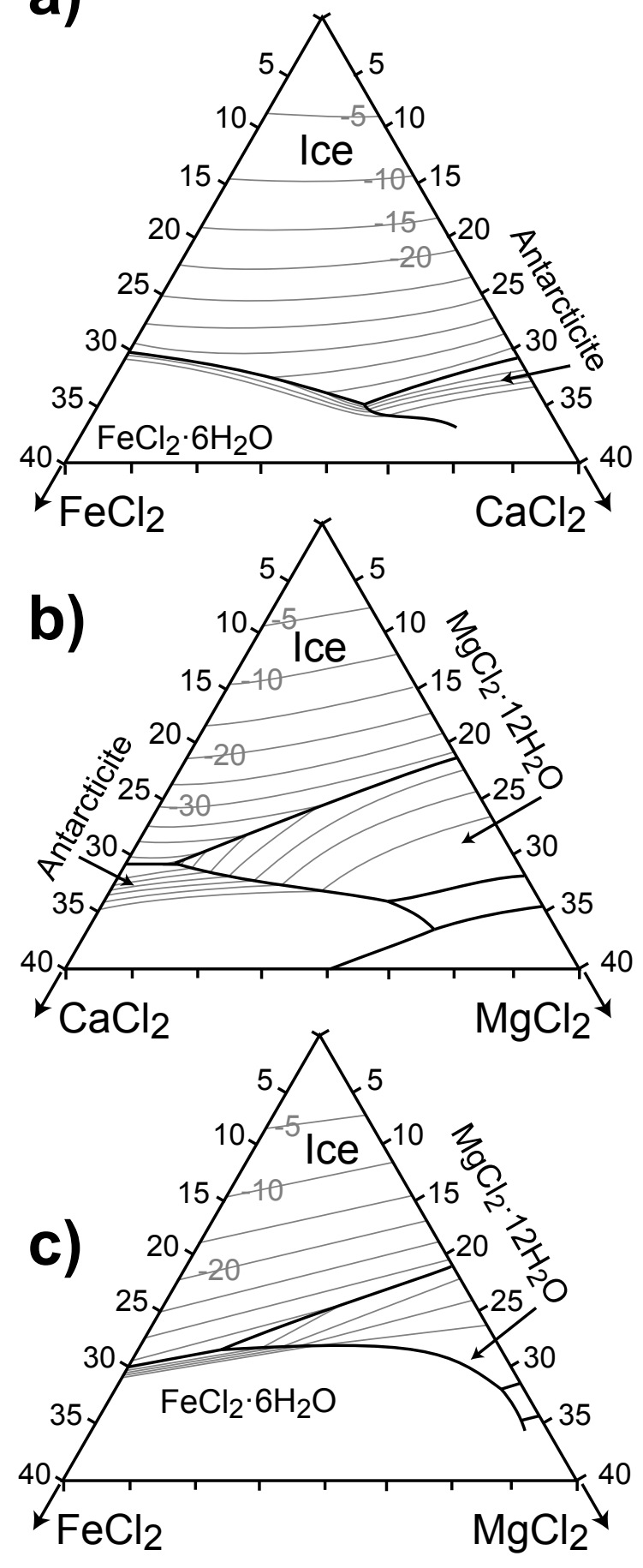




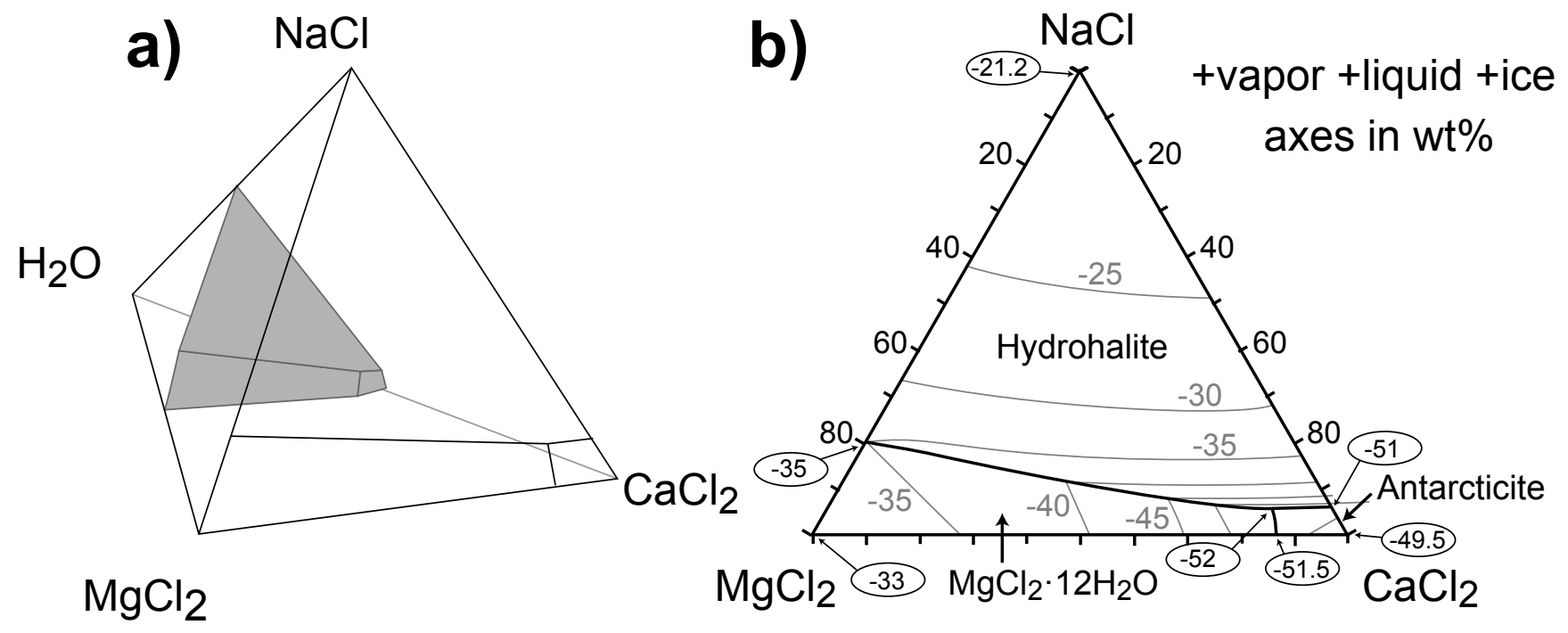



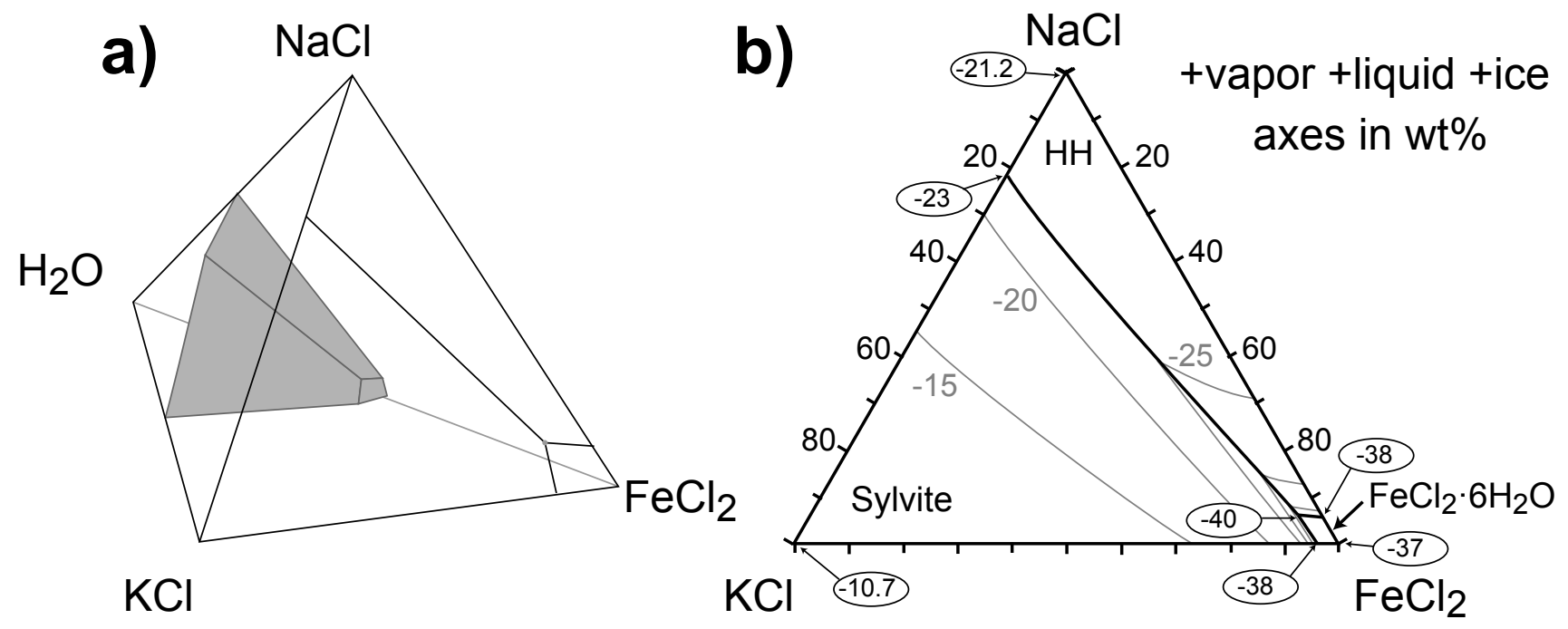

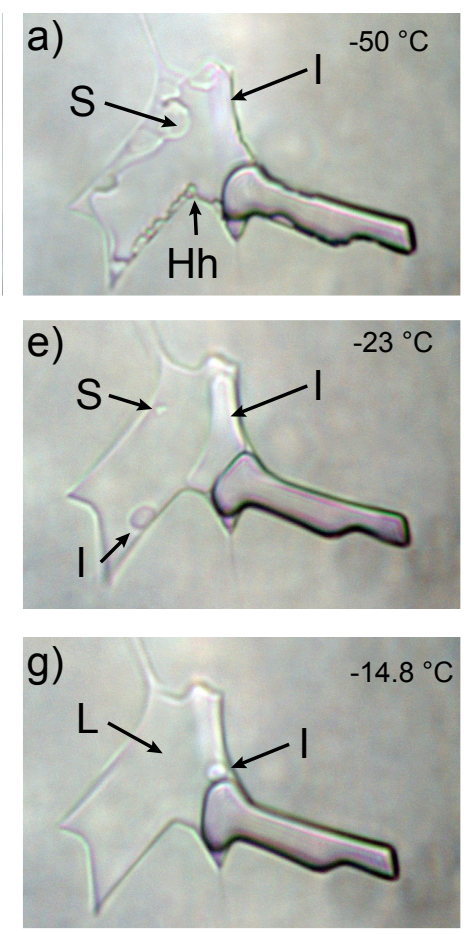
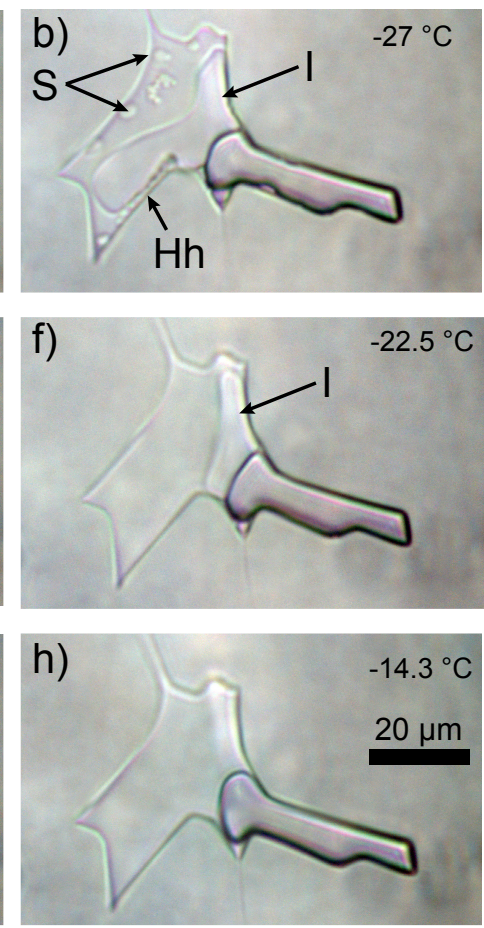
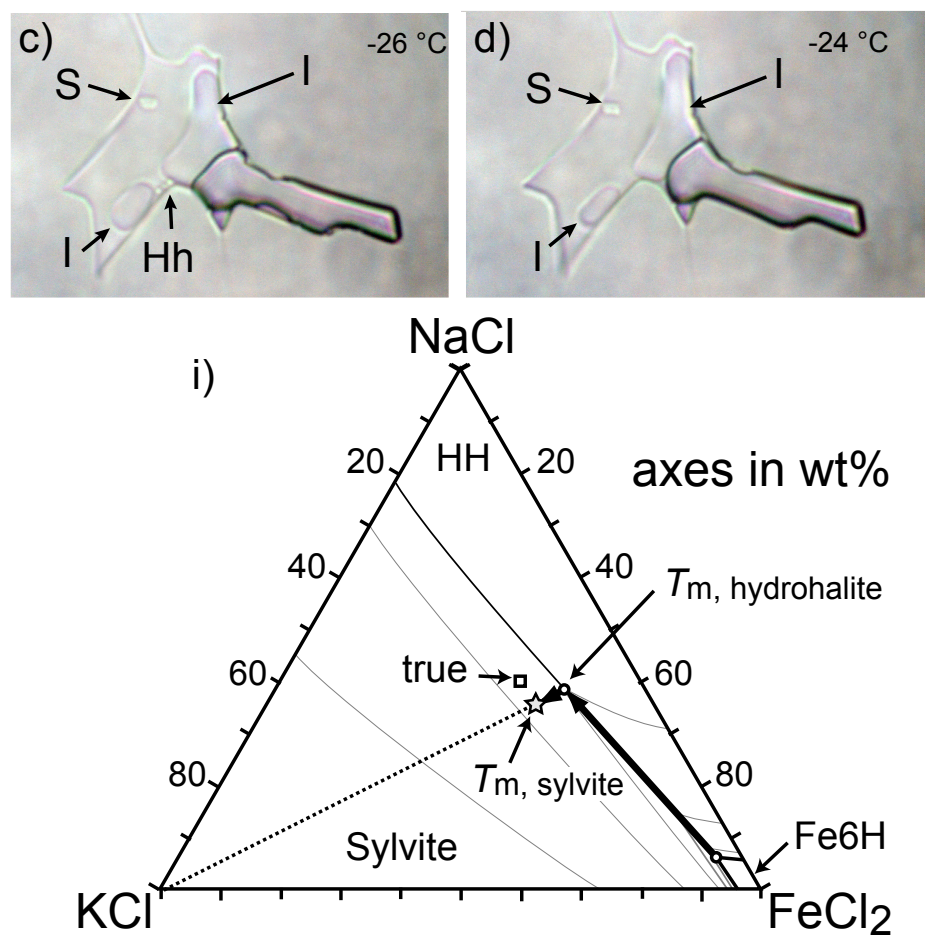